UNIVERSIDADE DE SÃO PAULO

FACULDADE DE FILOSOFIA, CIÊNCIAS E LETRAS DE RIBEIRÃO PRETO

DEPARTAMENTO DE PSICOLOGIA

ALINE MELINA VAZ

Leitura compartilhada de histórias e a aprendizagem

incidental de vocabulário

Ribeirão Preto 


\title{
Leitura compartilhada de histórias e a aprendizagem
}

\section{incidental de vocabulário}

\author{
Dissertação apresentada à Faculdade de \\ Filosofia, Ciências e Letras de Ribeirão \\ Preto - USP, como parte dos requisitos para \\ obtenção do grau de Mestre em Ciências.
}

Área de concentração: Psicobiologia

Orientadora: ANDRÉIA SCHMIDT

(versão corrigida)

Ribeirão Preto 
Autorizo a reprodução e divulgação total ou parcial deste trabalho, por qualquer meio convencional ou eletrônico, para fins de estudo e pesquisa, desde que citada a fonte.

FICHA CATALOGRÁFICA

Vaz, Aline Melina.

Leitura compartilhada de histórias e a aprendizagem incidental de vocabulário. Ribeirão Preto, 2015.

108 p.: il.; $30 \mathrm{~cm}$

Dissertação de Mestrado, apresentada à Faculdade de Filosofia, Ciências e Letras de Ribeirão Preto/USP. Área de concentração: Psicobiologia.

Orientadora: Schmidt, Andréia.

1. Aprendizagem de Vocabulário. 2. Leitura Compartilhada de Livros. 3. Responder por Exclusão. 4. Aprendizagem Incidental. 5. Discriminação condicional. 6. Comportamento Verbal. 
Nome: Aline Melina Vaz

Título: Leitura compartilhada de histórias e a aprendizagem incidental de vocabulário.

Dissertação apresentada à Faculdade de Filosofia, Ciências e Letras de Ribeirão Preto-USP, como parte dos requisitos para obtenção do grau de Mestre em Ciências.

Aprovado em:

Banca Examinadora

Prof ${ }^{\mathrm{a}}$. Dr. ${ }^{\mathrm{a}}$ Andréia Schmidt

Instituição: Faculdade de Filosofia Ciências e Letras de Ribeirão Preto-USP

Prof ${ }^{a}$. Dr. ${ }^{\text {a }}$ Deisy das Graças de Souza

Instituição: Centro de Educação e Ciências Humanas-UFSCar

Prof ${ }^{a}$. Dr. ${ }^{a}$ Aline Roberta Aceituno da Costa

Instituição: Faculdade de Odontologia de Bauru - USP

Ribeirão Preto 
Agradecimentos

Primeiramente agradeço a minha família, meu pai Edson, minha mãe Gina e minha dinda Maria da Conceição, pelo apoio todos esses anos, por aceitarem minha mudança e saída de casa, e, é claro, e por toda a participação na confecção de parte dos materiais desta pesquisa. Agradeço especialmente a minha irmã, Priscila, fotógrafa, produtora, revisora, consultora e amiga, por toda a paciência e atenção dedicadas a este trabalho e a mim, desde a confecção dos livrinhos de história, até às revisões textuais. Agradeço muito também ao meu amor e irmão, Carlos Eduardo, e a minha priminha Sarah, pela desinibição e disposição para serem "meus modelos infantis", essenciais na confecção do livrinho. Muito obrigada mesmo, família, e equipe produtora de brinquedos indefinidos!

Ao meu "casal vinte" entre Ribeirão Preto e Rio de Janeiro, Edson e Karla, por toda a enorme ajuda inicial no período de mudança, por serem "meus padrinhos" na Psicobiologia, por ajudarem desde a seleção, até às dicas práticas de como um carioca sobrevive em Ribeirão.

Aos primeiros amigos que fiz em Ribeirão Preto, Larissa, Bruno e Tábata, pelo acolhimento e força em um momento decisivo para a existência deste trabalho, e por todas as discussões e tentativas de grupo de estudo posteriores. A Sabrina, pela consultoria fonoaudiológica e por cada dica prática em relação à metodologia e outros aspectos práticos da vida. A Julia, por todas as discussões teóricas em Análise do Comportamento, pela afinidade quase que instantânea, e por entender todas minha referências nerds. A Camila, Pedro e a Thiago, por estarem sempre dispostos a me ouvir, seja sobre a análise de dados, seja sobre o que aconteceu no último fim de semana. À "Casina expandida": Ling, Bol, Simone, Jackie, Duda, por serem uma audiência disposta a tentar entender tudo o que eu faço, por todos os momentos de ajuda, e pela compreensão por todas as vezes que "não vou". Por fim, meu ao "amigo de infância”, Luiz Felipe, pelas discussões teórico-político-práticas e pelas revisões e consultorias urgentes (sempre!).

Aos colegas do Laboratório de Estudos Básicos e Aplicados em Análise do Comportamento - LEBAC (lindo esse nome!), Vinícius, Sara, Alana, Mariana e Matheus, por compartilharem a orientadora e os momentos de estudo, e por toda a disposição em ajudar sempre que necessário, seja emprestando a mão (às vezes, 
literalmente), seja com apoio técnico no tratamento de imagens, ou com uma carona e uma orientação de última hora, enfim, sempre auxiliando em qualquer dúvida cotidiana.

Às instituições que autorizaram minha entrada para a coleta de dados e também, em especial a minha tia Edda, e ao meu jovem amigo Alexandre, por me auxiliarem tanto no recrutamento dos participantes. E, é claro, aos meus participantes por quererem, tão dispostos, a ir "brincar comigo"!

E por fim, a minha querida orientadora, Andreia Schmidt, pelo acolhimento em um momento tão delicado. Por toda a dedicação, sinceridade, bom humor e paciência. Por ter aceitado o risco, e apostado e confiado em uma bióloga para a realização desde trabalho. Por ter me introduzido nas discussões e temas da Análise do Comportamento, pelo apoio na coleta de dados, e pela compreensão em ter aceitado minha decisão de começar outra graduação, sem ainda ter concluído este trabalho. Ter sido sua aluna esclareceu e mudou o rumo da minha carreira acadêmica. Muito obrigada por tudo!

E a todos os outros que se sintam merecedores de agradecimentos e que acabaram por não estar aqui, afinal a memória é fraca e o espaço é pouco (e espero que sempre seja) para agradecer cada contribuição feita a este trabalho. A todos, deixo o meu mais sincero "Valeu meeeexxxmo, pessoal!". 


\section{UMA PALAVRA}

Palavra prima

Uma palavra só, a crua palavra

Que quer dizer

Tudo

Anterior ao entendimento, palavra

Palavra viva

Palavra com temperatura, palavra

Que se produz

Muda

Feita de luz mais que de vento, palavra

Palavra dócil

Palavra d'água pra qualquer moldura

Que se acomoda em balde, em verso,

em mágoa

Qualquer feição de se manter palavra

Palavra minha

Matéria, minha criatura, palavra

Que me conduz

Mudo

E me escreve desatento, palavra

Talvez, à noite

Quase-palavra que um de nós murmura

Que ela mistura letras, que eu invento

Outras pronúncias do prazer, palavra

Palavra boa

Não de fazer literatura, palavra

Mas de habitar

Fundo

O coração do pensamento, palavra

Chico Buarque, Uma palavra. BMG/Ariola, 1995. 


\section{RESUMO}

Vaz, A. M. (2015). Leitura compartilhada de histórias e a aprendizagem incidental de vocabulário. Dissertação de Mestrado, Faculdade de Filosofia Ciências e Letras de Ribeirão Preto, Universidade de São Paulo, Ribeirão Preto.

A leitura repetida de uma mesma história favorece a aprendizagem incidental de vocabulário. Possivelmente, um dos processos envolvidos nesta aprendizagem seja o responder por exclusão (seleção de um estímulo indefinido dentre estímulos conhecidos) que pode ocorrer a partir da exposição a palavras indefinidas em contextos naturais diversos, como a leitura de livros. Muitos estudos indicam que o nível de vocabulário prévio da criança interfere na aprendizagem de novas palavras. Além disso, outros processos estão envolvidos neste tipo de aprendizagem, mas ainda não há clareza quanto às variáveis que podem favorecê-la ou dificultá-la. Este trabalho investigou a aprendizagem de novos substantivos em contexto de leitura compartilhada de livro infantil, manipulando a seguinte variável independente: a apresentação ou não da função/utilidade dos referentes (objetos desconhecidos que apareceram nas ilustrações) no contexto da história para crianças de três e sete anos (com desenvolvimento típico). Além disso, foi investigado: a) se as crianças aprenderiam quatro pseudopalavras; b) se as pseudopalavras e seus referentes apresentados na história sustentariam o posterior responder por exclusão na apresentação de uma nova pseudopalavra, e c) se a aprendizagem se mantinha em testes de retenção posteriores. Para tanto, uma história infantil (especialmente elaborada para esta pesquisa) foi lida para 10 crianças de cada grupo etário ( 3 e 7 anos), para as quais foram apresentadas quatro pseudopalavras (substantivos). Para duas palavras, a história definiu a função dos referentes; para as outras duas palavras, não foi apresentada essa definição. Sondas de Aprendizagem, Exclusão, Nomeação e Descrição da função foram aplicadas logo após a Fase de Leitura e uma semana após, verificando a aprendizagem imediata das pseudopalavras e a consolidação desta aprendizagem. Apenas o grupo de crianças mais velhas respondeu de forma consistente às sondas de exclusão. Os participantes de ambos os grupos demonstraram terem aprendido parcialmente as pseudopalavras apresentadas, desempenho que se manteve uma semana depois. Não foram encontradas diferenças significativas entre as pseudopalavras que haviam sido apresentadas com uma função específica daquelas que não tinham função. Parte das crianças mais velhas descreveu adequadamente a função das pseudopalavras. Pesquisas futuras devem investigar melhor o papel da apresentação da função/utilidade de uma palavra e de outras dicas contextuais neste tipo de aprendizagem.

Palavras-chave: aprendizagem de vocabulário; responder por exclusão; leitura compartilhada de livros; aprendizagem incidental; comportamento verbal. 


\begin{abstract}
Vaz, A. M. (2015). Shared book reading and the incidental vocabulary learning. Dissertação de Mestrado, Faculdade de Filosofia Ciências e Letras de Ribeirão Preto, Universidade de São Paulo, Ribeirão Preto.
\end{abstract}

Reading the same book more than once induces an improvement in the incidental vocabulary learning. One of the vocabulary learning process is denominated "responding by exclusion" (selection of an undefined stimulus among known stimuli) that may occur incidentally, when undefined words are exposed in natural contexts, such as shared book reading. Many studies indicate that child's prior vocabulary levels interfere in the process of learning a new word. Many processes are involved in vocabulary learning from shared book reading, and a series of variables can affect the learning process positively or negatively. This study investigated the learning of new nouns in the context of shared book reading manipulating the presentation of the function/utility of the referents (unknown objects that appeared in the illustrations) in the context of the story to three and seven years old children (with typical development). Furthermore, this study investigated: a) if children would be able to learn four pseudowords; b) if the pseudowords presented in the story would sustain the subsequent exclusion responding in the presentation of a new pseudoword, and c) if the learning would endure in later retention tests. Therefore, a children's story book (especially made for this research) was read to ten children in each age group (3 and 7 years old), in which four pseudowords were presented. Only two of the four words had their referents' function explicitly defined in the story while the others did not. Learning probes, Exclusion probes, Nomination and function description probes were applied firstly after the "reading phase" and also a week later, checking the immediate learning and its consolidation. Only the group of older children responded consistently to the exclusion probes. Participants in both groups showed they have partially learned the pseudowords presented, and the results remained the same a week later. No significant differences were found between the pseudowords that had been presented with a specific function and those which had not, part of the older children properly described the function of the former. Futher researches should investigate more the role of the presentation of the function/utility of a word and other contextual clues in this type of learning.

Key-words: vocabulary learning; responding by exclusion; shared book reading; verbal behavior. 


\section{Lista de Ilustrações}

Figura 1 - Os objetos indefinidos e seus nomes, confeccionados para esta pesquisa. Nezaca (I1), Vanito (I2) Fulito (I3) e Pafile (I4)foram os objetos apresentados na história. Tofema e Muvipo apareceram apenas no livro de testes, nas sondas de Exclusão.- Descrição das etapas dos processos

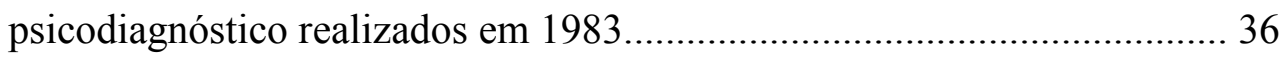

Figura 2 - A- Exemplo de uma página do livro de testes para a sonda de Seleção. Objetos definidos e indefinidos (I1 e I4) são apresentados na mesma página. B- Exemplo de uma página do livro de testes para a sonda de Exclusão, apresentando três objetos indefinidos (I1, I3 e I4) e um indefinido completamente novo (I5)............................................................... 38

Figura 3 - Exemplo de uma página do livro de testes para a sonda de Nomeação e de Descrição de Função. Todos os objetos definidos e indefinidos foram apresentados individualmente.

Figura4- Quantidade de participantes que apresentaram diferentes tipos de aprendizagem, segundo a classificação estabelecida de acordo com o desempenho de cada participante durante as fases de sondas de aprendizagem e de retenção. 53

Figura 5 - Soma da quantidade de acertos das pseudopalavras com e sem função (máximo de 20 acertos possíveis) para as sondas de seleção das fases de sondas de aprendizagem e retenção, por grupo etário. 54 


\section{Lista de Tabelas}

Tabela 1 - Configuração das páginas do Livro de Testes para cada tipo de sonda. As páginas seguintes às sondas de Exclusão eram compostas por apenas uma figura por página. Essas páginas (9-22) se alternavam entre imagens de objetos definidos (brinquedos conhecidos pelas crianças), e imagens dos objetos indefinidos (apresentados tanto na história, quanto nas sondas de Exclusão). 40

Tabela 2 - Configuração de cada tipo de sonda que compunha as duas Fases de Sondas: de Aprendizagem e de Retenção, evidenciando a ordem em que cada tipo de sonda era apresentada aos participantes em cada fase. 44

Tabela 3 - Respostas às sondas de exclusão dos participantes de 3 anos (P30 a P39) e dos participantes de 7 anos (P70 a P79), durante a fase de sondas de aprendizagem (realizada imediatamente após a leitura) e durante a fase de sondas de retenção (realizada 7 dias após a leitura). $\sqrt{ }$ indica acerto à tentativa - indica erro à tentativa.

Tabela 4 - Respostas as sondas de seleção dos participantes de 3 anos (P30 a P39) e dos participantes de 7 anos (P70 a P79) realizadas durante a fase de sondas de aprendizagem (realizada imediatamente após a leitura) e durante a fase de sondas de retenção (realizada 7 dias após a leitura). S1 - nezaca, S2 - fulito, S3 - vanito e S4 - pafile. $\sqrt{ }$ indica acerto à tentativa - indica erro à tentativa). 51

Tabela 5 - Classificação do desempenho dos participantes na sonda de seleção, e suas respectivas respostas na sonda de nomeação (fases de sondas de aprendizagem e de retenção) para as pseudopalavras que foram capazes de nomear de forma correta. 55

Tabela 6 - Respostas dos participantes na sonda de descrição da função nas fases de sondas de aprendizagem e de retenção para as duas pseudopalavras que foram apresentadas com função durante a história (S1-Nezaca - cuja função era prender/pendurar alguma coisa, e S2-Fulito - cuja função era guardar 
alguma coisa). $\quad$ *respostas classificadas como

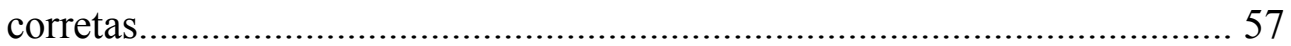

Tabela 7 - Respostas dos participantes na sonda de descrição da função nas fases de sondas de aprendizagem e de retenção para as duas pseudopalavras para as quais não foram apresentadas função específica durante a história (S3 Vanito e S4 - Pafile) 60

Tabela 8 - Respostas as sondas de generalização dos participantes de 3 anos (P30 a P39) e dos participantes de 7 anos (P70 a P79) realizadas durante a fase de sondas de retenção (realizada 7 dias após a leitura), em que era solicitada à criança que pegasse os objetos indefinidos tridimensionais diante de seu respectivo nome ditado pela pesquisadora.

Tabela 9 - Descrição dos participantes segundo suas respostas às sondas de exclusão e suas classificações de desempenho nas demais sondas para os dois estímulos que foram apresentados com função durante a história (S1-Nezaca, e S2Fulito). O grupo de crianças de 7 anos está destacado com a cor cinza...... 66

Tabela 10 - Descrição dos participantes segundo suas respostas às sondas de exclusão e suas classificações de desempenho nas sondas de nomeação e seleção para os dois estímulos que não possuíam função específica durante a história (S3-Vanito, e S4-Pafile). O grupo de crianças de 7 anos está destacado com a cor cinza.*participantes que se mantiveram na mesma posição, tanto para $\begin{array}{llllll}\text { S1 } & \text { e } & \text { S2, } & \text { quanto } & \text { para } & \text { S3 }\end{array}$ S4. 


\section{Sumário}

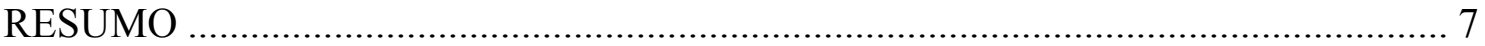

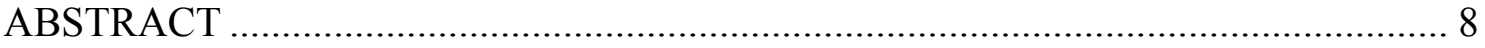

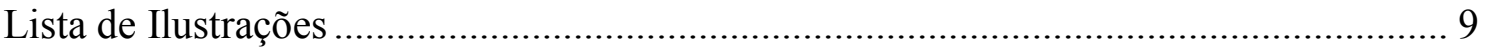

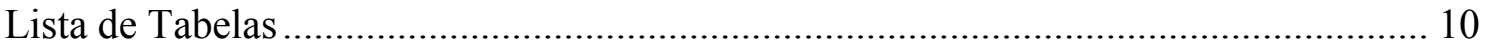

O comportamento verbal e o desenvolvimento da linguagem ................................. 10

O responder por exclusão como procedimento de ensino e de avaliação da

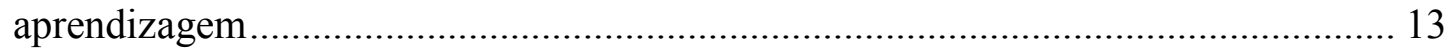

A leitura compartilhada de histórias e a aprendizagem incidental de palavras .......... 17

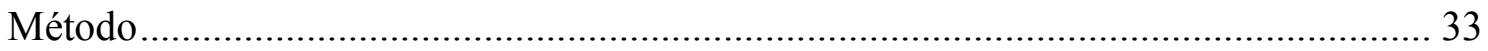

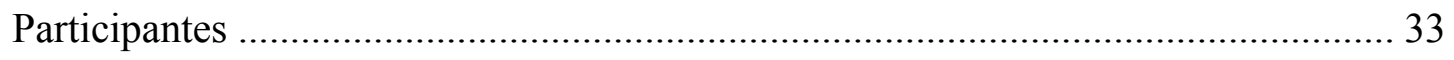

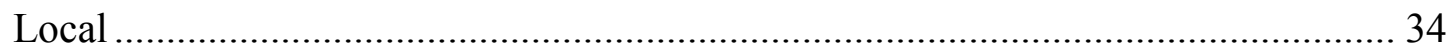

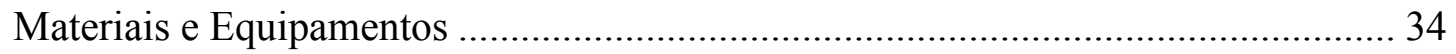

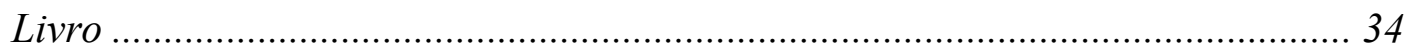

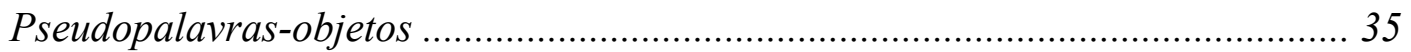

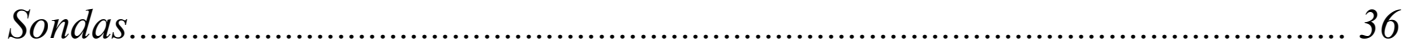

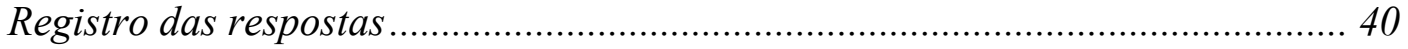

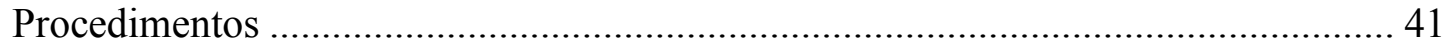

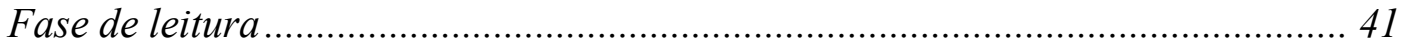

Fase de Sondas - Aprendizagem e Retenção ....................................................... 42

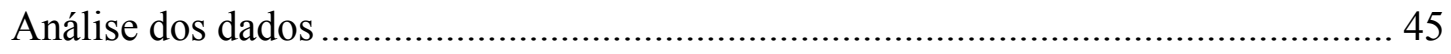

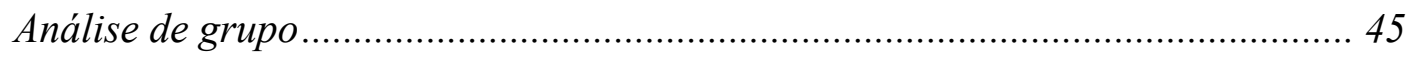

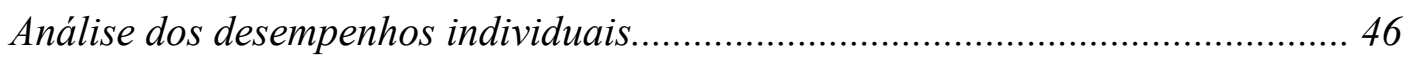

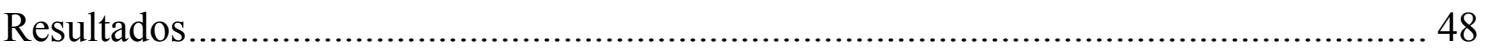

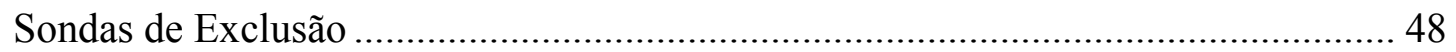

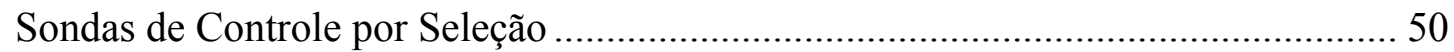




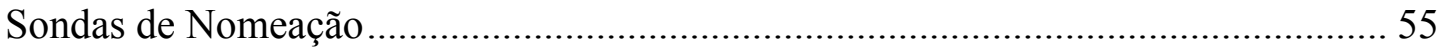

Sondas de Descrição da Função .................................................................................. 56

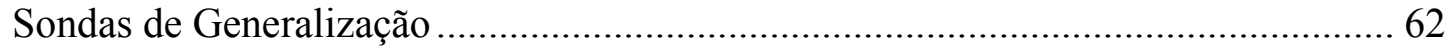

Desempenho geral dos participantes ao longo das sondas ..................................... 64

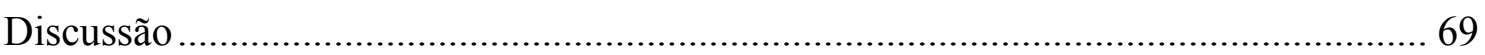

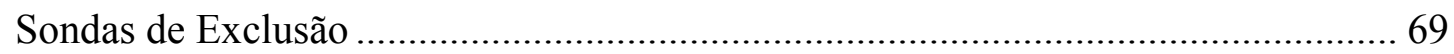

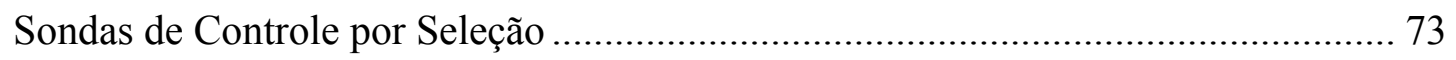

Sondas de Nomeação e de Descrição da Função........................................................ 79

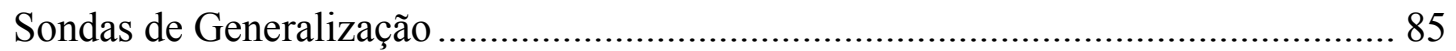

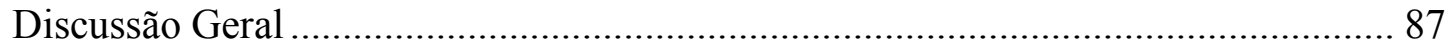

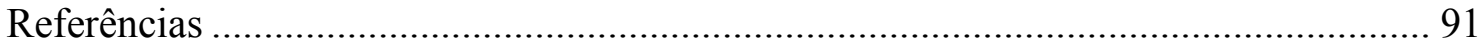

Apêndice A - Termo de Consentimento Livre e Esclarecido ........................................ 98

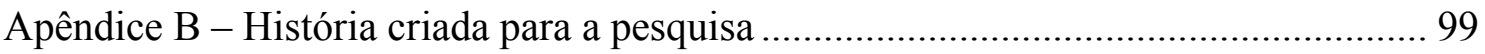

Anexo A - Parecer consubstanciado do Comitê de Ética em Pesquisa ....................... 101 


\section{O comportamento verbal e o desenvolvimento da linguagem}

Comportar-se verbalmente é uma forma dos indivíduos agirem no mundo de maneira não mecânica, por meio do efeito produzido sobre um ou mais indivíduos. Em outras palavras, o comportamento verbal é necessariamente reforçado por meio da mediação de outro indivíduo, assim sendo, é essencialmente um comportamento social (Skinner, 1957). As diferentes respostas verbais emitidas por um falante são mantidas pelas consequências produzidas no meio social, sendo, portanto, operantes. Por meio do comportamento verbal, o falante pode mudar o comportamento (verbal ou não verbal) do ouvinte, e suas respostas reforçam o comportamento verbal do falante (Catania, 1999). Catania (1999) afirma que consequências variadas que fazem parte das contingências naturais na interação organismo-meio mantêm o comportamento verbal, desde sua aquisição até o cotidiano de um falante adulto, estabelecendo uma rede complexa de esquemas de reforço.

Skinner (1974) aponta que o comportamento verbal da criança é aprendido a partir da seleção por contingências de reforço, conduzida pela comunidade verbal, em um processo que ocorre ao longo de todo o desenvolvimento da criança. Isto é, uma criança aprende a falar palavras, frases, e a construir discursos complexos em função das consequências reforçadoras produzidas por esse comportamento no meio social. Skinner ainda acrescenta que, para entender a complexidade deste fenômeno, é preciso olhar para além da topografia das respostas da criança, e investigar as circunstâncias em que o comportamento está sendo emitido.

O comportamento verbal é aprendido desde muito cedo no desenvolvimento humano, em um processo chamado de aquisição da linguagem, que ocorre de forma natural em todas as culturas. Por ser fundamental no desenvolvimento humano, o comportamento verbal tem sido alvo de estudos de autores de diferentes disciplinas e orientações teóricas. As teorias, mais aceitas na atualidade, sobre o tema destacam o 
importante papel desempenhado pela cultura na aprendizagem de repertórios verbais pelos indivíduos (Nelson, 2007, Skinner, 1957; Tomasello, 1999, Vigotsky, 1934).

Por meio de sua inserção na cultura, bebês muito jovens aprendem palavras gradualmente, ao ponto de uma criança de 3 anos já ser capaz de produzir sentenças completas (Bear, Connors, \& Paradiso, 2008). Tomasello (1999), considerando tanto aspectos biológicos quanto culturais na constituição do ser humano, defende que o desenvolvimento da linguagem é um processo sensório-motor gradual de apropriação dos símbolos linguísticos, em que o bebê, aos poucos, compreende a ação intencional de um co-específico, e já a partir dos 9 meses de idade é capaz de estabelecer com este uma situação de atenção compartilhada. Esse processo ocorre na medida em que estes dois organismos conseguem estabelecer uma relação compartilhada de controle de estímulos, em que ambos ficam sob controle dos mesmos aspectos do ambiente (MacDonald, Anderson, Dube, Geckeler, Green, Holcomb, Mansfield, \& Sanchez, 2006). A partir do momento em que a criança é capaz de discriminar as relações condicionais estabelecidas durante este processo, por exemplo, quando ela consegue discriminar que certa fala de um adulto só ocorre na presença de um determinado objeto, ela começa desenvolver o que pode ser chamado de uma capacidade comunicativa.

Esta habilidade para se comunicar parece iniciar-se, em várias línguas, predominantemente constituída por substantivos. Substantivos tendem a ser aprendidos que outras classe gramaticais (Elley, 1989), nesta fase inicial. Segundo Skinner (1974), a maioria das comunidades verbais está organizada de maneira a reforçar a emissão de substantivos por crianças pequenas, daí a razão desta classe gramatical ser, possivelmente, a primeira a ser encontrada no vocabulário das crianças.

Autores relacionados à Psicolinguística, como Gentner (1982), defendem que o mapeamento de relações objetos-referentes (substantivos) assegura à criança um 
repertório inicial que auxiliará na aprendizagem de palavras de outras classes gramaticais. Isto é, substantivos seriam aprendidos bem cedo durante o processo de aquisição de vocabulário, e de forma bem consistente, com mais facilidade que outras categorias gramaticais de palavras (ver Schmidt, Costa, Norberto, \& Voss, 2014; Tardiff, 1996).

Tomasello e Childers (2006) explicam a aprendizagem inicial de substantivos defendendo que os elementos que constituem um objeto concreto, identificado geralmente como um substantivo, tendem a ser "coesivos". Isto é, há uma contingência bem estabelecida entre a palavra e seu respectivo referente. Skinner (1974) define "referente" como sendo o aspecto ambiental que exerce controle sobre determinada resposta verbal. Por exemplo, sempre que uma bola está presente em um ambiente, todas as suas partes podem ser vistas pelos presentes, e essas partes constituem um referente à palavra "bola". Assim, a comunidade verbal, na presença desse objeto, pode reforçar diferencialmente vários repertórios relativos à aprendizagem da relação "palavra bola - objeto bola" (e.g., a nomeação desse objeto, apontar para ele diante da palavra "bola", emitir uma resposta convencional diante do objeto - por exemplo, chutar, etc.) (Skinner, 1957).

A aprendizagem de vocabulário é um processo complexo, que acontece em vários contextos ambientais nos quais a criança está inserida, como situações cotidianas de conversa, quando a criança está assistindo televisão, ou mesmo ouvindo histórias lidas por adultos. Além disso, a complexidade da aquisição da linguagem está relacionada com uma série de repertórios distintos envolvidos neste processo, que se interligam de maneira ainda não completamente entendida. Autores como Akhtar e Tomasello (2000) citam vários processos auxiliares nessa aprendizagem, tais como a segmentação do discurso para discriminação de palavras individuais; a retenção de 
fonemas que ocorrem juntos com mais frequência; o uso do contexto sintático para inferir o significado de novas palavras; o uso de palavras conhecidas como contraste para ajudar a definir novas palavras; entre outros. O uso de palavras conhecidas atuando como contraste, auxiliando assim a aprendizagem de outras palavras, é um processo básico envolvido no responder por exclusão, um dos objetos de estudo deste trabalho e fenômeno que será detalhado a seguir.

\section{O responder por exclusão como procedimento de ensino e de avaliação da aprendizagem}

Dentre os muitos processos envolvidos na aquisição da linguagem, o responder por exclusão tem se destacado como tema de pesquisa entre pesquisadores de diferentes correntes teóricas (e.g., Carey \& Bartlett, 1978; Dixon, 1977; Kaminski, Call, \& Fischer, 2004; Wilkinson, Dube, \& McIlvane, 1998; Wilkinson, Rosenquist, \& McIlvane, 2009). Oshiro, de Souza e Costa (2006) definem o responder por exclusão, como sendo um fenômeno comportamental emergente, em que, em um contexto de emparelhamento com o modelo, ocorre a seleção imediata de um estímulo comparação indefinido, diante da apresentação de um estímulo modelo também indefinido, ou seja, que não tenha uma história de reforço diferencial que torne o estímulo de comparação discriminativo para a resposta de seleção.

Desta forma, quando um adulto fala uma palavra desconhecida, diante de um objeto também desconhecido (dentre outros conhecidos disponíveis), a relação entre a palavra e o objeto pode ser estabelecida pela criança mesmo sem a intenção direta do adulto de ensinar esta nova palavra. Por exemplo, um adulto solicita a uma criança que pegue a "mariola" (nome de um doce). A criança, tendo diante de si vários doces cujo nome ela conhece e apenas um desconhecido, pode selecionar corretamente o doce, respondendo por exclusão nessa situação (relacionando o nome desconhecido ao doce 
que ela não conhece). Vários autores, tanto da Análise do Comportamento quanto da Psicolinguística, acreditam ser bastante provável que o responder por exclusão (emergente) esteja presente em diversos contextos de aprendizagem de vocabulário, aumentando a quantidade de palavras aprendidas sem que estas sejam diretamente ensinadas (Carey \& Bartlett, 1978; Domeniconi, Costa, de Souza, \& De Rose, 2007; McIlvane, Wilkinson, \& de Souza, 2000).

Possivelmente, este fenômeno ocorre durante uma sessão de leitura compartilhada de livros (quando um adulto lê um livro para pelo menos uma criança) auxiliando a aprendizagem de novas palavras. Quando a criança ouve palavras conhecidas e desconhecidas durante a sessão de leitura, e é capaz de identificar, na ilustração da história, as figuras conhecidas referentes àquelas palavras conhecidas que estão sendo ditas, estas figuras conhecidas estabelecem o contraste necessário para que possa haver um desempenho por exclusão, quando uma nova palavra é dita, na presença de estímulos conhecidos e desconhecidos (a criança assim, pode relacionar a nova palavra desconhecida à figura desconhecida presente na ilustração). Assim, acredita-se que parte da aprendizagem de vocabulário decorrente de situações de leitura compartilhada possa se dar em função de um desempenho via responder por exclusão.

O termo "exclusão" foi inicialmente utilizado por Dixon (1977), em um estudo com orientação analítico-comportamental, que objetivou investigar os processos envolvidos no ensino de habilidades básicas a indivíduos com deficiência intelectual. Estes participantes aprenderam, inicialmente, a selecionar um estímulo apresentado em um computador, a letra grega "Pi" (S+), diante de uma palavra ditada (a palavra "Pi"). Na tela, além da letra grega "Pi", uma outra letra grega também era apresentada ("Upsilon" ou "Theta" - S-, que se alternavam como comparações de forma irregular). Assim que a relação entre a palavra e a letra "Pi" foi bem estabelecida, sondas de 
exclusão foram apresentadas, isto é, o nome de uma das outras letras era ditado e, como alternativas de escolha, eram apresentadas a letra "Pi" e uma das outras letras, que assumia o papel do $\mathrm{S}+$. Todos os adolescentes foram capazes de responder a estes estímulos corretamente. De acordo com Dixon (1977), a resposta dos participantes foi baseada na história anterior de discriminação: após aprenderem a relação entre a letra impressa e a palavra "Pi", os participantes excluíram a letra impressa Pi nas tentativas em que o modelo ditado era diferente do inicialmente treinado.

Esse mesmo fenômeno tem sido estudado pela Psicolinguística como parte de um fenômeno mais amplo, denominado de fast mapping. O estudo que inaugurou esta linha de investigação para a Psicolinguística foi o de Carey e Bartlett (1978), que sugerim que a partir de um único episódio de exposição a uma palavra desconhecida (dadas as condições de linha de base bem estabelecidas), é possível que ocorra sua aprendizagem em um contexto casual e incidental. O interesse em comum destas áreas justifica-se pelo fato de que há evidências de que o desempenho por exclusão tenha relação com a aprendizagem de vocabulário, uma vez que, ao excluir o S- (escolha por rejeição), e/ou escolher o estímulo de comparação correspondente à nova palavra, o indivíduo poderia já começar a estabelecer uma relação nome-objeto com este novo estímulo (Oshiro et al., 2006).

Ainda que este fenômeno seja bem consistente, parece que sua ocorrência não garante que a criança tenha, de fato, aprendido a relação nome-objeto. Pesquisas experimentais (e.g., Domeniconi et al., 2007; Wilkinson \& McIlvane, 1997) apresentam dados de desempenhos variáveis de aprendizagem entre seus participantes, mas que, em geral, indicam que uma única exposição à tentativa de exclusão parece insuficiente (a despeito das afirmações iniciais de Carey \& Bartlett, 1978). Pesquisas como as de Ribeiro (2013) e de Costa, Grisante, de Rose e de Souza (2013) indicam a necessidade 
de um número entre três e 10 exposições para que ocorra essa aprendizagem, mas outras variáveis, além da repetição, podem estar envolvidas na manutenção da relação, como as variáveis de contexto de apresentação da palavra.

Diante disso, é possível supor, por exemplo, que um contexto mais natural, no qual outras dicas, além da própria relação de novidade da relação nome-objeto, favoreçam a aprendizagem de novas palavras. É possível pensar, por exemplo, que situações cotidianas (como a leitura de histórias) auxiliem esse processo de aprendizagem, e que o fenômeno do responder por exclusão esteja presente como uma forma de aprendizagem indireta. Quando a criança ouve uma história, as palavras por ela conhecidas podem servir como os estímulos contrastes necessários para que a criança consiga rastrear, via responder por exclusão (tanto na ilustração da história, quanto na fala do adulto que lê a história) a presença dos novos estímulos.

Além disso, considerando que a aprendizagem de palavras consiste em aprender uma série de diferentes repertórios (e.g. identificar a palavra alvo dentre outros estímulos, selecionar corretamente o objeto referente a esta palavra, nomear o objeto referente em um contexto adequado, etc), o fenômeno do responder por exclusão também pode ser útil para a avaliação da aprendizagem de novas palavras. Esse tipo de aplicação é relatado por Wilkinson et al. (1998) em uma revisão sobre o fenômeno. Quando o objetivo da investigação é verificar quais os repertórios presentes e que estão envolvidos na aprendizagem de palavras, a aplicação de uma sonda de exclusão pode ser útil. No caso deste trabalho, por exemplo, a aplicação deste tipo de sonda (na qual é apresentado um estímulo completamente novo, e os estímulos comparações são as pseudopalavras apresentadas na história) permite verificar se os participantes aprenderam alguma coisa referente àqueles estímulos de comparação. Permite avaliar se a exposição proporcionada pela leitura promoveria aprendizagem suficiente para que 
estas pseudopalavras funcionassem como estímulos linha de base na presença de um estímulo completamente novo. Com a intenção de contribuir para a melhor compreensão do papel deste fenômeno em contextos naturais e sua utilização pra a investigação de parte dos repertórios envolvidos na aprendizagem de novas palavras, o presente estudo teve como parte de seus objetivos investigar o papel do desempenho por exclusão na aprendizagem de novas palavras por meio da leitura de histórias. A aprendizagem decorrente deste tipo de contexto, chamada de aprendizagem incidental, é o assunto a ser detalhado no próximo tópico.

\section{A leitura compartilhada de histórias e a aprendizagem incidental de palavras}

Crianças aprendem novas palavras em contextos diversos, sejam eles diretos e explícitos, como quando um adulto diretamente ensina alguma coisa para uma criança, como em situações em que se fala: "Olha a bola do neném! Isso aqui é o quê? A bola! Fala bola para a mamãe". Ou ainda em episódios incidentais, como ouvindo conversas entre adultos ou entre seus pares, assistindo televisão, ou mesmo ouvindo histórias. Nesses episódios incidentais, a aprendizagem pode ser influenciada por uma série de fatores, como o número de ocorrências da palavra desconhecida, a concretude desta palavra, as dicas apresentadas no contexto, a importância da palavra desconhecida para o entendimento do contexto, entre vários outros aspectos (Robbins \& Ehri, 1994).

Ler histórias para crianças é um dos contextos de aprendizagem incidental que tem sido uma prática comum em diferentes famílias, de diferentes culturas (Bus, Leseman, \& Keultjes, 2000; Cornell, Sénéchal, \& Broda, 1985; Pellegrini, Brody, \& Sigel, 1985). Não apenas no contexto familiar, mas também na escola, os professores têm o hábito de ler para seus alunos, especialmente para as crianças mais jovens, que estão começando a desenvolver suas habilidades de linguagem oral (Elley, 1989, Wilkinson \& Houston-Price, 2013). 
A prática de leitura compartilhada de livros tem sido defendida como tendo um importante papel no desenvolvimento de uma série de habilidades na criança, como a melhora na compreensão de textos e no desempenho escolar em geral, maior facilidade para aprendizagem da leitura, e também na aprendizagem de novas palavras (Debaryshe, 1993; Farrant \& Zubrick, 2013, Fontes \& Cardoso-Martins, 2004; Ninio, 1983). Diante disso, surgem algumas questões, tais como: quais elementos presentes em uma situação de leitura compartilhada são particularmente importantes para a aprendizagem de novas palavras? Quais variáveis e processos estão envolvidos na situação de leitura, que são capazes de afetar a aprendizagem de repertórios futuros da criança, como o desempenho escolar, por exemplo? Estes tipos de questionamentos são oriundos de um campo de estudo que vem investigando há, aproximadamente, 40 anos (Bus et al., 1995), as variáveis que estão envolvidas nos diferentes tipos de aprendizagem decorrentes do hábito de leitura compartilhada de histórias.

É um conhecimento de senso comum que ler para crianças é uma prática que melhora o desempenho delas em vários aspectos de seu desenvolvimento da linguagem, e que esta é uma rotina que deve ser estimulada e mantida, tanto no contexto escolar, como no familiar. Contudo, o que as pesquisas vêm investigando é, justamente, de que maneira, e por que, este hábito tem efeito tão positivo, verificando quais variáveis estão de fato relacionadas a seus respectivos efeitos.

Um dos trabalhos pioneiros neste campo é o de Elley (1989), que objetivou investigar a extensão de ganhos de vocabulário por crianças de 7 a 8 anos, a partir de uma sessão de leitura compartilhada. Em seu primeiro estudo, o autor submeteu 157 crianças de 7 anos a pré-testes para avaliar se conheciam as 20 palavras-alvo (10 substantivos e 10 verbos) que seriam apresentadas, sete dias depois, durante a leitura da história. Em seguida, essas crianças foram submetidas a três sessões de leitura 
compartilhada em suas classes, com seus professores e outros professores da escola, durante 7 dias (a segunda leitura sendo realizada três dias depois da primeira, e a terceira e ultima sessão sendo feita no sétimo dia). Dois dias depois da terceira leitura, as crianças eram submetidas ao pós-teste com as mesmas 20 palavras-alvo. Tanto o préteste, quanto o pós-teste consistiam em uma tarefa de múltipla escolha com quatro alternativas possíveis. Essas alternativas eram figuras referentes ao significado das palavras, e a criança deveria escolher aquela figura que se aproximasse do significado da palavra ditada por seu professor (uma tarefa de discriminação auditivo-visual). Os resultados desta pesquisa indicaram um ganho de $15 \%$ no vocabulário destas crianças em relação às palavras alvo.

O autor (Elley, 1989) replicou o primeiro experimento e adicionou uma segunda questão experimental: investigou os efeitos de explicações adicionais dos professores (feitas durante a leitura) para as palavras-alvo. Participaram deste segundo experimento 178 crianças de 8 anos, divididas em dois grupos experimentais e um grupo controle (que não ouviu nenhuma das histórias, mas que foi submetido ao pré e pós-testes nos mesmos momentos que os grupos experimentais). Os procedimentos foram semelhantes aos do primeiro experimento, contudo havia duas condições de leitura (com e sem explicação adicional) que foram contrabalanceadas entre dois livros de histórias e entre os dois grupos experimentais. Na primeira condição, o professor da classe lia a história para as crianças sem nenhuma explicação adicional; na segunda condição, era apresentando, junto à palavra não-familiar, algum tipo de explicação: parafrasear a sentença em que a palavra aparecia por meio do uso de sinônimos, modificar a entonação da voz (por exemplo, falar a palavra baixo num tom de voz baixo) ou, ainda, explicar o significado da palavra não-familiar com o auxílio das figuras da história (apontando para o contexto em que a palavra se inseria). Para o grupo 
de participantes da condição "leitura sem explicação" o ganho de vocabulário foi, tal como no Experimento 1, de cerca de $15 \%$, enquanto que para o grupo da condição "leitura com explicação" foi de 40\%. Esses resultados confirmaram os achados do primeiro estudo, e mostraram que as crianças que ouviram explicações adicionais tiveram um ganho maior no vocabulário. Além disso, este trabalho indicou uma alta correlação positiva entre algumas variáveis envolvidas neste processo, como: o número de ocorrências da palavra no texto; o número de ocorrências da figura referente à palavra; a utilização de dicas referentes ao significado da palavra; a importância da palavra para a compreensão da história; a clareza com que a palavra aparecia na história; e a familiaridade da criança com o conceito da palavra.

A pesquisa de Elley (1989) foi importante por ser uma das primeiras a demonstrar evidências empíricas de como a leitura de histórias auxilia o processo de aquisição de vocabulário, e por apresentar um campo de investigação rico para outras pesquisas continuarem investigando como diferentes variáveis podem influenciar a aquisição da linguagem. Contudo, é importante salientar a ausência de alguns controles experimentais neste estudo, na medida em que as 20 palavras-alvo investigadas eram palavras correntes da língua materna dos participantes. Esta escolha metodológica não garantiu controle sobre exposições prévias e adicionais a estas palavras (o que afetaria os resultados tanto do pré, quanto do pós-teste). Além disso, a influência da familiaridade pode ser um ponto ainda mais crítico quando a história usada nos procedimentos é uma história comercialmente disponível, o que, mais uma vez, dificulta o controle sobre exposições prévias àquele contexto literário, variável que foi investigada por trabalhos seguintes (Horst, Parsons, \& Bryan, 2011; Wilkinson \& Houston-Price, 2013), e demonstrada como tendo um papel de grande influência na aprendizagem de novas palavras. 
Pesquisas posteriores, utilizando-se de diferentes estratégias metodológicas, investigaram o papel de outras variáveis sobre a aprendizagem de novas palavras por meio da leitura compartilhada de histórias, como: a) a interferência da repetição de uma mesma palavra na sua aprendizagem; b) a interferência da repetição da leitura da mesma história na aprendizagem das palavras apresentadas (a influência do contexto literário); c) se a forma como o adulto lê a história para a criança (fazendo perguntas, dando ênfase a algumas palavras, apontando figuras, etc) pode ter efeito sobre a aprendizagem de certas palavras; d) e se dicas contextuais podem facilitar a aprendizagem de uma palavra; entre outras tantas questões. Alguns dos trabalhos que apontaram respostas a parte destas perguntas serão apresentados a seguir.

Um exemplo é o trabalho de Horst et al. (2011), em que as autoras manipularam o número de repetições de pseudopalavras que eram apresentadas em diferentes histórias infantis. Neste trabalho foram criadas nove histórias com o objetivo de ensinar três pares de nomes-figuras para as crianças de 3 anos, no decorrer de uma semana. Os participantes foram divididos em dois grupos: o primeiro grupo passava por três sessões consecutivas de leitura; em cada uma, a mesma história (contendo um par nome-objeto novo) era contada por três vezes; para o outro grupo, em cada sessão, eram contadas três histórias diferentes, e o mesmo par nome-objeto novo se repetia entre as histórias. Logo após as leituras, as autoras aplicaram sondas para verificar a aprendizagem destes pares nome-figura, nas quais solicitavam que o participante selecionasse (dentre quatro opções) a palavra alvo que era ditada pela pesquisadora. Após uma semana, reaplicavam estas mesmas sondas para verificar a retenção da aprendizagem. Os resultados demonstraram que crianças de 3 anos conseguiram aprender acuradamente duas novas palavras ouvindo histórias, e que esta aprendizagem se consolidava na retenção, principalmente para as crianças que ouviram a mesma 
história repetidas vezes, em relação àquelas que ouviram o mesmo par nome-figura em diferentes histórias (ainda que nas duas condições os pares fossem repetidos o mesmo número de vezes). Esse estudo sugeriu que o número de apresentações e o contexto de repetições das palavras novas, pode ter efeito considerável sobre a aprendizagem. Outros trabalhos corroboram essas conclusões, e apresentaram resultados semelhantes (Robbins, \& Ehri, 1994, Trivett, Simkus, Dunst, \& Hamby, 2012; Wilkinson \& Houston-Price, 2013).

Outros estudos (Blewitt, Rump, Shealy, \& Cook, 2009; Hargrave \& Sénéchal, 2000) têm mostrado, ainda, que a forma como o adulto faz a leitura da história na presença da criança pode influenciar na aprendizagem de um novo vocábulo. Em 2013, em um estudo com crianças pré-escolares, Walsh e Rose demonstraram que a solicitação de perguntas sobre as palavras novas mencionadas durante a leitura de histórias, cujas respostas não eram facilmente dedutíveis, melhorava a compreensão dessas palavras, assim como facilitava a formação de relações dessas palavras novas com seus referentes. Quando comparados os desempenhos das crianças para as palavras-alvo que tiveram perguntas cujas respostas não eram facilmente dedutíveis, com aquelas palavras em que as perguntas indicavam respostas dedutíveis, o maior número de acertos ocorreu na primeira situação.

De forma semelhante, Smeets e Bus (2012) examinaram se informações extratextuais de vocabulário embutidas em livros de histórias facilitavam a aprendizagem de palavras em comparação a uma situação sem estas informações. Além disso, investigaram também se as informações que exigiam das crianças mais esforço (perguntas que solicitavam definições) eram mais eficazes do que os formatos que exigiam menos esforço (definições que forneciam descrições). Seus resultados indicaram que as crianças aprenderam mais palavras quando a leitura apresentava 
informações extratextuais de vocabulário, do que sem elas, e observaram, também, que as questões (situações com maior esforço) foram mais benéficas do que apenas fornecer uma definição (situações de menor esforço). Esta forma de leitura compartilhada tem sido demonstrada como eficiente para ganhos significativamente maiores no vocabulário, do que situações regulares de leitura de livro (Blewitt, et al., 2009; Hargrave \& Sénéchal, 2000).

Além da influência da forma como a leitura é feita, outros elementos contextuais podem exercer um papel facilitador na aprendizagem de palavras por meio da leitura de livros. Por exemplo, Elley (1989) encontrou resultados positivos na aprendizagem de palavras quando eram fornecidas explicações adicionais acerca do seu significado. Em um estudo semelhante, Wilkinson e Houston-Price (2013) investigaram se a apresentação do significado de novas palavras, no decorrer da história, influenciaria sua aprendizagem. As autoras propuseram um experimento em que as palavras desconhecidas eram apresentadas em duas condições: apresentação explícita da definição da palavra, e definição da palavra por meio de indícios apresentados no contexto narrativo. Também foi manipulado o contexto de apresentação das novas palavras: se seriam feitas três leituras da mesma história, ou se as mesmas palavras iriam ser apresentadas em três diferentes histórias. O experimento foi conduzido com crianças mais novas (em torno de seis anos) e crianças mais velhas (em torno de nove anos). Os resultados demonstraram que palavras podem ser incidentalmente aprendidas por crianças enquanto elas ouvem uma história, e que não se trata de um aprendizado momentâneo/transitório. Além disso, a idade e o vocabulário prévio determinaram a extensão da aprendizagem da criança. A aprendizagem foi beneficiada pela apresentação explícita do significado da palavra a ser conhecida, e pela apresentação das palavras na mesma história repetidas vezes, em contraposição à apresentação em 
diferentes histórias. Assim, a aprendizagem de uma nova palavra foi beneficiada pela apresentação de explicações adicionais a respeito de seu significado, e pela repetição desta palavra na mesma história, o que sugere que a compreensão inicial do significado de uma palavra em um certo contexto tem um papel crucial na sua aprendizagem. Contudo, as mesmas críticas feitas anteriormente ao trabalho de Elley (1989), podem ser repetidas para este e outros trabalhos que não fazem uso de pseudopalavras, nem de histórias não comerciais.

Por isso, considerando o que foi exposto até o momento sobre a importância da apresentação do significado para a aprendizagem de uma nova palavra, é interessante questionar quais dicas contextuais auxiliam a criança a compreender o significado de uma nova palavra, e se a criança consegue abstrair essa informação do contexto geral da história. Além disso, é importante saber se, em um delineamento de controle experimental mais restrito (com a utilização de pseudopalavras apresentadas em uma história não comercial) os resultados positivos encontrados na literatura sobre a apresentação de informações adicionais de uma palavra poderiam ser replicados. Uma das possíveis variáveis que podem influenciar este processo de abstração de informações a partir do contexto é a apresentação de informações sobre a função de um objeto desconhecido no contexto da história. Possivelmente, a compreensão do significado completo de uma palavra seja construída a partir de elementos mais simples, como a discriminação da função que esta palavra, e seu objeto referente, exercem no contexto em que estão sendo apresentados. Desta forma, chega-se à seguinte questão: a aprendizagem de uma palavra nova é facilitada quando dicas relacionadas à função/utilidade de seu referente são apresentadas no contexto da história? Provavelmente, relacionar uma palavra desconhecida a um referente que tenha uma função definida (por exemplo, servir para guardar coisas) seja mais fácil que relacionar 
dois estímulos novos (palavra e referente) sem que haja sobre eles quaisquer informações adicionais. Considerando que o fornecimento de informações, como o significado da palavra, podem auxiliar sua aprendizagem, a apresentação de informações sobre a função do referente de uma palavra poderiam servir como dicas contextuais adicionais para sua aprendizagem. Um dos objetivos do presente estudo foi, portanto, investigar o papel da apresentação da função na aprendizagem de novas palavras, dentro de um delineamento experimental que busca evitar variáveis intervenientes.

Outra questão relacionada à apresentação da utilidade de um objeto refere-se ao quanto esse tipo de dica pode ser útil para crianças em diferentes fases do desenvolvimento da linguagem. A literatura não apresenta trabalhos em que dicas contextuais mais elaboradas (como a apresentação do significado das palavras) são apresentadas para crianças mais jovens. Assim, outra questão empírica que foi investigada no presente estudo foi: crianças mais jovens (em torno dos 3 anos) são sensíveis à apresentação da função específica de uma palavra (da utilidade de seu referente), quando apresentada no contexto da história, em comparação com crianças em idade escolar (7 anos)? Quanto crianças mais novas conseguem discriminar a apresentação da utilidade de um dado referente, quando comparadas às crianças mais velhas? Uma diferença muito evidente entre esses desempenhos indicaria que nem todo recurso utilizado durante a leitura de histórias é igualmente relevante para todas as faixas etárias, isto é, o quanto algumas variáveis podem auxiliar a aprendizagem de novas palavras durante a leitura de histórias pode depender da idade das crianças para as quais a história está sendo contada.

Esta diferença pode ocorrer em função do fato de que crianças pequenas respondem diferentemente a situações de aprendizagem de novas palavras, e crianças 
mais velhas, evidentemente com maior vocabulário, são mais capazes de usar dicas do contexto para aprender uma quantidade maior de novas palavras. Este tipo de fenômeno, em que há uma influência positiva do vocabulário prévio da criança durante a aprendizagem de palavras, tem sido conhecido como Matthew Effect. Stanovich (1986), em uma revisão acerca da habilidade de leitura, descreve este fenômeno e inaugura o uso deste termo. $\mathrm{O}$ autor defende que o vocabulário prévio da criança influencia a aprendizagem de novas palavras, dizendo que, quanto maior o vocabulário da criança, maior será a sua aprendizagem de vocabulário.

A ocorrência deste fenômeno tem sido também relatada em pesquisas sobre leitura compartilhada de livros (mesmo quando não se está avaliando a habilidade de ler do participante). Por exemplo, Robbins e Ehri (1994) realizaram um estudo com crianças de 6 anos, em que investigavam como crianças aprendem novas palavras por meio da leitura de histórias, e classificaram seus participantes em três grupos, de acordo com seus respectivos níveis de vocabulário prévios: com baixo, médio e alto. Seus resultados demonstraram que crianças do grupo de maior nível de vocabulário aprenderam uma quantidade maior de palavras que as crianças dos demais grupos. $\mathrm{Na}$ pesquisa de Wilkinson e Houston-Price (2013), as autoras compararam, entre algumas condições experimentais (descritas anteriormente), o desempenho da aprendizagem de novas palavras de crianças de 6 e 9 anos, em situação de leitura compartilhada de história. Elas avaliaram o tamanho do vocabulário prévio dos participantes (classificados em "maior vocabulário" e "menor vocabulário") e seus resultados indicaram que os melhores desempenhos foram do grupo de participantes de crianças mais velhas e das crianças que possuíam um vocabulário prévio maior, e que essas duas variáveis apresentaram um efeito aditivo responsável por uma variância de cerca de $20 \%$ do desempenho destes participantes. No estudo de Sénéchal, Thomas e Monker 
(1995), conduzido com crianças de 4 anos, as autoras investigaram a influência do vocabulário prévio na aprendizagem de palavras, e de diferentes formas das crianças interagirem com o adulto (apontado figuras, respondendo a perguntas, ou apenas ouvindo a história) durante diferentes sessões de leitura de história. As autoras demonstraram que crianças com maior vocabulário, e que participavam ativamente da leitura da história (apontado figuras, ou respondendo a perguntas), aprendiam mais palavras que aquelas crianças com menor vocabulário, e mais palavras que aquelas crianças que passaram pelas condições de leitura passiva (apenas ouvindo a história).

A influência do vocabulário prévio da criança na aprendizagem de novas palavras, em que crianças com maior o vocabulário se beneficiam mais em situações de aprendizagem, do que crianças de menor vocabulário pode decorrer, provavelmente, do fato de que as crianças com maior vocabulário são mais capazes de realizar discriminações condicionais com maior grau de refinamento que aquelas crianças com menor vocabulário. Ou seja, estas crianças conseguem formar e manter mais classes de estímulos de relações arbitrárias, repertórios intrinsicamente relacionados ao desenvolvimento da linguagem (De Rose, 1993). Esta capacidade das crianças mais velhas pode ser decorrente de maior experiência dessas crianças com o idioma e com a comunidade verbal, que possivelmente lhes proporcione melhores condições de ficar sob controle de dicas contextuais. Desta forma, ainda que os estudos descritos anteriormente tenham investigado a ocorrência do Matthew Effect sobre a aprendizagem de novas palavras, geralmente, utilizando algum tipo de instrumento para aferir o nível de vocabulário da criança antes da realização do procedimento de leitura (e.g., Peabody Pictures Vocabulary Test - PPVT, British Picture Vocabulary Scale - BPVS, ABFW: teste de linguagem infantil nas áreas de fonologia, vocabulário, fluência e pragmática), é 
factível pensar que a comparação entre o desempenho de crianças diferentes idades seja possível.

É necessário considerar as evidentes diferenças apresentadas no desenvolvimento linguístico de cada faixa etária. Crianças de 3 anos encontram-se em um estágio em que acabaram de passar por um fenômeno chamado de explosão nominal. A partir deste ponto, as crianças passam a aprender novas palavras em uma velocidade muito maior que quando mais jovens, tornando-se capazes de aprender de dez a 20 palavras por semana, o que caracteriza este período como uma etapa de rápida expansão de vocabulário (Shafer, 2005). Apresentam ainda, frases que possuem de três a quatro elementos linguísticos, e conseguem produzir sentenças simples (Vila, 1995). Fonologicamente, este é um período caracterizado por omissões e substituições de várias sílabas, ainda que haja também um aumento do inventário fonético usado nas estruturas silábicas (Wertzner, 2009).

As crianças de 7 anos, por outro lado, já apresentam conhecimento morfológico elaborado, e sintaxe completa, usando a gramática de forma coerente com o uso convencional de sua comunidade verbal (Vila, 1995). São capazes de detectar erros gramaticais, discriminam regras sintáticas complexas, e são capazes de compreender aproximadamente 10 mil palavras (Shafer, 2005). Nesta idade, também, o sistema fonológico está se estabilizando, e as crianças são capazes de produzir, de forma adequada, os sons das palavras de sua língua materna (Wertzner, 2009). Diante dessas claras diferenças, e levando em consideração o que a literatura apresenta sobre o fenômeno do Matthew Effect, é possível supor que, em situações de leitura de histórias, as crianças mais velhas se beneficiem muito mais que as crianças mais novas, em função justamente de seu repertório verbal mais amplo e bem estabelecido. 
Apesar de se verificar que as diferenças entre idade ou níveis de vocabulário são variáveis que interferem na aprendizagem de novas palavras em situação de leitura compartilhada, verifica-se que a maioria das pesquisas tende a homogeneizar suas amostras: ou crianças mais velhas, em estágio de alfabetização (Wilkinson \& HoustonPrice, 2013), ou crianças mais jovens, em idade pré-escolar (McLoad \& McDade, 2011; Robbins \& Ehri, 1994). Não se encontram, na literatura, trabalhos que comparem diretamente o desempenho de crianças, em que a diferença em termos de desenvolvimento linguístico seja significativa, como seriam as idades de 3 e 7 anos. Em função dessa diferença de idade, seriam esperados desempenhos bastante distintos entre estes dois grupos etários em relação à aprendizagem de novas palavras. Possivelmente, assumindo as considerações sobre o Matthew Effect, o grupo de crianças mais velhas teria um desempenho expressivamente melhor que o das crianças mais jovens, mas esta é uma questão empírica ainda não respondida. Dado este fato, uma das propostas do presente estudo foi investigar se essa diferença de idade tem efeito sobre a aprendizagem de novas palavras na situação de leitura compartilhada de histórias, comparando desempenhos de crianças de 3 e 7 anos (idades distintas em termos de desenvolvimento da linguagem), e a provável existência do Matthew Effect entre este dois grupos etários.

É importante ainda, considerar a quantidade de palavras-alvo que serão solicitadas às crianças durante as tarefas experimentais. Horst et al. (2011) apresentaram, em uma sessão de leitura, pares de pseudopalavras a crianças de 3 anos, e seus resultados indicaram que as crianças aprenderam de forma consistente as duas pseudopalavras apresentadas na história. Considerando o estudo de Horst et al., em que as crianças aprenderam duas palavras, uma última proposição é feita no presente trabalho: um número maior de palavras (em uma situação controlada) pode ser 
aprendida por meio da leitura de histórias? Assim, investigou-se a aprendizagem de quatro novas palavras por crianças de 3 anos e 7 anos.

Outra consideração a ser feita sobre os detalhes metodológicos das pesquisas que investigam a aprendizagem de palavras refere-se à natureza dos estímulos empregados nos experimentos. Alguns dos trabalhos, apresentados anteriormente, utilizaram como estímulos palavras existentes na língua materna das crianças (e.g., Robbins \& Ehri, 1994; Wilkinson \& Houston-Price, 2013), apresentadas em histórias comerciais. Ainda que sejam realizados pré-testes, tais instrumentos não garantem que o contato prévio que o participante possa ter com as palavras-alvo não possa interferir na aprendizagem durante a leitura. Desta forma, é desejável, para um controle mais refinado das variáveis experimentais, a utilização de pseudopalavras em estudos que investigam aprendizagem de vocabulário (Horst et.al., 2011), garantindo que os participantes não terão sido expostos anteriormente às palavras alvo, e que os resultados do estudo são decorrentes da manipulação experimental, e não de alguma exposição adicional.

Faz-se necessário ainda, definir claramente os parâmetros empregados para verificar a aprendizagem das novas palavras no contexto estudado. Em um estudo de revisão a respeito de aprendizagem a partir da leitura de livros, Horst (2013), trata sobre a dificuldade de indicar o exato momento em que uma palavra desconhecida passa a ser conhecida, defendendo que há um contínuo de familiaridade entre palavras novas e palavras conhecidas e que, desta forma, este processo pode envolver uma série de repertórios distintos e de diferentes complexidades em relação a um único vocábulo. Por isso, esta autora defende que é preciso um controle experimental muito adequado, em que seja considerada a influência do tipo das palavras, da história e das ilustrações, para que todos esses elementos possam estar sob controle experimental. De modo geral, as 
pesquisas que investigam a ocorrência de aprendizagem de palavras, utilizam apenas tarefas de escolha forçada, nas quais se solicita à criança que indique a palavra alvo (apresentada anteriormente durante a sessão de leitura) tendo, geralmente, quatro figuras como possíveis opções (McLoad \& McDade, 2011; Wilkinson \& Houston-Price, 2013). No entanto, parece importante investigar indícios adicionais de aprendizagem de pseudopalavras a partir da situação de leitura de livros. Considera-se que a aprendizagem de palavras compreende um contínuo de repertórios, dos mais simples, como ser capaz de selecionar um novo estímulo diante de um novo nome ditado (responder por exclusão), até ser capaz se nomear um determinado estímulo em sua presença (aprender a relação condicional existente entre o nome do estímulo e a presença do próprio estímulo - que pode ser visto com um estímulo discriminativo para a resposta de nomeação). Por isso, além das tarefas comumente empregadas em pesquisas sobre o tema (sondas de escolha forçada), o presente estudo investigou a aprendizagem de novas palavras por meio de sondas de responder por exclusão, em que a criança deveria selecionar o objeto indefinido completamente novo tendo como comparações os objetos indefinidos apresentados na história, o que indicaria que a situação de leitura com a apresentação das novas palavras poderia começar a estabelecer uma linha base que daria suporte a esta tarefa. Mais indícios adicionais de aprendizagem foram investigados ainda por meio de sondas de nomeação e de descrição da função/utilidade do referente; e também por meio de sondas de generalização, em que se investigou a ocorrência de generalização dos nomes e figuras dos objetos indefinidos apresentados na história para seus objetos referentes tridimensionais. Os detalhes metodológicos de cada uma destas tarefas serão descritos na sessão seguinte deste estudo. 
Sumarizando, esse estudo teve como objetivo investigar a aprendizagem de relações que envolvem substantivos (pseudopalavras) por crianças de três e sete anos, a partir da leitura compartilhada de livro infantil; comparar a aprendizagem dessas pseudopalavras em dois contextos distintos - com a apresentação da função dos referentes e sem a apresentação desta função; e comparar, também, a aprendizagem de pseudopalavras em diferentes grupos etários (crianças de 3 e de 7 anos). A avaliação da aprendizagem dessas pseudopalavras foi verificada por meio dos seguintes indicadores: a) acertos e erros em sondas de seleção (tarefa de discriminação auditivo-visual); b) desempenho em sondas de exclusão diante de novos estímulos indefinidos (novas pseudopalavras); c)emissão dos nomes dos estímulos indefinidos em sondas de nomeação desses objetos; d) descrição de suas respectivas funções de acordo com o que foi apresentado na história, e) manutenção de todos estes repertórios após uma semana (sondas de retenção), e por fim, f) seleção de objetos tridimensionais correspondentes aos apresentados nas figuras da história, em sondas de generalização. 


\section{Método}

\section{Participantes}

Participaram deste estudo 10 crianças de 3 anos de idade (média de idade: 36,5 meses, dp: 2,8 meses, 31 - 40 meses) de duas escolas filantrópicas de Educação Infantil da cidade de Ribeirão Preto- SP, e 10 crianças de 7 anos de idade (média de idade: 87 meses, dp: 7,4 meses, 75 - 98 meses) recrutadas a partir de uma amostra de conveniência.

O critério de inclusão na amostra, além das respectivas idades, foi a ausência de indicativos de atraso no desenvolvimento, aferido por meio do Teste de Triagem Denver II, adaptado para o português (Pedromônico, Bragatto, \& Strobilus, 1999) nas crianças de 3 anos, e sem relatos de indicativos de atraso no desenvolvimento nas crianças de 7 anos. Esta pesquisa foi aprovada pelo Comitê de Ética e Pesquisa da Faculdade de Filosofia, Ciências e Letras de Ribeirão Preto (Anexo A - Parecer $n^{\circ}$ 639.890; CAAE 19044013.0.0000.5407).

Os responsáveis pelos participantes foram informados sobre a pesquisa, e a autorização para a participação das crianças foi solicitada por meio de um Termo de Consentimento Livre e Esclarecido (Apêndice A). Um pequeno questionário socioeconômico relevou que 54\% dos responsáveis pelos participantes possuía escolaridade até o Ensino Médio, 22\% dos responsáveis possuíam até o Ensino Fundamental, e 18\% apresentavam Ensino Superior. Além disso, a maior parte das famílias dos participantes (64\%) apresentava renda mensal de R\$ 678,01 até R\$ 2.034,00 (entre um e três salários mínimos), e tinha responsáveis com jornada de trabalho de mais de 30 horas semanais (57\%). 


\section{Local}

Para o grupo de crianças de 3 anos, a coleta de dados ocorreu em local cedido pelas duas instituições escolares, na cidade de Ribeirão Preto- SP, no qual a pesquisadora ficou com um participante por vez, sentado ao seu lado, a fim de assegurar que as figuras (ilustrações) do livro estivessem sendo vistas. Ambas as instituições eram religiosas (uma espírita e outra católica), filantrópicas e funcionavam em período integral, atendendo crianças na faixa etária dos 2 aos 6 anos.

Para o grupo de crianças de 7 anos, a coleta de dados foi realizada na casa dos participantes, com a pesquisadora se dirigindo até a residência das crianças, em um horário previamente combinado.

\section{Materiais e Equipamentos}

\section{Livro}

Foi elaborado um livro com uma história infantil simples, sobre uma situação cotidiana e apropriada à idade das crianças. A pesquisadora e uma fotógrafa produziram as ilustrações, que consistiam em fotografias de cenas montadas em cenários construídos na casa da pesquisadora, sendo os atores seus familiares. As imagens foram tratadas e editadas no Photoshop usando efeitos blur (para destacar os objetos indefinidos em cada ilustração) e poster edges (para que as ilustrações parecessem traços de desenhos), tornando-as mais parecidas com as ilustrações típicas dos livros infantis (Horst et al., 2011). Todas as imagens apresentaram conteúdo adequado para crianças (por exemplo, uma criança segurando um dos brinquedos em seu quarto).

O livro continha 16 páginas, de tamanho A4 $(297 \mathrm{~mm} \times 210 \mathrm{~mm})$, impressas em papel couche, gramatura $180 \mathrm{~mm}$ e encadernação em espiral. Cada página do livro foi composta por ilustração e pelo o texto (abaixo da imagem), cujo conteúdo 
máximo foi de cinco linhas (fonte: Berlin Sans FB, tamanho: 24). O roteiro da história é apresentado no Apêndice B.

\section{Pseudopalavras-objetos}

Ao longo da história foram apresentados quatro substantivos indefinidos (pseudopalavras inventadas): "Nezaca" (I1), "Vanito" (I2) "Fulito" (I3), e "Pafile" (I4). Todas as palavras foram substantivos concretos, trissílabos, formados a partir de sílabas simples (junção consoante-vogal). As consoantes escolhidas para compor cada sílaba das pseudopalavras foram selecionadas obedecendo ao quadro fonético de classificação das consoantes segundo a norma gramatical brasileira (Wertzner, 2009), em que cada fonema deveria pertencer a um modo de articulação diferente (oclusivas, fricativas, laterais, vibrantes e sonoras) entre os modos de articulação que crianças de 3 anos são capazes de produzir. Metade destas palavras não teve função definida na história ("Vanito" e "Pafile"). As outras palavras ("Nezaca" e "Fulito") foram apresentadas junto com alguma função, que lhe era definida no contexto (por exemplo, "Vou pegar meu fulito para guardar o giz de cera").

Nas ilustrações da história os atores apareceram manuseando os objetos indefinidos referentes às pseudopalavras. Todos os objetos (seis - quatro presentes na história, e mais dois para as sondas de Exclusão) foram construídos pela pesquisadora, especificamente para esta pesquisa, com material de sucata (ver Figura 1). Cada substantivo foi apresetando três vezes na história junto com sua respectiva imagem. Em nenhuma das ilustrações mais de um objeto indefinido foi apresentado. 


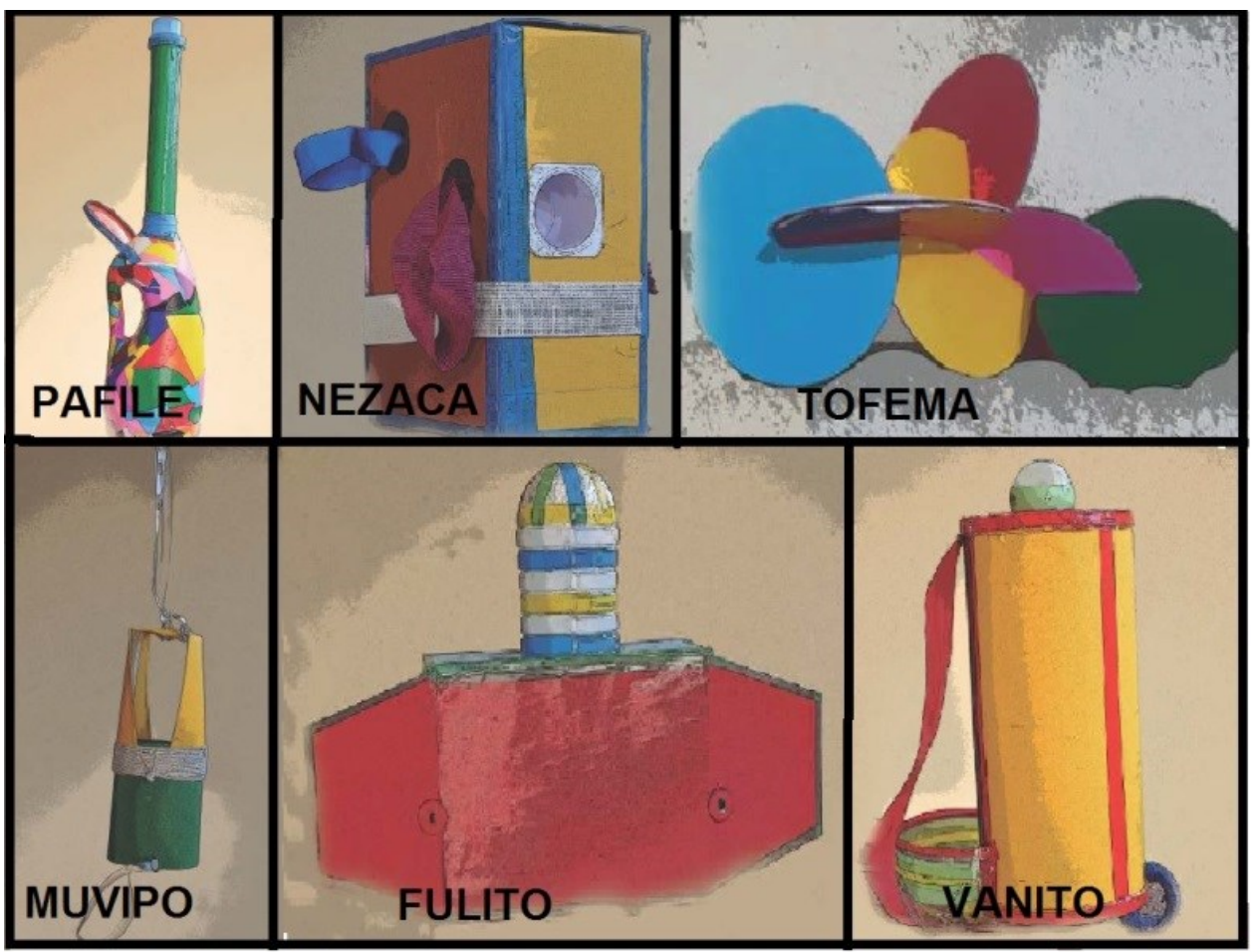

Figura 1- Os objetos indefinidos e seus nomes, confeccionados para esta pesquisa. Nezaca (I1), Vanito (I2) Fulito (I3) e Pafile (I4)foram os objetos apresentados na história. Tofema e Muvipo foram apresentados apenas no livro de testes, nas sondas de Exclusão.

\section{Sondas}

Para a realização das sondas, foi confeccionado um Livro de Testes, composto por 22 páginas (igualmente produzidas com o auxílio do Photoshop, impressas em papel off-set e plastificadas) que continham tanto imagens dos objetos indefinidos que eram apresentados na história e nas sondas de Exclusão, como imagens de objetos definidos (por exemplo, carrinho de brinquedo, bola, boneca, ou seja, figuras com as quais a criança possivelmente já estivesse familiarizada e cujos nomes ela conhecesse).

As primeiras duas páginas do Livro de Testes continham apenas figuras definidas (quatro por página). A tarefa da criança era identificar os objetos cujos nomes eram ditados pela pesquisadora (discriminação auditivo-visual). As quatro páginas seguintes do livro foram empregadas em Sondas de Controle por Seleção, e tiveram configuração semelhante às páginas de compreensão da tarefa. Em duas delas, foram 
apresentadas quatro figuras, duas de objetos definidos e as outras duas de objetos indefinidos (os mesmos que apareceram na história - I1 e I4 em uma, e I2 e I3 na outra). Para cada uma dessas páginas foram conduzidas duas tentativas de sonda, em que os modelos auditivos eram, ora as pseudopalavras, ora palavras conhecidas (ver Figura 2-A). As outras duas páginas continham apenas imagens dos objetos indefinidos (os quatro apresentados na história), e era conduzida apenas uma tentativa por página (os modelos ditados eram as duas pseudopalavras que não foram apresentadas nas tentativas anteriores - I3 e I4). Portanto, havia duas configurações para as sondas de Seleção, e tanto na primeira (que continha objetos conhecidos e indefinidos), quanto na segunda configuração (apenas com objetos indefinidos), havia um modelo ditado com função, e um modelo ditado sem função. As respostas corretas $(\mathrm{S}+)$ nunca estavam no mesmo quadrante por duas vezes consecutivas, e a posição de todos os objetos indefinidos foi contrabalanceada entre os quadrantes. O objetivo desta tarefa foi verificar se a criança aprendeu a relação nome-objeto a partir das figuras apresentadas na história.

As duas páginas seguintes foram empregadas nas sondas de Exclusão (ver Figura 2-B). Eram apresentados três objetos indefinidos já vistos na história e um objeto indefinido completamente novo (I5- "Tofema" na primeira página, e I6“Muvipo” na segunda página). O objetivo destas sondas foi verificar se a aprendizagem dos objetos indefinidos se estabeleceu de tal forma, que a criança fosse capaz de responder por exclusão diante de uma matriz de escolhas que contivesse os estímulos "indefinidos" apresentados na história e outro estímulo completamente novo. Com isso, seria possível verificar se a aprendizagem das relações nome-figura apresentadas na história foi suficiente para garantir a estes objetos o status de "objetos definidos", o que sustentaria o responder por exclusão diante de um novo estímulo indefinido. 


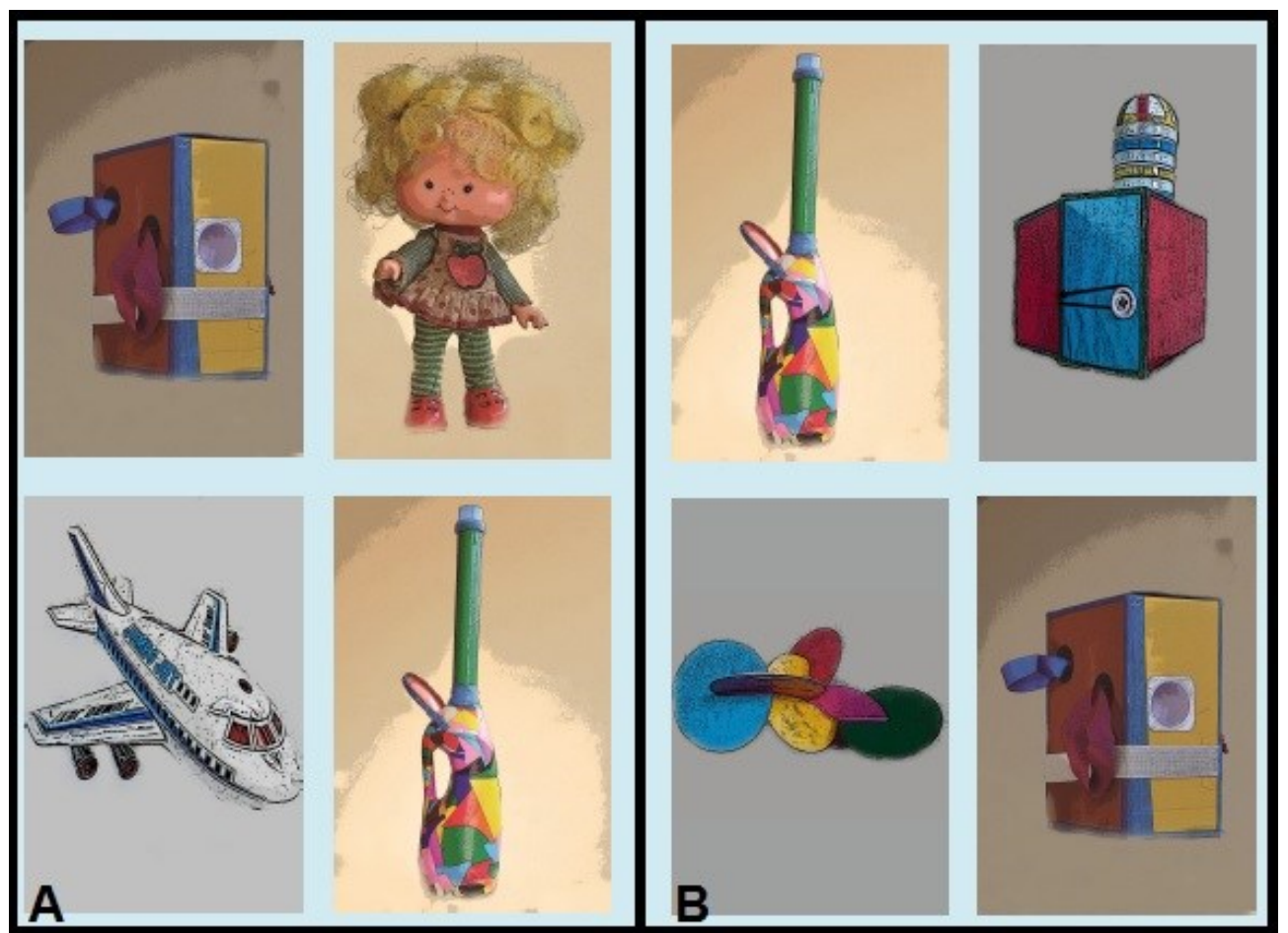

Figura 2- A- Exemplo de uma página do livro de testes para a sonda de Seleção. Objetos definidos e indefinidos (I1 e I4) são apresentados na mesma página. B- Exemplo de uma página do livro de testes para a sonda de Exclusão, apresentando três objetos indefinidos (I1, I3 e I4) e um indefinido completamente novo (I5).

As 14 páginas finais do Livro de Testes continham imagens individuais de cada objeto (definidos, indefinidos e indefinidos empregados nas sondas de Exclusão). Estas figuras foram utilizadas para as sondas de Nomeação e de Descrição de Função (ver Figura 3). A cada página, foi pedido que a criança nomeasse a figura e dissesse sua função (a pesquisadora perguntava: "Qual o nome disso? Você sabe para que isso serve?). 


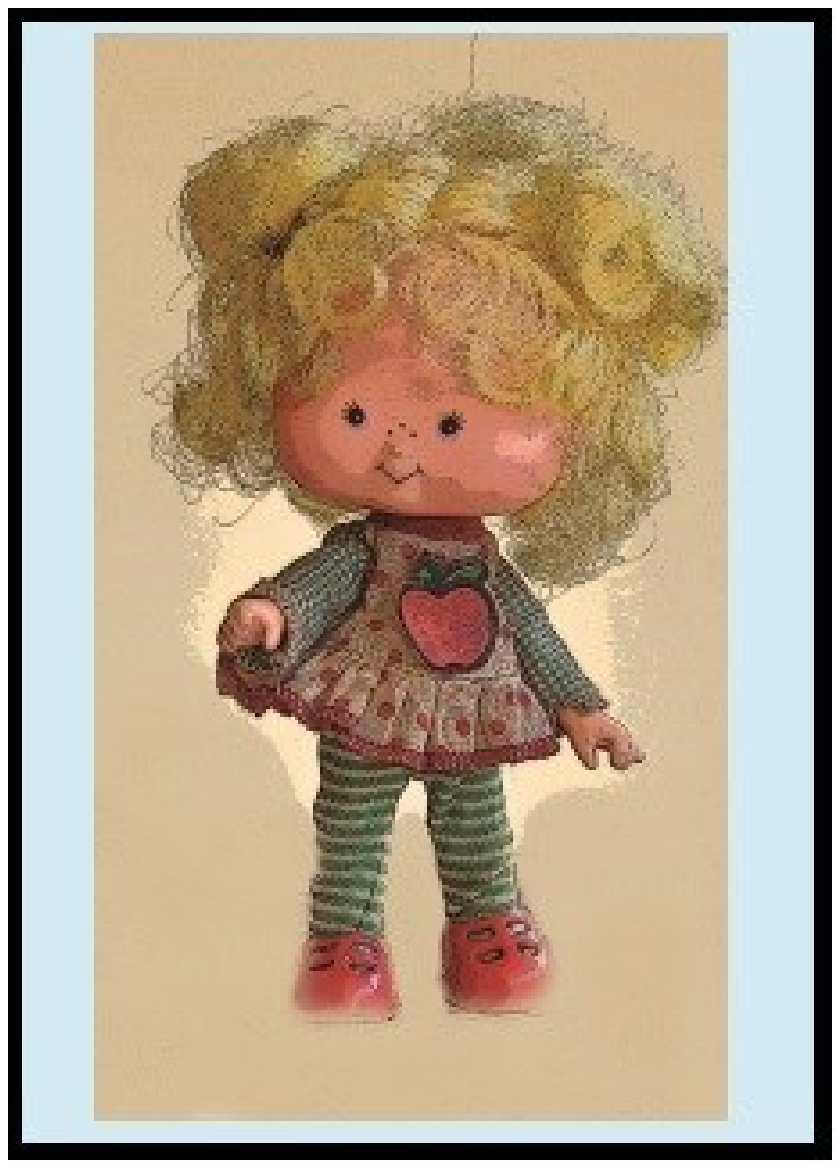

Figura 3- Exemplo de uma página do livro de testes para a sonda de Nomeação e de Descrição de Função. Todos os objetos definidos e indefinidos foram apresentados individualmente.

Durante a Fase de Sondas de Retenção (realizadas, em média, sete dias após a leitura), além das sondas já descritas, apresentadas com o auxílio do Livro de Testes, foram apresentados os objetos tridimensionais de sucata na condução de uma Sonda de Generalização (ver Procedimentos). Pretendeu-se verificar se a criança era capaz de selecionar os objetos tridimensionais a partir do seu nome ditado. A Tabela 1 ilustra a composição das tentativas que foram conduzidas com o Livro de Testes, detalhando os estímulos presentes em cada tentativa por tipo de sonda. 


\section{Tabela 1}

Configuração das páginas do Livro de Testes para cada tipo de sonda. As páginas seguintes às sondas de Exclusão eram compostas por apenas uma figura por página. Essas páginas (9-22) se alternavam entre imagens de objetos definidos (brinquedos conhecidos pelas crianças), e imagens dos objetos indefinidos (apresentados tanto na história, quanto nas sondas de Exclusão).

\begin{tabular}{|c|c|c|c|c|c|c|c|}
\hline \multirow{2}{*}{$\begin{array}{l}\text { Tipo de Sonda } \\
\text { Compreensão }\end{array}$} & \multirow{2}{*}{$\begin{array}{c}\text { Página } \\
1\end{array}$} & \multirow{2}{*}{$\begin{array}{c}\text { Tentativas } \\
1\end{array}$} & \multirow{2}{*}{$\begin{array}{c}\text { Modelo } \\
\text { Avião }\end{array}$} & \multicolumn{4}{|c|}{ Comparações } \\
\hline & & & & Avião & Piano & Boneca & Bola \\
\hline \multirow[t]{3}{*}{ da tarefa } & & 2 & Bola & Avião & Piano & Bola & Boneca \\
\hline & 2 & 3 & Relógio & Trem & Relógio & Macaco & Carro \\
\hline & & 4 & Carro & Trem & Relógio & Macaco & Carro \\
\hline Sondas de & 3 & 1 & Boneca & Nezaca & Boneca & Avião & Pafile \\
\hline Controle por & & 2 & Nezaca & Nezaca & Boneca & Avião & Pafile \\
\hline \multirow[t]{4}{*}{ seleção } & 4 & 3 & Macaco & Trem & Fulito & Vanito & Macaco \\
\hline & & 4 & Vanito & Trem & Fulito & Vanito & Macaco \\
\hline & 5 & 5 & Fulito & Fulito & Nezaca & Pafile & Vanito \\
\hline & 6 & 6 & Pafile & Vanito & Pafile & Nezaca & Fulito \\
\hline \multirow[t]{2}{*}{ Exclusão } & 7 & 1 & Tofema & Pafile & Fulito & Tofema & Nezaca \\
\hline & 8 & 2 & Muvipo & Fulito & Vanito & Pafile & Muvipo \\
\hline
\end{tabular}

\section{Registro das respostas}

Para registrar as respostas da criança nas Sondas de Seleção e de Exclusão foi pedido que a criança colasse um adesivo (fornecido pela pesquisadora) sobre a figura escolhida. Além disso, a pesquisadora gravou o áudio das sessões experimentais e utilizou uma ficha de registro das respostas, na qual transcreveu as informações 
registradas no Livro de Testes e as respostas às sondas de Nomeação e Descrição da Função. Foram filmadas as respostas dos participantes na presença dos objetos tridimensionais das Sondas de Generalização.

\section{Procedimentos}

As sessões experimentais se iniciaram logo após a avaliação de todas as crianças autorizadas a participar da pesquisa. Foram realizadas duas sessões experimentais: a primeira era composta pela Fase de Leitura e pela Fase de Sondas de Aprendizagem - sondas de Seleção, de Exclusão, de Nomeação e Descrição da Função; a segunda sessão, conduzida cerca de sete dias depois da primeira, foi composta pela Fase de Sondas de Retenção, novamente repetindo-se as sondas Seleção, de Exclusão, de Nomeação e Descrição da Função, e ainda composta pelas sondas de Generalização.

\section{Fase de leitura}

A primeira sessão experimental se iniciava com a leitura do livro. A pesquisadora leu a história para a criança por três vezes consecutivas, apresentando as imagens ilustrativas de cada trecho da história, conforme seguia a leitura. Possíveis perguntas das crianças sobre a história eram respondidas com a seguinte frase: "Vamos ver o que acontece agora?". Ao fim da primeira e da segunda leitura, a pesquisadora dizia “Vamos ler de novo?”. Logo em seguida, a leitura era reiniciada. 


\section{Fase de Sondas - Aprendizagem e Retenção}

\section{Compreensão da tarefa}

Após as leituras, cada criança passou individualmente por um conjunto de tentativas de sonda, conduzidas a partir do Livro de Testes. Nas sondas de compreensão da tarefa, a pesquisadora ditou o nome de um objeto conhecido e pediu para a criança indicar (colando um adesivo em cima) qual das figuras da página do livro correspondia à palavra ditada (por exemplo, a pesquisadora disse: "Cola pra mim onde está a bola?", e a criança deveria colar o adesivo sobre a figura da bola na página do Livro de Teste). Eram feitas quatro tentativas de compreensão da tarefa, duas para cada página do livro (ver Tabela 1). As respostas corretas emitidas pela criança eram seguidas de elogios, tais como "Parabéns!", "Você acertou!". Caso a criança errasse a escolha, a pesquisadora apresentava uma tentativa de correção na mesma página do livro, dizendo, por exemplo: "Não, X, essa não é a figura da bola. Vamos tentar de novo? Mostre para mim a figura do avião”. Se a criança errasse três tentativas consecutivas (incluindo as tentativas de correção) a Fase de Sondas era encerrada, a criança era novamente encaminhada para a classe e seus dados excluídos da análise.

\section{Sondas de Controle por Seleção e Exclusão}

Em seguida foram apresentadas as Sondas de Controle Seleção, em que a criança deveria, também, apontar para as figuras correspondentes às palavras ditadas pela pesquisadora. Nessas tentativas, as figuras dos objetos indefinidos estavam entre as alternativas de escolha. A pesquisadora perguntava, por exemplo: "Onde está o fulito?", e a criança deveria indicar, dentre as opções disponíveis, a imagem correspondente ao objeto indefinido fulito. Nessas tentativas, a criança não recebia 
nenhum feedback da pesquisadora em relação às suas respostas específicas (corretas ou não). A primeira e a terceira tentativas solicitavam que a criança indicasse figuras de objetos definidos. Desta forma, nas duas primeiras páginas, eram realizadas duas tentativas por página. Ao final da(s) tentativa(s) de cada página, a pesquisadora apenas dizia: "Vamos ver quais são as figuras da próxima página?", e apresentava a próxima folha do teste. A configuração das folhas de cada tipo de prova deste teste foi descrita na Tabela 1 e parcialmente ilustrada pela Figura 2A. O mesmo procedimento se repetiu durante as seis tentativas deste tipo de sonda.

Em seguida, foram conduzidas as Sondas de Exclusão. Nessas tentativas apareciam mais dois objetos indefinidos (não apresentados na história: I5 e I6). Da mesma forma que nas sondas anteriores, a pesquisadora perguntava: "Onde está o tofema?", e a criança deveria selecionar a figura correspondente dentre as opções (ver Figura 2B).

\section{Sondas de Nomeação e Descrição da Função}

Finalmente, foram apresentadas, individualmente, as figuras dos objetos definidos e indefinidos, e a criança deveria nomeá-los e descrever sua respectiva função. A pesquisadora perguntava: "Qual o nome disso? Você sabe para que isso serve?" e a criança tinha como tarefa responder com o nome e a função do objeto. As figuras se alternavam entre imagens dos objetos definidos e imagens dos objetos indefinidos (apresentados na história e indefinidos novos, apresentados na sonda de Exclusão), totalizando 14 tentativas.

Todos esses quatro tipos de sonda foram apresentados, tanto na Fase de Sondas de Aprendizagem, que acontecia imediatamente após a leitura do livro, quanto na Fase de Sondas de Retenção, que acontecia após, pelo menos, sete dias a Fase de 
Leitura. A única diferença entre as Fases de Sondas de Aprendizagem e de Retenção era a ordem em que as sondas que as compunham eram apresentadas, e a adição de uma quinta sonda (de Generalização). Durante a Retenção as sondas de Nomeação e Descrição da Função foram apresentadas antes das Sondas de Compreensão da tarefa, de Seleção e de Exclusão, para evitar que a apresentação das palavras pela pesquisadora facilitasse a nomeação das figuras. A Tabela 2 ilustra a ordem de apresentação de cada tipo de sonda durante as Fases de Sondas, tanto de Aprendizagem, quanto de Retenção.

Tabela 2

Configuração de cada tipo de sonda que compunha as duas Fases de Sondas: de Aprendizagem e de Retenção, evidenciando a ordem em que cada tipo de sonda era apresentada aos participantes em cada fase.

\begin{tabular}{ccc}
\hline Fase de & Ordem de & Tipo de Sonda \\
Sondas & apresentação & \\
\hline Fase de & $1^{\mathrm{a}}$ & Compreensão da tarefa \\
Sondas de & $2^{\mathrm{a}}$ & Controle por Seleção \\
Aprendizagem & $3^{\mathrm{a}}$ & Exclusão \\
Fase de & $4^{\mathrm{a}}$ & Nomeação e Descrição da Função e Descrição da Função \\
Sondas de & $1^{\mathrm{a}}$ & Compreensão da tarefa \\
Retenção & $2^{\mathrm{a}}$ & Controle por Seleção \\
& $3^{\mathrm{a}}$ & Exclusão \\
& $4^{\mathrm{a}}$ & $5^{\mathrm{a}}$ \\
\end{tabular}




\section{Sondas de Generalização}

Ao final da apresentação do Livro de Testes, para finalizar a Fase de Sondas de Retenção, a pesquisadora conduzia as Sondas de Generalização, na qual a criança tinha contato com os objetos tridimensionais apresentados na história. A tarefa consistia em entregar para a pesquisadora o objeto que esta solicitasse: a pesquisadora dispunha oito objetos (os seis objetos confeccionados para o estudo, e dois brinquedos conhecidos) no chão, lado a lado, em frente à criança, e pedia: "Pegue para mim o nezaca". Depois de pegar o objeto que foi entregue pela criança, a pesquisadora o devolvia para a mesma posição em que ele estava anteriormente e solicitava o próximo objeto. Foram solicitados dois objetos conhecidos (linhas de base) e os quatro objetos correspondentes aos nomes indefinidos apresentados na história, totalizando seis tentativas para cada participante. As escolhas das crianças não eram consequenciadas diferencialmente; ao pegar o objeto, a pesquisadora agradecia, devolvia o objeto à sua posição inicial, e solicitava o próximo objeto.

Esta fase era filmada para posterior registro das respostas das crianças. Ao final de cada sessão, a pesquisadora agradecia à criança, elogiando seu desempenho (sua atenção e colaboração) e deixando-a brincar com os brinquedos (manipulando-os de forma livre), se assim ela desejasse, antes de conduzi-la de volta para a classe.

\section{Análise dos dados}

\section{Análise de grupo}

As respostas das crianças aos testes foram anotadas na folha de registro, e foram computados os erros e acertos às tentativas, conforme a apresentação do modelo em cada tipo de sonda.

Para a análise quantitativa dos dados, foi utilizado um Teste $t$ de Student para amostras pareadas a fim de: a) comparar os diferentes desempenhos apresentados pelos participantes entre as palavras indefinidas apresentadas na história; b) avaliar os 
efeitos da apresentação da função das palavras indefinidas; e c) verificar as possíveis diferenças entre as sondas realizadas. Todas as análises foram realizadas no programa Bioestat 5.3.

\section{Análise dos desempenhos individuais}

\section{Sondas de Controle por Seleção}

O desempenho de cada participante, para cada palavra, nas Sondas de Controle por Seleção foi classificado em quatro categorias de aprendizagem, de acordo com os critérios descritos abaixo.

Aprendizagem consistente- A aprendizagem da palavra era considerada consistente quando o participante respondia corretamente as sondas realizadas durante a Fase de Sondas de Aprendizagem, e durante a Fase de Sondas de Retenção.

Aprendizagem imediata- A aprendizagem da palavra era considerada imediata quando o participante respondia corretamente somente na sonda realizada durante a Fase de Sondas de Aprendizagem.

Aprendizagem posterior- Ao contrário da categoria anterior, este tipo de aprendizagem era computada quando o participante respondia corretamente somente na sonda realizada durante a Fase de Sondas de Retenção.

Não aprendeu- O desempenho era classificado desta forma quando o participante não apresentava acerto em nenhuma das Fases de Sondas.

\section{Sondas de Exclusão}

As respostas de cada participante foram registradas, e foram computados apenas seus os erros e acertos em cada uma das duas tentativas realizadas tanto Fase de Aprendizagem, quanto na Fase de Retenção. 


\section{Sondas de Nomeação}

Assim como feito nas Sondas de Controle por Seleção, o desempenho dos participantes foi classificado para cada palavra nas mesmas quatro categorias de aprendizagem usadas na categorização das Sondas de Controle por Seleção, utilizandose dos mesmos critérios. Foi considerado acerto, nessas tentativas, apenas nomeações que respeitaram a relação nome-objeto de forma correspondente (falar Fulito diante da figura do mesmo, não diante da figura de outro objeto indefinido).

\section{Sondas de Descrição da Função}

O processo de classificação das Sondas de Descrição da Função foi semelhante ao processo de classificação das Sondas de Controle por Seleção e de Nomeação, isto é, considerou-se o desempenho dos participantes para cada palavra nas mesmas quatro categorias de aprendizagem (Aprendizagem consistente, Aprendizagem imediata, Aprendizagem posterior), utilizando-se dos mesmos critérios. Foi considerado acerto a estas sondas as respostas que descreviam adequadamente a função correspondente à função dos objetos indefinidos apresentada durante a historia.

\section{Sondas de Generalização}

Os desempenhos de cada participante nessas sondas, para cada palavra, foram analisados à parte, uma vez que essas sondas eram aplicadas somente durante a Fase de Sondas de Retenção. Desta forma, foram computados apenas os erros e acertos de cada participante em cada tentativa. 


\section{Resultados}

Inicialmente, serão apresentados os resultados das sondas de exclusão; seguidos pelos resultados das sondas de seleção (evidenciando o efeito da apresentação da funcionalidade das palavras para sua aprendizagem) e os resultados das sondas de nomeação e de descrição da função, tanto para a Fase de Sondas de Aprendizagem quanto para a Fase de Sondas de Retenção. Em seguida serão apresentados os resultados das sondas de Generalização. Por fim, serão apresentadas as principais diferenças de desempenho entre os participantes de cada grupo etário, assim como um panorama geral do desempenho de cada participante, ao longo de todas as sondas.

\section{Sondas de Exclusão}

A Tabela 3 apresenta as respostas de todos os participantes às sondas de exclusão. Nela, observa-se que todos os participantes de 7 anos apresentaram o responder por exclusão, e que os participantes de 3 anos tiveram desempenhos muito variáveis neste tipo de sonda. 
Tabela 3

Respostas às sondas de exclusão dos participantes de 3 anos (P30 a P39) e dos participantes de 7 anos (P70 a P79), durante a fase de sondas de aprendizagem (realizada imediatamente após a leitura) e durante a fase de sondas de retenção (realizada 7 dias após a leitura). $\sqrt{ }$ indica acerto à tentativa - indica erro à tentativa.

\begin{tabular}{|c|c|c|c|c|}
\hline \multirow[b]{2}{*}{ P30 } & \multicolumn{2}{|c|}{ Fase de Aprendizagem } & \multicolumn{2}{|c|}{ Fase de Retenção } \\
\hline & - & - & - & - \\
\hline P31 & $\sqrt{ }$ & - & - & - \\
\hline P32 & - & $\sqrt{ }$ & $\sqrt{ }$ & - \\
\hline P33 & - & - & - & - \\
\hline P34 & - & $\sqrt{ }$ & - & - \\
\hline P35 & $\sqrt{ }$ & $\sqrt{ }$ & - & - \\
\hline P36 & - & - & - & - \\
\hline P37 & $\sqrt{ }$ & $\sqrt{ }$ & $\sqrt{ }$ & $\sqrt{ }$ \\
\hline P38 & - & - & $\sqrt{ }$ & $\sqrt{ }$ \\
\hline P39 & - & - & - & - \\
\hline P70 & $\sqrt{ }$ & $\sqrt{ }$ & $\sqrt{ }$ & $\sqrt{ }$ \\
\hline P71 & $\sqrt{ }$ & $\sqrt{ }$ & $\sqrt{ }$ & $\sqrt{ }$ \\
\hline P72 & $\sqrt{ }$ & $\sqrt{ }$ & $\sqrt{ }$ & $\sqrt{ }$ \\
\hline P73 & $\sqrt{ }$ & $\sqrt{ }$ & $\sqrt{ }$ & $\sqrt{ }$ \\
\hline P74 & $\sqrt{ }$ & $\sqrt{ }$ & $\sqrt{ }$ & $\sqrt{ }$ \\
\hline P75 & $\sqrt{ }$ & $\sqrt{ }$ & $\sqrt{ }$ & $\sqrt{ }$ \\
\hline P76 & $\sqrt{ }$ & $\sqrt{ }$ & $\sqrt{ }$ & $\sqrt{ }$ \\
\hline P77 & $\sqrt{ }$ & $\sqrt{ }$ & $\sqrt{ }$ & $\sqrt{ }$ \\
\hline P78 & $\sqrt{ }$ & $\sqrt{ }$ & $\sqrt{ }$ & $\sqrt{ }$ \\
\hline P79 & - & $\sqrt{ }$ & $\sqrt{ }$ & $\sqrt{ }$ \\
\hline
\end{tabular}

Seis dos dez participantes mais jovens apresentaram responder por exclusão em pelo menos uma das sondas apresentadas nas duas fases. Apenas P37 respondeu corretamente a todas as sondas de exclusão (aprendizagem e retenção); os demais, ou responderam às duas sondas de exclusão na fase de aprendizagem (P36) ou na fase de retenção (P38). Os demais (P31, P34 e P32) responderam por exclusão em apenas uma 
das tentativas apresentadas, ou na fase de sondas de aprendizagem ou na fase de retenção. Quatro participantes (P30, P33, P35 e P39) não apresentaram o responder por exclusão em nenhuma das tentativas de sonda realizadas.

No grupo de crianças de 7 anos, todos participantes apresentaram o responder por exclusão nas duas fases. Apenas um participante (P79) não apresentou esse desempenho em uma tentativa (a primeira) da fase de sondas de aprendizagem. Todos os demais apresentaram um desempenho por exclusão consistente, em ambas as fases de sondas e em todas as tentativas.

\section{Sondas de Controle por Seleção}

A Tabela 4 apresenta as respostas às sondas de controle por seleção (de ambas as fases- aprendizagem e retenção) de todos os participantes para todas as palavras indefinidas. 
Tabela 4

Respostas as Sondas de Controle por Seleção dos participantes de 3 anos (P30 a P39) e dos participantes de 7 anos (P70 a P79) realizadas durante a fase de sondas de aprendizagem (realizada imediatamente após a leitura) e durante a fase de sondas de retenção (realizada 7 dias após a leitura). S1 - nezaca, S2 - fulito (estímulos com função específica definida), S3 - vanito e S4 - pafile (estímulos sem função específica

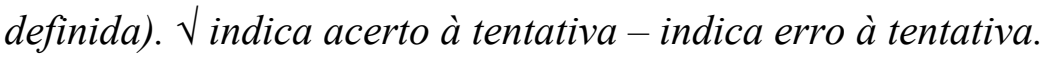

\begin{tabular}{lllllllll}
\hline & \multicolumn{3}{c}{ Fase de Aprendizagem } & \multicolumn{5}{c}{ Fase de Retenção } \\
& S1 & S2 & S3 & S4 & S1 & S2 & S3 & S4 \\
\hline P30 & - & - & $\sqrt{ }$ & $\sqrt{ }$ & - & - & $\sqrt{ }$ & $\sqrt{ }$ \\
P31 & - & - & - & $\sqrt{ }$ & $\sqrt{ }$ & - & - & $\sqrt{ }$ \\
P32 & - & - & - & - & $\sqrt{ }$ & - & $\sqrt{ }$ & - \\
P33 & $\sqrt{ }$ & $\sqrt{ }$ & - & $\sqrt{ }$ & - & - & $\sqrt{ }$ & $\sqrt{ }$ \\
P34 & - & $\sqrt{ }$ & - & $\sqrt{ }$ & - & $\sqrt{ }$ & - & $\sqrt{ }$ \\
P35 & - & $\sqrt{ }$ & $\sqrt{ }$ & - & - & - & $\sqrt{ }$ & $\sqrt{ }$ \\
P36 & - & $\sqrt{ }$ & $\sqrt{ }$ & $\sqrt{ }$ & - & - & - & - \\
P37 & - & - & $\sqrt{ }$ & - & - & - & $\sqrt{ }$ & - \\
P38 & - & - & $\sqrt{ }$ & - & - & - & - & - \\
P39 & $\sqrt{ }$ & $\sqrt{ }$ & $\sqrt{ }$ & $\sqrt{ }$ & $\sqrt{ }$ & $\sqrt{ }$ & $\sqrt{ }$ & $\sqrt{ }$ \\
& & & & & & & & \\
P70 & $\sqrt{ }$ & - & - & $\sqrt{ }$ & $\sqrt{ }$ & $\sqrt{ }$ & $\sqrt{ }$ & $\sqrt{ }$ \\
P71 & $\sqrt{ }$ & $\sqrt{ }$ & $\sqrt{ }$ & $\sqrt{ }$ & $\sqrt{ }$ & - & - & $\sqrt{ }$ \\
P72 & $\sqrt{ }$ & - & - & - & $\sqrt{ }$ & - & - & - \\
P73 & - & - & - & - & $\sqrt{ }$ & - & - & $\sqrt{ }$ \\
P74 & - & - & - & $\sqrt{ }$ & - & $\sqrt{ }$ & $\sqrt{ }$ & - \\
P75 & - & $\sqrt{ }$ & $\sqrt{ }$ & - & - & $\sqrt{ }$ & - & $\sqrt{ }$ \\
P76 & - & - & - & - & - & - & - & - \\
P77 & $\sqrt{ }$ & $\sqrt{ }$ & $\sqrt{ }$ & $\sqrt{ }$ & - & $\sqrt{ }$ & $\sqrt{ }$ & - \\
P78 & - & - & - & - & $\sqrt{ }$ & - & - & $\sqrt{ }$ \\
P79 & - & - & - & - & - & - & - & $\sqrt{ }$ \\
\hline & & & & & & & & \\
\hline
\end{tabular}


Como é possível observar na Tabela 4 o desempenho dos participantes é muito variado, tanto no grupo de crianças mais jovens quanto no de crianças mais velhas. Apenas uma participante (P39) selecionou corretamente todos os estímulos, em ambas as fases de sondas para todas as pseudopalavras apresentadas na história. Outros participantes selecionaram corretamente dois estímulos nas duas sondas aplicadas (P30, P34, P70, P71, P77), ou ainda, para apenas um estímulo (P31, P33, P35, P37, P72, P57), entre os quatro apresentados na história. E alguns participantes (P32, P36, P38, P74, P76, P78, P79) selecionaram corretamente uma pseudopalavra, ora na fase de sondas de aprendizagem, ora na fase de sondas de retenção. Um participante (P76) não selecionou corretamente nenhuma pseudopalavra em nenhuma das sondas.

O desempenho de um mesmo participante em relação a um único estímulo pode ter variado entre as fases de sondas. Em função de suas respostas para cada estímulo, foi atribuída uma classificação de aprendizagem (como já descrito na sessão Materiais e Métodos). Além da aprendizagem consistente, o desempenho dos participantes foi classificado ainda em aprendizagem imediata (seleção correta apenas na fase de sondas de aprendizagem), e posterior (seleção correta apenas na fase de sondas de retenção) e ausência de aprendizagem (seleção incorreta em ambas as fases de sondas). A Figura 4 apresenta, por grupo etário, os resultados dos participantes depois que suas respostas foram classificadas de acordo com estes critérios de aprendizagem. 

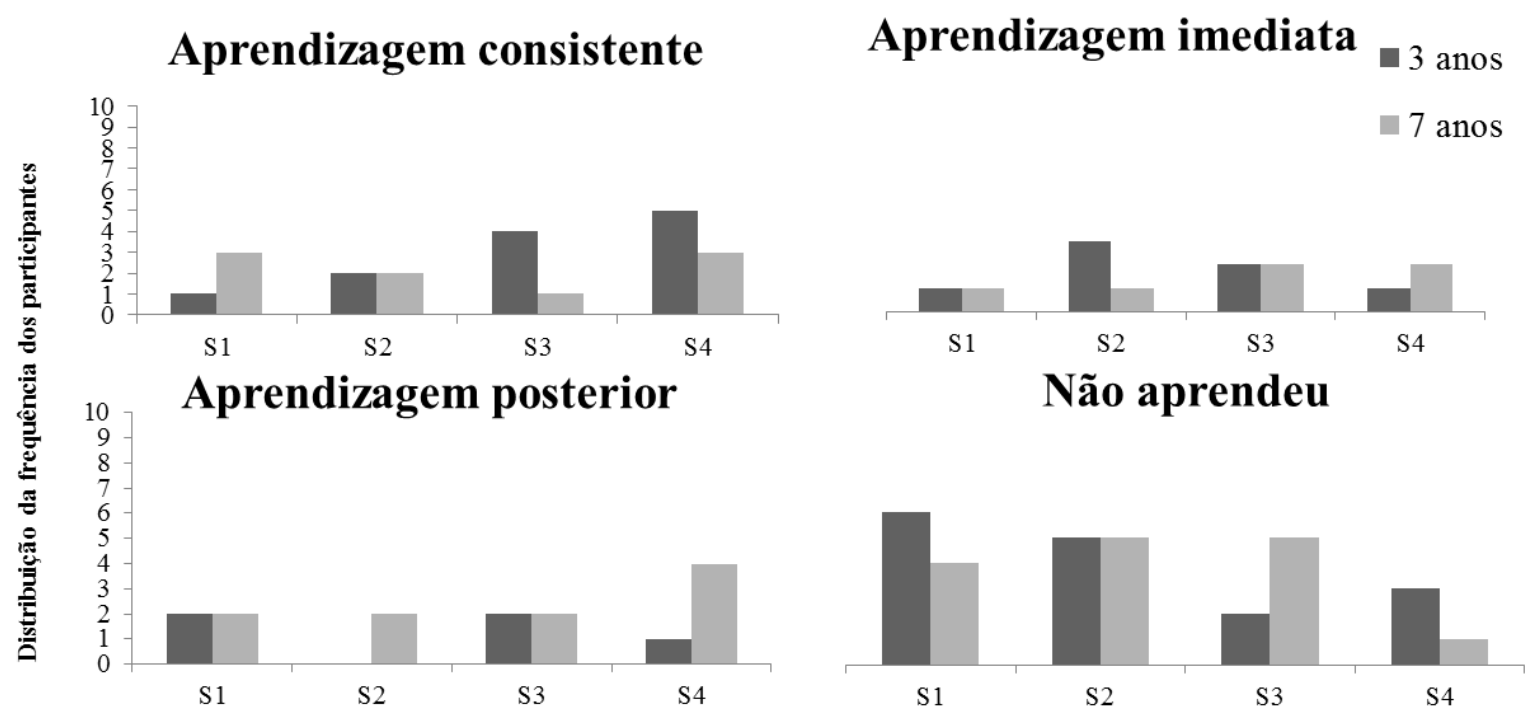

Figura 4- Distribuição de frequência dos participantes que apresentaram diferentes tipos de aprendizagem, segundo a classificação estabelecida de acordo com o desempenho de cada participante durante as fases de sondas de aprendizagem e de retenção.

De modo geral, observa-se que para todas as pseudopalavras, (exceto S3 e S4 para as crianças de 3 anos, e S4 para as crianças de 7 anos), foi constatada maior ocorrência da categoria "Não aprendeu", indicando que a aprendizagem de quatro pseudopalavras por meio da leitura de histórias não foi uma tarefa fácil, mesmo para crianças mais velhas: o desempenho das crianças de 3 anos foi semelhante ao das crianças de 7 anos. Contudo, as crianças jovens tiveram aprendizagem consistente de mais palavras sem função (S3 e S4), enquanto as mais velhas apresentaram aprendizagem consistente tanto de palavras com função quanto sem função. Considerando-se os tipos de estímulos (com e sem função), aqueles em que a função específica era apresentada durante a leitura, ocasionaram menor quantidade de indivíduos que aprenderam as relações nome-figura. Esta diferença de desempenho entre as pseudopalavras que eram apresentadas com uma função específica durante a história, com aquelas pseudopalavras que não tinham função também aparece no total de acertos para estes tipos de estímulos por grupo etário. A Figura 5 ilustra estes dados: 
o eixo y apresenta o número de vezes em que uma das duas pseudopalavras de cada categoria (com ou sem função) foi selecionada corretamente por um participante (por isso o máximo ser 20 - duas pseudopalavras por cada participante); o eixo x apresenta as divisões entre as categorias dos estímulos e dos grupos etários, e essas informações são apresentadas para as duas fases de sondas.

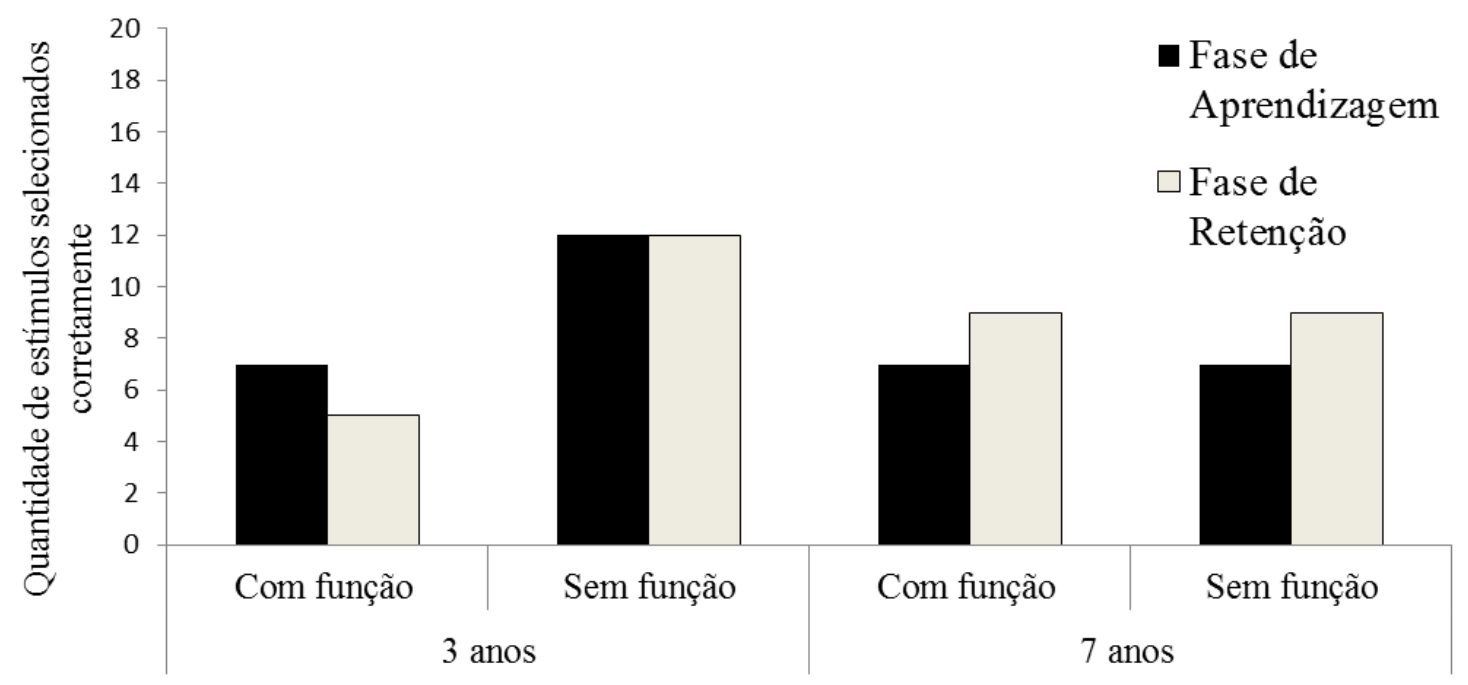

Figura 5- Soma da quantidade de acertos das pseudopalavras com e sem função (máximo de 20 acertos possíveis) para as Sondas de Controle por Seleção das fases de Sondas de Aprendizagem e Retenção, por grupo etário.

Observa-se na Figura 5 que a presença da descrição da função não foi uma variável facilitadora para a aprendizagem destas pseudopalavras, independente da idade dos participantes. Ainda que as crianças mais jovens tenham apresentado um desempenho melhor para as pseudopalavras sem função, esta diferença não foi significativa $(\mathrm{p}=0.072)$. Outro dado de interesse na Figura 5 refere-se à diferença de desempenho entre as duas fases de sondas (fase de aprendizagem e de retenção). Comparando-se os desempenhos de todos os participantes entre os estes dois tipos de fase de sondas, não foram verificadas diferenças significativas $(p=0.4)$. 


\section{Sondas de Nomeação}

Todas as crianças responderam adequadamente às tarefas de nomeação e descrição da função dos estímulos de linha de base (brinquedos comuns, conhecidos pelas crianças), em ambas as fases de sondas de nomeação.

Contudo apenas quatro crianças foram capazes de nomear as figuras dos objetos indefinidos apresentados durante a leitura. As respostas às sondas de nomeação destes quatro participantes encontram-se detalhadas na Tabela 5, assim como as classificações da aprendizagem em função do desempenho nas sondas de seleção.

Tabela 5

Classificação do desempenho dos participantes nas Sondas de Seleção, e suas respectivas respostas na Sonda de Nomeação (Fases de Sondas de Aprendizagem e de Retenção) para as pseudopalavras que foram capazes de nomear de forma correta.

\begin{tabular}{ccll}
\hline & Classificação da Aprendizagem & Fase de Sondas de Fase de Sondas de \\
Participantes & nas Sondas de Seleção & Aprendizagem & Retenção \\
\hline P71 & Aprendizagem consistente & Pafile & Não respondeu \\
P73 & Aprendizagem posterior & Não respondeu & Pafile \\
P74 & Aprendizagem posterior & Fulito & Não respondeu \\
P78 & Não aprendeu & Fulito & Não respondeu \\
\hline
\end{tabular}

Os quatro participantes que nomearam corretamente pertenciam ao grupo de crianças de 7 anos, e cada um nomeou apenas uma das quatro pseudopalavras. Dois deles (P74 e P78) nomearam Fulito, durante a fase de sondas de aprendizagem; e outros dois (P71 e 73) nomearam Pafile, o primeiro durante a fase de sondas de aprendizagem, e o segundo durante a fase de sondas de retenção. As demais crianças não apresentaram resposta alguma (respondiam às tentativas ficando caladas diante da pergunta referente à nomeação), ou apresentaram respostas tais como "Não sei", "Não lembro". Algumas responderam, possivelmente, sob controle de aspectos físicos dos objetos indefinidos, 
atribuindo-os nomes de objetos definidos (e.g. "caixa", "casinha", "mochila"). Outros participantes criaram suas próprias pseudopalavras, ou usaram uma, ou alguma das pseudopalavras apresentadas durante a leitura, de forma indiscriminada.

\section{Sondas de Descrição da Função}

Todas as crianças responderam adequadamente às tarefas de descrição da função dos estímulos de linha de base (brinquedos comuns, conhecidos pelas crianças), em ambas as fases de sondas de descrição de função. A Tabela 6 apresenta as respostas dos participantes, quando solicitados a responder "Para que isso serve?”, em relação às pseudopalavras cujos referentes possuíam função definida durante a história.

Nenhum participante do grupo de 3 anos foi capaz de descrever adequadamente a função dos referentes destas pseudopalavras (S1 e S2). Deste grupo etário, vale destacar as respostas de dois participantes. O primeiro, $\mathrm{P} 37$, que apesar de apresentar um desempenho inadequado a uma solicitação de descrição da função, apresenta respostas que rementem a elementos apresentados na história que tinham estreita relação com o estímulo $\mathrm{S} 2$, do qual a descrição da função foi solicitada. $\mathrm{O}$ segundo participante, P34, apresentou uma resposta adequada, porém ampla em relação à função do objeto solicitado, indicando não ter ficado sob controle da função específica apresentada na história, mas do contexto geral, uma vez que todos os estímulos se tratavam de brinquedos. 
Tabela 6

Respostas dos participantes na Sonda de Descrição da Função nas Fases de Sondas de Aprendizagem e de Retenção para as duas pseudopalavras que foram apresentadas com função durante a história.

\begin{tabular}{lcc}
\hline & $\begin{array}{c}\text { S1-Nezaca } \\
\text { Fase de Aprendizagem }\end{array}$ & Fase de Retenção \\
\hline P30 & isso canta música & para cantar \\
P31 & - & bip bip-onomatopéia de buzina/andar \\
P32 & - & - \\
P33 & - & saco/pra colocar o boliche \\
P34 & lavar roupa & para lavar roupa \\
P35 & de fugir & porque vai fugir \\
P36 & - & apertar/fechar \\
P37 & - & - \\
P38 & - & pra fazer... \\
P39 & - & põe na mão e tá pelado \\
& & pra pendurar coisas* \\
P70 & pra pendurar as coisas* & pra pendurar as coisas* \\
P71 & pra guardar as coisas e pendurar* & acho que é pra guardar coisinha \\
P72 & colocar as coisas* & pra botar giz de cera dentro \\
P73 & negocinho de guardar giz de cera & - \\
P74 & - & - \\
P75 & pra guardar o giz & esqueci \\
P76 & nunca ouvi falar disso & Eu sei pra que que serve, pra guardar coisa, mas eu não sei o nome \\
P77 & - & Prander coisas* \\
P78 & pra prender coisas* & \\
P79 & - &
\end{tabular}

Nota: O asterisco indica respostas classificadas como corretas. 
Tabela 6- Continuação.

\begin{tabular}{|c|c|c|}
\hline & S2-Fulito & \\
\hline & Fase de Aprendizagem & Fase de Retenção \\
\hline P30 & - & contar \\
\hline $\mathrm{P} 31$ & - & - \\
\hline P32 & para dentro & - \\
\hline P33 & - & no saco \\
\hline P34 & brincar & - \\
\hline P35 & dormir & de fechar a porta e abrir \\
\hline P36 & para por do lado & abrir \\
\hline P37 & giz & tem a boneca dentro, abre aqui e aqui \\
\hline P 38 & - & - \\
\hline P39 & blusa & pinta assim \\
\hline $\mathrm{P} 70$ & pra guardar coisas* & pra por coisas dentro* \\
\hline P71 & pra guardar as coisas dentro, ele tava guardando o giz, né* & pra guardar as coisas* \\
\hline P72 & pra muita coisa & pra guardar coisa, tem um botão pra abrir* \\
\hline $\mathrm{P} 73$ & pra guardar coisa* & pra botar dvd dentro \\
\hline P74 & coloca todas as coisas aqui dentro. Pode colocar o giz, qualquer coisa que quiser* & - \\
\hline $\mathrm{P} 75$ & - & - \\
\hline P76 & pra guardar giz de cera* & esqueci \\
\hline P77 & O nome eu não sei, mas eu sei pra que que serve. Pra guardar uma coisinha aqui dentro* & eu sei pra que ele serve. Serve pra guardar coisinha dentro* \\
\hline $\mathrm{P} 78$ & pra guardar coisas* & pra guardar coisas* \\
\hline P79 & - & - \\
\hline
\end{tabular}


No grupo de crianças de 7 anos, três participantes (P70, P71 e P78) descreveram corretamente a função de S1 em ambas as fases de sondas, caracterizando, portanto, uma aprendizagem consistente da função desta pseudopalavra. Um participante ainda (P72), respondeu corretamente apenas na fase de sondas de aprendizagem, caracterizando uma aprendizagem imediata da função de S1. Para S2 observa-se aprendizagem consistente de sua função por quatro participantes (P70, P71, P77 e P78). Observa-se ainda, que um participante (P73) respondeu de forma adequada apenas na fase de sondas de aprendizagem (aprendizagem imediata da função desta pseudopalavra), e outro participante respondeu de forma adequada apenas na fase de sondas de retenção (aprendizagem posterior da função desta pseudopalavra). Nota-se ainda na Tabela 7, que dois participantes (P73 e P75) confundiram a função entre os dois estímulos ( $\mathrm{S} 1$ e $\mathrm{S} 2)$, respondendo as sondas referentes à $\mathrm{S} 1$ com a descrição da função adequada à S2.

Em relação aos demais estímulos, que não apresentavam função específica durante a história, a Tabela 7 apresenta as respostas dos participantes. 
Tabela 7

Respostas dos participantes na Sonda de Descrição da Função nas Fases de Sondas de Aprendizagem e de Retenção para as duas pseudopalavras para as quais não foram apresentadas função específica durante a história.

\begin{tabular}{lcc}
\hline & $\begin{array}{c}\text { S3-Vanito } \\
\text { Fase de Aprendizagem }\end{array}$ & Fase de Retenção \\
\hline P30 & para arrumar o quarto & - \\
P31 & - & sacode \\
P32 & pega lá dentro, lito & - \\
P33 & jogar esse aqui, aqui & - \\
P34 & - & - \\
P35 & de bater & bater \\
P36 & - & - \\
P37 & - & - \\
P38 & - & andar \\
P39 & anda & - \\
P70 & - & - \\
P71 & - & pra guardar coisa, sei lá \\
P72 & - & pra botar água \\
P73 & - & - \\
P74 & - & não sei \\
P75 & - & - \\
P76 & - & - \\
P77 & - & - \\
P79 & - & - \\
\hline
\end{tabular}


Tabela 7- Continuação.

\begin{tabular}{|c|c|c|}
\hline \multicolumn{3}{|c|}{ S4-Pafile } \\
\hline & Fase de Aprendizagem & Fase de Retenção \\
\hline $\mathrm{P} 30$ & - & não sei \\
\hline P31 & - & - \\
\hline P32 & de abrir & - \\
\hline P33 & pegar ele & para por coca \\
\hline P34 & brincar & a música \\
\hline P35 & - & não sei \\
\hline P36 & de fechar & - \\
\hline P37 & - & - \\
\hline P38 & - & - \\
\hline P39 & - & anda e põe o outro na árvore \\
\hline P70 & - & também não lembro \\
\hline P71 & brinca & pra brincar \\
\hline P72 & colocar produto aqui dentro & colocar líquido/sabão aqui dentro \\
\hline P73 & jogar no chão, pra lavar o chão, porque tem um negócio dentro pra lavar o chão. & pra jogar sabão no chão \\
\hline P74 & - & - \\
\hline P75 & - & brincar \\
\hline P76 & pra brincar & - \\
\hline P77 & - & - \\
\hline P78 & toca música & pra tocar música \\
\hline P79 & - & - \\
\hline
\end{tabular}


Para os estímulos S3 e S4 não foi possível considerar a falta de respostas para esta sonda como uma situação de falta de aprendizagem, tal como feito para as pseudopalavras anteriores. Como esses estímulos não foram relacionados na história a uma função específica, não era esperado que os participantes fossem capazes de atribuir função alguma para tais objetos indefinidos, ou esperava-se que a resposta mais provável diante da pergunta "Para que isso serve?" seria apenas "Brincar", uma vez que todos os estímulos indefinidos foram tratados como brinquedos.

Este tipo de resposta, que diz respeito à função da pseudopalavra de forma ampla, foi observado apenas em relação à S4. Responderam "brincar": um participante do grupo de 3 anos (P34 - na fase de sondas de aprendizagem) e três participantes do grupo de 7 anos (P71 - em ambas as fases de sondas, P76 - na fase de sondas de aprendizagem, e P75 - na fase de sondas de retenção).

Mais duas formas de respostas merecem destaque. A primeira é a do participante P30, que atribuiu a função de "arrumar o quarto" para S3. Este tipo de resposta indica que o participante ficou sob controle de aspectos gerais do contexto da história (Ver Apêndice B - Roteiro da História). O outro tipo de resposta é encontrado para S4, em que duas crianças (P72 e P73) ficaram sob controle de propriedades físicas deste objeto, especialmente de sua forma, e suas respostas acerca da função estão próximas da função de produtos (de limpeza) armazenados na embalagem usada para confecção deste objeto indefinido, feito de sucata (amaciante de roupas).

\section{Sondas de Generalização}

A Tabela 8 apresenta as respostas dos participantes nas sondas de generalização, realizadas durante a fase de sondas de retenção após a aplicação das demais sondas, de todos os participantes para todas as palavras indefinidas (S1 nezaca, $\mathrm{S} 2$ - fulito, S3 - vanito e S4 - pafile). 
Tabela 8

Respostas as Sondas de Generalização dos participantes de 3 anos (P30 a P39) e dos participantes de 7 anos (P70 a P79) realizadas durante a Fase de Sondas de Retenção (realizada 7 dias após a leitura), em que era solicitada à criança que pegasse os objetos indefinidos tridimensionais diante de seu respectivo nome ditado pela pesquisadora.

\begin{tabular}{|c|c|c|c|c|}
\hline \multicolumn{5}{|c|}{ Estímulos } \\
\hline & \multicolumn{2}{|c|}{ Com função } & \multicolumn{2}{|c|}{ Sem Função } \\
\hline & S1 & $S 2$ & S3 & $S 4$ \\
\hline P30 & - & - & - & $\sqrt{ }$ \\
\hline P31 & - & - & - & $\sqrt{ }$ \\
\hline P32 & $\sqrt{ }$ & - & - & - \\
\hline P33 & - & - & - & $\sqrt{ }$ \\
\hline P34 & - & $\sqrt{ }$ & - & $\sqrt{ }$ \\
\hline P35 & - & $\sqrt{ }$ & - & - \\
\hline P36 & $\sqrt{ }$ & - & - & - \\
\hline P37 & - & - & - & $\sqrt{ }$ \\
\hline P38 & - & - & - & - \\
\hline P39 & - & - & - & - \\
\hline P70 & $\sqrt{ }$ & - & - & $\sqrt{ }$ \\
\hline P71 & $\sqrt{ }$ & $\sqrt{ }$ & $\sqrt{ }$ & $\sqrt{ }$ \\
\hline P72 & - & - & - & - \\
\hline P73 & - & - & - & $\sqrt{ }$ \\
\hline P74 & - & - & - & - \\
\hline P75 & - & - & - & $\sqrt{ }$ \\
\hline P76 & - & - & - & $\sqrt{ }$ \\
\hline P77 & - & - & - & $\sqrt{ }$ \\
\hline P78 & $\sqrt{ }$ & - & - & $\sqrt{ }$ \\
\hline P79 & - & - & - & - \\
\hline
\end{tabular}

É possível observar que a generalização da função discriminativa das figuras dos estímulos apresentadas na história para os objetos tridimensionais referentes não ocorreu para a maior parte dos estímulos. Entre os participantes de 3 anos, sete crianças (P30, P31, P32, P33, P35, P36, P37) foram capazes de escolher corretamente 
um dos objetos indefinidos, e apenas uma escolheu corretamente dois dos estímulos (P34), e duas (P38 e P39) não foram capazes de generalizar corretamente nenhum dos estímulos solicitados. Estes participantes também não tiveram um bom desempenho nas Sondas de Nomeação e Descrição da Função, com é possível observar a partir das Tabelas 6 e 7 .

No grupo de crianças de 7 anos, um participante (P71) apresentou generalização para os quatro estímulos solicitados. Duas crianças (P70 e P78) escolheram corretamente dois estímulos entre os quatro apresentados, quatro crianças (P73, P75, P76 e P77) acertaram apenas uma dentre as quatro tentativas desta sonda, e ainda duas crianças (P72 e P79) não acertaram nenhuma das tentativas apresentadas.

É importante ressaltar que S4 foi corretamente escolhido por 5 participantes do grupo de 3 anos, e por 7 participantes do grupo de 7 anos. Entre as crianças mais jovens parece ter havido uma preferência por este brinquedo (uma vez que o selecionavam também diante da solicitação dos outros brinquedos), mas entre as crianças mais velhas não houve preferência e os acertos referem-se a escolhas adequadas. Este dado é interessante diante do fato de que este estímulo não foi apresentado com uma função específica durante a história.

\section{Desempenho geral dos participantes ao longo das sondas}

As Tabelas 9 e 10 apresentam os dados organizados segundo os desempenhos de cada participante nas diferentes sondas que foram realizadas nas duas fases (aprendizagem e retenção - as respostas às sondas de generalização, portanto, não compõem este quadro), sumarizando os resultados anteriormente expostos. A ordem de apresentação das sondas foi escolhida com base na diferença de desempenhos entre os grupos etários, partindo da maior diferença, para a menor diferença. A ordem em que os participantes estão apresentados está de acordo com os níveis de aprendizagem de seu 
desempenho geral: Não aprendeu (0) < Aprendizagem Imediata $(1)<$ Aprendizagem Posterior (2) < Aprendizagem Consistente (3). Os participantes estão listados partindo do pior desempenho (mais de respostas "Não aprendeu") para o maior melhor desempenho (maior número de respostas “Aprendizagem consistente”).

Nas sondas de exclusão encontra-se a diferença mais evidente entre os dois grupos de participantes: todos os participantes de 7 anos apresentaram o responder por exclusão e apenas algumas das crianças mais jovens responderam adequada e consistentemente a esta sonda. Esta diferença se mantém nas sondas de descrição da função, em que as crianças mais velhas responderam corretamente, enquanto as mais novas não apresentaram respostas correspondentes às funções dos objetos apresentadas durante a história.

Nos resultados das sondas de nomeação é possível observar um desempenho mais semelhante entre os dois grupos de participantes: a maior parte das crianças não conseguiu nomear os estímulos apresentados, mas algumas das crianças mais velhas o fizeram, ainda que apenas dois dos estímulos apresentados. Por fim, as diferenças entre os grupos etários ficam menos evidentes quando se analisam os resultados das sondas de seleção, em que se encontram diferentes níveis de aprendizagem em ambos os grupos etários, há uma grande variabilidade no desempenho dos participantes dos dois grupos, o que torna possível identificar algum efeito do grupo etário para este resultado. 


\section{Tabela 9}

Descrição dos participantes segundo suas respostas às Sondas de Exclusão e suas classificações de desempenho nas demais sondas para os dois estímulos que foram apresentados com função durante a história (S1-Nezaca, e S2-Fulito). O grupo de crianças de 7 anos está destacado com a cor cinza.

\begin{tabular}{|c|c|c|c|c|c|c|c|c|}
\hline \multirow{2}{*}{\multicolumn{3}{|c|}{$\begin{array}{r}\text { Sondas de Exclusão } \\
\text { Aprendizagen Retenção }\end{array}$}} & \multicolumn{2}{|c|}{ Sondas de Descrição da Função } & \multicolumn{2}{|c|}{ Sondas de Nomeação } & \multicolumn{2}{|c|}{ Sondas de Seleção } \\
\hline & & & S1 & $S 2$ & S1 & $S 2$ & $S 1$ & $S 2$ \\
\hline P30 & -- & -- & Não aprendeu & Não aprendeu & Não aprendeu & Não aprendeu & Não aprendeu & Não aprendeu \\
\hline P36 & -- & -- & Não aprendeu & Não aprendeu & Não aprendeu & Não aprendeu & Não aprendeu & Aprendizagem imediata \\
\hline P33 & -- & -- & Não aprendeu & Não aprendeu & Não aprendeu & Não aprendeu & Aprendizagem imediata & Aprendizagem imediata \\
\hline P39 & -- & -- & Não aprendeu & Não aprendeu & Não aprendeu & Não aprendeu & Aprendizagem consistente & Aprendizagem consistente \\
\hline P38 & -- & $\sqrt{ } \sqrt{ }$ & Não aprendeu & Não aprendeu & Não aprendeu & Não aprendeu & Não aprendeu & Não aprendeu \\
\hline P34 & $-\sqrt{ }$ & -- & Não aprendeu & Não aprendeu & Não aprendeu & Não aprendeu & Não aprendeu & Aprendizagem consistente \\
\hline P32 & $-\sqrt{ }$ & $V_{-}$ & Não aprendeu & Não aprendeu & Não aprendeu & Não aprendeu & Aprendizagem posterior & Não aprendeu \\
\hline P79 & $-\sqrt{ }$ & $\sqrt{ } \sqrt{ }$ & Não aprendeu & Não aprendeu & Não aprendeu & Não aprendeu & Não aprendeu & Não aprendeu \\
\hline P31 & $V_{-}$ & -- & Não aprendeu & Não aprendeu & Não aprendeu & Não aprendeu & Aprendizagem posterior & Não aprendeu \\
\hline P35 & $\sqrt{ } \sqrt{ }$ & -- & Não aprendeu & Não aprendeu & Não aprendeu & Não aprendeu & Não aprendeu & Aprendizagem imediata \\
\hline P37 & $\sqrt{ } \sqrt{ }$ & $\sqrt{ } \sqrt{ }$ & Não aprendeu & Não aprendeu & Não aprendeu & Não aprendeu & Não aprendeu & Não aprendeu \\
\hline P75 & $\sqrt{ } \sqrt{ }$ & $\sqrt{ } \sqrt{ }$ & Não aprendeu & Não aprendeu & Não aprendeu & Não aprendeu & Não aprendeu & Aprendizagem consistente \\
\hline P76 & $\sqrt{ } \sqrt{ }$ & $\sqrt{ } \sqrt{ }$ & Não aprendeu & Aprendizagem imediata & Não aprendeu & Não aprendeu & Não aprendeu & Não aprendeu \\
\hline P73 & $\sqrt{ } \sqrt{ }$ & $\sqrt{ } \sqrt{ }$ & Não aprendeu & Aprendizagem imediata & Não aprendeu & Não aprendeu & Aprendizagem posterior & Não aprendeu \\
\hline P74 & $\sqrt{ } \sqrt{ }$ & $\sqrt{ } \sqrt{ }$ & Não aprendeu & Aprendizagem imediata & Não aprendeu & Aprendizagem imediata & Não aprendeu & Aprendizagem posterior \\
\hline P77 & $\sqrt{ } \sqrt{ }$ & $\sqrt{ } \sqrt{ }$ & Não aprendeu & Aprendizagem consistente & Não aprendeu & Não aprendeu & Aprendizagem imediata & Aprendizagem consistente \\
\hline P72 & $\sqrt{ } \sqrt{ }$ & $\sqrt{ } \sqrt{ }$ & Aprendizagem imediata & Aprendizagem posterior & Não aprendeu & Não aprendeu & Aprendizagem consistente & Não aprendeu \\
\hline P71 & $\sqrt{ } \sqrt{ }$ & $\sqrt{ } \sqrt{ }$ & Aprendizagem consistente & Aprendizagem consistente & Não aprendeu & Não aprendeu & Aprendizagem consistente & Aprendizagem imediata \\
\hline P70 & $\sqrt{ } \sqrt{ }$ & $\sqrt{ } \sqrt{ }$ & Aprendizagem consistente & Aprendizagem consistente & Não aprendeu & Não aprendeu & Aprendizagem consistente & Aprendizagem posterior \\
\hline P78 & $\sqrt{ } \sqrt{ }$ & $\sqrt{ } \sqrt{ }$ & Aprendizagem consistente & Aprendizagem consistente & Não aprendeu & Aprendizagem imediata & Aprendizagem posterior & Não aprendeu \\
\hline
\end{tabular}




\section{Tabela 10}

Descrição dos participantes segundo suas respostas às sondas de exclusão e suas classificações de desempenho nas sondas de nomeação e seleção para os dois estímulos que não possuíam função específica durante a história (S3-Vanito, e S4-Pafile). O grupo de crianças de 7 anos está destacado com a cor cinza.

\begin{tabular}{|c|c|c|c|c|c|c|}
\hline & Sonda & clusão & Sonda & le Nomeação & Sondas d & e Seleção \\
\hline & Aprendiz. & etenção & S3 & $S 4$ & $S 3$ & 54 \\
\hline P33 & -- & -- & Não aprendeu & Não aprendeu & Aprendizagem posterior & Aprendizagem consistente \\
\hline P36* & -- & -- & Não aprendeu & Não aprendeu & Aprendizagem consistente & Aprendizagem posterior \\
\hline P30 & -- & -- & Não aprendeu & Não aprendeu & Aprendizagem consistente & Aprendizagem consistente \\
\hline P39* & -- & -- & Não aprendeu & Não aprendeu & Aprendizagem consistente & Aprendizagem consistente \\
\hline P38* & -- & $\sqrt{ } \sqrt{ }$ & Não aprendeu & Não aprendeu & Aprendizagem imediata & Não aprendeu \\
\hline P34* & $-\sqrt{ }$ & -- & Não aprendeu & Não aprendeu & Não aprendeu & Aprendizagem consistente \\
\hline P32* & $-\sqrt{ }$ & $V_{-}$ & Não aprendeu & Não aprendeu & Aprendizagem posterior & Não aprendeu \\
\hline P79* & $-\sqrt{ }$ & $\sqrt{ } \sqrt{ }$ & Não aprendeu & Não aprendeu & & Aprendizagem posterior \\
\hline P31* & $\sqrt{-}$ & -- & Não aprendeu & Não aprendeu & Não aprendeu & Aprendizagem consistente \\
\hline P35* & $\sqrt{ } \sqrt{ }$ & -- & Não aprendeu & Não aprendeu & Aprendizagem imediata & Aprendizagem imediata \\
\hline P76 & $\sqrt{ } \sqrt{ }$ & $\sqrt{ } \sqrt{ }$ & Não aprendeu & Não aprendeu & Não aprendeu & Não aprendeu \\
\hline P72 & $\sqrt{ } \sqrt{ }$ & $\sqrt{ } \sqrt{ }$ & Não aprendeu & Não aprendeu & Não aprendeu & Aprendizagem posterior \\
\hline P78 & $\sqrt{ } \sqrt{ }$ & $\sqrt{ } \sqrt{ }$ & Não aprendeu & Não aprendeu & Não aprendeu & Aprendizagem posterior \\
\hline P75 & $\sqrt{ } \sqrt{ }$ & $\sqrt{ } \sqrt{ }$ & Não aprendeu & Não aprendeu & Aprendizagem imediata & Aprendizagem consistente \\
\hline P74* & $\sqrt{ } \sqrt{ }$ & $\sqrt{ } \sqrt{ }$ & Não aprendeu & Não aprendeu & Aprendizagem posterior & Aprendizagem imediata \\
\hline P70 & $\sqrt{ } \sqrt{ }$ & $\sqrt{ } \sqrt{ }$ & Não aprendeu & Não aprendeu & Aprendizagem posterior & Aprendizagem consistente \\
\hline P37 & $\sqrt{ } \sqrt{ }$ & $\sqrt{ } \sqrt{ }$ & Não aprendeu & Não aprendeu & Aprendizagem consistente & Não aprendeu \\
\hline P77 & $\sqrt{ } \sqrt{ }$ & $\sqrt{ } \sqrt{ }$ & Não aprendeu & Não aprendeu & Aprendizagem consistente & Aprendizagem imediata \\
\hline P71 & $\sqrt{ } \sqrt{ }$ & $\sqrt{ } \sqrt{ }$ & Não aprendeu & Aprendizagem imediata & Aprendizagem imediata & Aprendizagem consistente \\
\hline P73 & $\sqrt{ } \sqrt{ }$ & $\sqrt{ } \sqrt{ }$ & Não aprendeu & Aprendizagem posterior & Não aprendeu & Aprendizagem posterior \\
\hline
\end{tabular}


Avaliando o desempenho dos participantes de forma geral, observa-se que as crianças mais velhas apresentaram um melhor desempenho em termos de aprendizagem das pseudopalavras, e que as foram mais sensíveis à dica referente à função dos estímulos, apresentada durante a história. 


\section{Discussão}

O presente trabalho teve como objetivo investigar a aprendizagem de pseudopalavras apresentadas a partir da leitura compartilhada de livro infantil, por crianças de três e sete anos, comparando a aprendizagem dessas pseudopalavras em dois contextos distintos - com a apresentação da função/utilidade dos referentes e sem a apresentação desta função. A discussão está organizada da mesma forma como foram apresentados os desempenhos dos participantes nos resultados, ou seja, por tipo de sonda. Os aspectos referentes às diferenças de cada grupo etário e à influência da dica contextual "apresentação da função" permeiam a discussão de cada tipo de sonda, sendo abordados em cada um dos tópicos apresentados a seguir. Por fim, será feita uma discussão geral, em que se pretende fazer uma avaliação das limitações metodológicas do presente estudo, assim como apontamentos sobre perspectivas para futuras pesquisas sobre o tema.

\section{Sondas de Exclusão}

Todos os participantes de 7 anos apresentaram o responder por exclusão na condição em que os estímulos de comparação eram os correspondentes às pseudopalavras apresentadas na história. Os participantes de 3 anos, porém, tiveram desempenhos muito variáveis. Este foi o desempenho no qual foram encontradas as diferenças mais evidentes entre os grupos etários.

O primeiro aspecto que pode ser explorado acerca do responder por exclusão é apresentado por Horst et al. (2011). As autoras sugerem que, além do emparelhamento entre a pseudopalavra ditada e a figura do objeto indefinido, realizado durante a leitura, a aprendizagem de novas palavras neste contexto é favorecida pelo processo de responder por exclusão (referido pelas autoras como fast mapping). De acordo essa 
hipótese, uma ilustração contendo uma série de elementos familiares (definidos - já relacionados a palavras na história do indivíduo) poderia servir de contraste para que a criança relacionasse a palavra indefinida apresentada na história ao estímulo visual também indefinido, presente na ilustração (em meio a outros estímulos definidos).

Portanto, tal como empregados no presente estudo, os estímulos de comparação poderiam não atender ao requisito de "familiaridade", tido com base para ocorrência do responder por exclusão ou fast mapping. Por outro lado, esta característica do procedimento permitiria avaliar exatamente isto: se as relações nome-figura se tornaram suficientemente definidas experimentalmente, para funcionarem como controle para a seleção do novo estímulo indefinido, como sugerido por Wilkinson et al. (1998). Estes autores relatam, em uma revisão sobre o fenômeno do responder por exclusão, que a solicitação de um estímulo completamente novo entre comparações pouco conhecidos é uma maneira de verificar se os participantes aprenderam alguma coisa referente a estes estímulos de comparação (no caso deste trabalho, a relação entre os nomes ditados das pseudopalavras apresentadas na história e as figuras de seus objetos referentes). Nesse sentido, o presente trabalho pretendeu verificar se, ainda que não ocorresse a aprendizagem completa das pseudopalavras apresentadas na história, a exposição proporcionada pela leitura promoveria aprendizagem suficiente para que, em um teste de exclusão posterior, a criança fosse capaz de selecionar uma figura de um objeto completamente novo tendo como alternativas, além desse estímulo, três figuras dos objetos indefinidos apresentados na história. Dessa forma, procurou-se verificar se as figuras apresentadas na história passaram a fazer parte de uma possível classe de figuras/objetos "definidos", ainda que a aprendizagem da relação nome-figura não tivesse se estabelecido de forma consistente. 
Esse desempenho foi apresentado pelas crianças mais velhas, indicando que elas aprenderam as relações, mas não pelas mais jovens. Esta diferença pode ser explicada em função do não estabelecimento de uma linha de base adequada para o grupo das crianças mais jovens e da instabilidade na inclusão dos estímulos indefinidos em uma suposta classe de estímulos definidos por esses participantes. Quanto mais velha a criança, mais oportunidades ela teve de aprender uma série de relações entre os estímulos ambientais, e quanto maior essa experiência de aprender a fazer relações, maior sua capacidade de pensar ou agir de modo mais abstrato (De Rose \& Rabelo, 2012). Formar classes de estímulos é um comportamento em que as crianças mais velhas são mais hábeis que as mais novas, justamente em função desta maior experiência em aprender relações entre estímulos. Desta forma, a exposição indireta às palavras indefinidas durante a leitura foi ocasião suficiente para as crianças mais velhas conseguirem formar essa classe inicial de "estímulos definidos", mas não foi suficiente para as crianças mais novas, que possivelmente demandariam um ensino mais direto dessas relações, ou uma quantidade maior de exposições à leitura (Costa et al., 2013, Domeniconi et al., 2007).

Para que o desempenho por exclusão seja apresentado é necessário que a linha de base de estímulos conhecidos (definidos) esteja bem estabelecida, a fim de que o contraste entre os estímulos conhecidos e o desconhecido seja possível (Dixon, 1977; Wilkinson, de Souza, \& McIlvane, 2000). O estabelecimento (ou a existência prévia) de uma linha de base consistente garantiria a discriminação entre duas classes de estímulos: a dos "conhecidos" e a dos "desconhecidos" (Costa, de Rose, \& de Souza, 2010). Qualquer perturbação nessa linha de base poderia afetar a ocorrência do responder por exclusão. Em um estudo sobre a aprendizagem da relação nome-objeto após um número mínimo de exposições as tentativas de exclusão, Antoniazzi, Domeniconi e Schmidt. 
(2014) investigaram o efeito da pré-exposição ao objeto indefinido no desempenho por exclusão de crianças de 2 anos. Seus resultados indicaram que a pré-exposição ao objeto indefinido interferiu negativamente nos desempenhos dos participantes nas sondas de exclusão, de tal maneira que, diante de um nome completamente novo, as crianças não selecionavam de forma consistente o objeto indefinido, mas distribuíam seu responder entre a máscara e um objeto definido. Possivelmente, no caso do estudo de Antoniazzi et.al. (2014), a pré-exposição ao objeto favoreceu uma fusão (ao menos parcial) das classes de estímulos definidos e indefinidos. A pré-exposição, nesse caso, parece ter afetado a linha de base dos objetos "conhecidos", dificultando o contraste necessário para a emergência de exclusão.

No caso do presente trabalho, as crianças mais jovens não foram capazes de formar uma possível classe de "figuras definidas pela história", o que explicaria a distribuição das respostas das crianças deste grupo, nas sondas de exclusão, entre os estímulos indefinidos apresentados na história, e os apresentados apenas nas sondas de exclusão. Possivelmente, o pequeno número de exposições da relação auditivo-visual, assim como o número elevado de figuras indefinidas presente na história (em comparação com outras pesquisas sobre aprendizagem de vocabulário) dificultou a formação de tal classe para as crianças mais jovens.

O desempenho positivo neste tipo de sonda mostra o estabelecimento de relações emergentes entre estímulos modelo e comparação, o que seria semelhante aos participantes dizerem sobre o objeto novo (apresentado apenas na sonda de exclusão), em relação aos demais objetos indefinidos (apresentados na história): “eu não sei o que é, mas sei que não são esses outros" (Wilkinson \& McIlvane, 1997). No entanto, vários trabalhos que estudam a aprendizagem de novas palavras por meio da leitura de histórias (e.g., Elley, 1989; Robbins \& Ehri, 1994; Wilkinson \& Houston-Price, 2013) 
não utilizam sondas desta natureza em suas investigações, e tal como defendido por Horst (2013), a aprendizagem de novas palavras implica em um contínuo de repertórios, que vão desde o "não saber uma palavra", até conhecê-la completamente, ou seja, apresentar diferentes desempenhos, tanto em relação à palavra, em si, quanto em relação ao seu "referente". Neste sentido, as sondas de exclusão são uma forma de investigar um dos repertórios que, possivelmente, está entre os mais iniciais neste contínuo de aprendizagem.

Por outro lado, um bom desempenho em sondas de exclusão não significa aprendizagem consistente de uma relação nome-objeto (Costa et al., 2010; Dixon, 1977; Domeniconi et al., 2007; Wilkinson \& McIlvane, 1997). O que o presente trabalho mostra, no entanto, é que, mesmo não ocorrendo o estabelecimento completo de uma relação palavra-figura, a apresentação do desempenho por exclusão nas sondas apresentadas neste trabalho indica, ao menos, um nível inicial de aprendizagem, demonstrado com maior consistência pelas crianças mais velhas que pelas mais jovens. Por isso, defende-se aqui a importância da aplicação deste tipo de sonda para investigações sobre a aprendizagem de novas palavras, como uma forma de avaliação dos repertórios simples envolvidos nessa aprendizagem, e não apenas a utilização isolada de sondas de seleção, que demandariam um desempenho mais complexo dos participantes desses estudos.

\section{Sondas de Controle por Seleção}

O desempenho nas sondas de controle por seleção (de ambas as fases aprendizagem e retenção) foi variável entre os participantes de ambos os grupos etários, para todas as palavras indefinidas. $\mathrm{O}$ primeiro ponto a ser discutido refere-se à quantidade de palavras-alvo apresentadas: a aprendizagem de quatro pseudopalavras por meio da leitura de histórias parece não ter sido uma tarefa fácil, mesmo para crianças 
mais velhas. Em estudos com delineamento semelhante, Horst et al. (2011) e Garcia, Vaz e Schmidt (submetido) utilizaram apenas duas pseudopalavras e obtiveram bons resultados (pelo menos $70 \%$ de acertos no primeiro estudo, e $50 \%$ no segundo). Em contrapartida, estudos que investigaram a aprendizagem de palavras por crianças jovens (cerca de 2 anos) com a apresentação de um número maior de estímulos (de 4 a 8 palavras) não apresentam resultados com desempenhos tão bons (Horst \& Samuelson, 2008 - cerca de 40\% de acertos; Horst \& Axelsson, 2013 - de 25 a 42\% de acertos na situação de exposição a 4 palavras).

A forma como as palavras são apresentadas às crianças também parece interferir em sua aprendizagem. Dados do estudo de Wilkinson, Ross e Diamond (2003) apontaram que a forma de apresentação de um estímulo pode interferir negativamente na aprendizagem de um segundo estímulo, anteriormente apresentado. Assim, a apresentação de uma segunda relação nome-figura pode ter interferido na aprendizagem da primeira, dificultando seu estabelecimento (especialmente nas condições aqui apresentadas, em que não havia propriamente um procedimento de ensino envolvido) e assim sucessivamente. É necessário ponderar também que, por se tratar justamente de uma situação experimental que buscou simular um contexto natural de aprendizagem, os estímulos não foram apresentados todas as vezes de forma sequencial (três apresentações sucessivas da primeira relação nome-figura, seguidas por três apresentações da segunda relação e assim por diante), o que pode ter aumentando ainda mais a interferência de um estímulo na apresentação do outro.

Além disso, é preciso considerar ainda alguns dos comportamentos envolvidos na aprendizagem incidental durante uma leitura de livros. É preciso que os participantes: a) rastreiem o estímulo alvo (o brinquedo indefinido) entre os estímulos conhecidos apresentados juntos (os demais brinquedos conhecidos), sem ter, para isso, 
nenhuma dica contextual direta que pudesse tornar o estímulo indefinido saliente entre os demais; b) discriminem estes estímulos indefinidos dos demais conhecidos; e c) pareiem o estímulo auditivo (nome indefinido do brinquedo) à sua respectiva figura. Trata-se de um conjunto de comportamentos complexos, que deveriam se repetir todas as vezes que uma das quatro pseudopalavras era apresentada na história. Por fim, evidências empíricas ainda indicam que crianças de 3 anos aprendem, aproximadamente, duas palavras durante uma sessão de três leituras consecutivas de livros (Horst et al. 2011, Garcia, et al., submetido) e, portanto, a apresentação de quatro palavras em uma única sessão parece ter excedido o número já encontrado em outras pesquisas.

Os resultados obtidos neste estudo se tornam mais interessantes quando confrontados com os de outros estudos que investigam a aprendizagem de palavras por meio da leitura de livros, e que apresentam resultados superiores. Elley (1989), por exemplo, estudou a aprendizagem de 20 palavras com crianças de 7 anos, e encontrou um ganho considerável de vocabulário de, pelo menos, quatro dessas palavras (20\%). Já Wilkinson e Houston-Price (2013), que investigaram a aprendizagem de oito palavras com crianças mais jovens (6-7 anos) e crianças mais velhas (8-9 anos), encontraram que as primeiras aprenderam cerca de quatro palavras (50\%), enquanto as segundas cerca de cinco palavras (62,5\%). Resultado semelhante (média de acertos de 4 palavras aproximadamente 30\%) também foi encontrado por Sénéchal et al.(1995), que investigaram a aprendizagem de 13 palavras por crianças de 4 a 5 anos. Ainda que os resultados encontrados nesses estudos sejam semelhantes entre si - aprendizagem de, em média, quatro palavras, indicando que há consistência nesses dados-, este fato pode se justificar pelas escolhas metodológicas apresentadas por esses autores: nos estudos citados não foi feito um controle refinado sobre a exposição adicional da criança às 
palavras investigadas, uma vez que as palavras-alvo eram palavras da língua corrente dos participantes, e foram empregados livros comerciais nas sessões experimentais. Considerando que a aprendizagem de novas palavras ocorre de forma contínua (Horst, 2013), o uso de palavras correntes da língua aumenta a probabilidade de que o participante já tenha tido algum contato prévio com essas palavras (ainda que não a ponto de ter uma aprendizagem completa delas), o que pode ser suficiente para justificar a maior quantidade de palavras aprendidas nestes trabalhos. Desta forma, o uso de palavras correntes da língua do participante não permite acesso aos efeitos da exposição à leitura compartilhada, o que é o interesse fundamental de pesquisas básicas sobre o tema. É nesse sentido que Horst (2013) recomenda a investigação básica desse processo com palavras inventadas, o que garantiria que a aprendizagem decorrente da sessão de leitura se dê apenas em função da manipulação experimental realizada. O presente estudo contribuiu para essa linha de investigação.

O segundo ponto a ser discutido sobre o desempenho dos participantes nas sondas de seleção refere-se ao fenômeno do Matthew Effect (Stanovich, 1986), que descreve que crianças que possuem um vocabulário prévio maior aprendem novas palavras com maior facilidade do que àquelas crianças com vocabulário reduzido. Como já dito, os participantes do presente estudo, de ambos os grupos etários, tiveram uma aprendizagem inconsistente das pseudopalavras. Portanto, considerando os resultados das sondas de seleção, é possível dizer que o fenômeno do Matthew Effect não foi encontrado no presente trabalho. Esses dados são diferentes dos encontrados por Sénéchal et al. (1995) em um estudo sobre a aprendizagem de palavras por crianças de 4 anos. Os participantes foram divididos em dois grupos: crianças com alto nível de vocabulário, e crianças com baixos níveis (avaliados por meio do Peabody Pictures Vocabulary Test - PPVT). Os resultados dos testes de aprendizagem (semelhantes às 
sondas de seleção) aplicados logo após a leitura demonstram que os participantes com maior vocabulário prévio aprenderam mais palavras (cerca de 5 palavras, de um total de 13 palavras-alvo) que aqueles com menores níveis de vocabulário (cerca de 4 palavras). A ocorrência de Matthew Effect também foi encontrada no trabalho de Robbins e Ehri (1994), no qual as autoras investigaram a aprendizagem de palavras por crianças de 6 anos, divididas em três grupos: baixo, médio e alto vocabulário. Na pesquisa, as crianças com maior vocabulário prévio apresentaram melhor desempenho nos testes de múltipla escolha (semelhantes às sondas de seleção aqui apresentadas). Diante disso, por mais que as informações a respeito do desenvolvimento da linguagem (Vila, 1995; Shafer, 2005) indiquem que as diferenças sejam marcantes entre as duas faixas etárias investigadas na presente pesquisa, elas podem não ter sido suficientes para tornar evidente tal efeito.

Entretanto, é preciso ponderar novamente a questão da investigação da aprendizagem de novas palavras utilizando palavras de uso corrente na língua: o uso delas não permite o controle do contato prévio dos participantes com essas palavras. $\mathrm{O}$ nível de vocabulário (maior ou menor) das crianças poderia aumentar a probabilidade de um contato prévio do participante com as palavras-alvo investigadas, o que certamente aumentaria a probabilidade de aprendizagem dessas novas palavras para aquelas crianças com maior contato prévio (maior vocabulário). Esta é uma hipótese que carece de comprovação empírica, mas que poderia justificar, em parte, o fato de não se ter encontrado o efeito característico do fenômeno do Matthew Effect na presente pesquisa. Considerando que o contato com uma palavra interfere na velocidade de sua aprendizagem, crianças com maior vocabulário, por terem tido contato com um número muito maior de palavras do que crianças com vocabulário menor, tem uma probabilidade maior de terem sido expostas a alguma das palavras-alvo previamente. 
Assim, o Matthew Effect pode ser uma descrição deste efeito do tamanho de vocabulário, em que as crianças com maior vocabulário aprendem mais em estudos que utilizam palavras de uso corrente na língua, simplesmente porque podem ter tido contato prévio com as palavras do experimento. No presente estudo esse efeito não foi encontrado porque foram utilizadas pseudopalavras, o que garante que nenhum dos participantes tenha tido contato prévio com nenhuma das palavras-alvo ou seus objetos referentes.

A utilização de pseudopalavras em situação experimental garante que todas as crianças, independente da idade (ou do nível de vocabulário prévio), tenham sido apresentadas pela primeira vez às palavras-alvo, não havendo probabilidade maior ou menor de contato prévio, o que poderia eliminar o efeito observado nos trabalhos que relatam a ocorrência do fenômeno do Matthew Effect. Mais evidências a esse respeito podem ser encontradas no estudo de Walsh e Blewitt (2006) sobre leitura dialógica. As autoras, além de avaliarem o vocabulário prévio dos participantes, dividiram os participantes em grupos que foram submetidos a diferentes condições de leitura: leitura com perguntas que requeriam respostas com o nome da palavra-alvo, leitura com perguntas que requeriam que a criança falasse necessariamente o nome da palavra-alvo, e um grupo controle (leitura sem perguntas). Seus resultados indicaram diferença entre os grupos experimentais e o grupo controle, mas não indicaram efeito do vocabulário prévio do participante na aprendizagem das palavras. Neste caso, é possível que a manipulação experimental (fazer perguntas durante a leitura) tenha sobrepujado qualquer efeito do vocabulário prévio dos participantes. Além disso, apesar deste estudo ter-se utilizado de palavras de uso corrente, as autoras relatam que as palavras-alvo escolhidas foram previamente estabelecidas por meio de uma pesquisa anterior como sendo não familiares às crianças de 3 anos, o que evidencia, mais uma vez, que o 
Matthew Effect pode ser decorrente de um contato prévio com as palavras alvo investigadas.

Além disso, é necessário considerar, também, que o número de palavras-alvo (como já discutido anteriormente) pode ter sido um complicador para esta aprendizagem (junto com o fato de terem sido utilizadas pseudopalavras como palavras-alvo). Reiterando o que já foi dito a respeito de considerar a aprendizagem de palavras como um processo contínuo de repertórios, o próximo tópico discutirá os resultados das sondas de nomeação e de descrição da função.

\section{Sondas de Nomeação e de Descrição da Função}

Os resultados destas sondas, em conjunto com os resultados das sondas de exclusão, compõem o conjunto de dados em que foram demonstradas as diferenças mais evidentes entre os grupos etários. Ainda que a maioria dos participantes não tenha tido um desempenho adequado na tarefa de nomeação das figuras dos objetos indefinidos, uma vez que apenas quatro crianças de 7 anos nomearam efetivamente as figuras, os resultados dessas sondas e das sondas de descrição da função apresentaram diferenças claras entre os repertórios dos dois grupos etários.

Enquanto nenhuma das crianças de 3 anos descreveu corretamente a função dos objetos indefinidos, parte das crianças de 7 anos foi capaz de responder adequadamente a estas sondas. Entretanto, dois dos participantes de 3 anos foram capazes de relacionar as pseudopalavras com informações pertinentes ao conteúdo apresentado na história. Estas respostas (ainda que incorretas para os critérios de acertos nas sondas) rementem a elementos apresentados na história que tinham estreita relação com o estímulo solicitado: "giz" e "tem boneca dentro, abre aqui e aqui" foram as respostas apresentadas por um dos participantes para o estímulo S2, estímulo que, durante a história, servia para guardar tanto a boneca quanto o giz; e "arrumar o 
quarto" para descrever a função de S3 (Ver Apêndice B - Roteiro da História). Respostas dessa natureza indicam que os participantes podem não ter ficado sob controle da função específica apresentada na história, mas do contexto geral. Neste caso, a criança estabeleceu uma relação entre os estímulos visuais que apareciam nas ilustrações do livro, ou entre palavras da história e a figura. $\mathrm{O}$ estabelecimento dessas relações demanda aprendizagem específica, que pode estar relacionada a uma maior experiência em situações de leitura compartilhada de histórias para estes participantes. Além disso, esses resultados sugerem que, possivelmente, o participante foi capaz de compreender a história, apesar da presença das quatro palavras indefinidas, e que a experiência de leitura compartilhada pode oferecer à criança a oportunidade de estabelecer relações não diretamente ensinadas entre os estímulos (via pareamento direto, por exemplo).

Com relação à apresentação da função das palavras, ao contrário do que se esperava, esta dica contextual não se mostrou facilitadora para a aprendizagem das relações entre as pseudopalavras e as figuras dos objetos indefinidos. Diversos trabalhos (Elley, 1989; Penno, Wilkinson, \& Moore, 2002; Wilkinson \& Houston-Price, 2013) observaram que, na leitura de uma história, quando as palavras vinham acompanhadas explicações adicionais sobre seu significado no contexto da história (seja pela história em si ou pela explicação que o adulto dava sobre a palavra, no decorrer da leitura) a palavra era aprendida mais frequentemente, em comparação com palavras em que o significado não era apresentado. De forma semelhante, acreditava-se que a apresentação da função do referente da pseudopalavra seria uma dica contextual que auxiliaria a aprendizagem daquelas palavras. Ainda que os resultados das sondas de seleção tenham demonstrado que a presença da função não foi uma variável facilitadora para a aprendizagem das pseudopalavras (independente da idade dos participantes), os 
resultados das sondas de descrição da função apontam que as crianças mais velhas foram mais sensíveis a este tipo de dica contextual. Apesar deste tipo de dica não ter sido suficiente para a emergência de um repertório indicativo de aprendizagem nas sondas de seleção e de nomeação das figuras indefinidas, indicou que houve alguma aprendizagem sobre variáveis relacionadas a estes estímulos. Para compreender porque crianças mais jovens não puderam beneficiar-se deste tipo de dica, é preciso discutir o que a apresentação de função/utilidade de um objeto representa em termos de controle de estímulos.

A aprendizagem de novas palavras está intimamente relacionada com o estabelecimento (ou ampliação) de classes de estímulos (De Rose, 1993; Devany, Hayes, \& Nelson, 1986). Todas as pseudopalavras apresentadas na história foram relacionadas a brinquedos. Assim, uma primeira aprendizagem a ser feita, a partir da apresentação da história, seria a inclusão daqueles objetos indefinidos da história em uma classe de estímulos mais ampla e, possivelmente, já existente: a de "brinquedos". A relação entre os estímulos indefinidos e a classe a que, eventualmente, eles deveriam ser incluídos, poderia ser estabelecida de duas formas: pelo contexto da ilustração (quando os objetos indefinidos eram apresentados junto a brinquedos que já pertenciam a essa classe funcional), ou de forma condicional, pelas descrições na própria história (a descrição de que os personagens estavam guardando brinquedos, por exemplo). Entretanto, os objetos indefinidos que tinham uma utilidade específica, definida pelo contexto da história (guardar e prender), deveriam ser incluídos em outra classe, a de "brinquedos que servem para alguma coisa específica além de brincar", ou de "objetos que servem para alguma coisa específica durante a brincadeira". Algumas das crianças (a maioria do grupo de 7 anos) demonstraram claramente, por meio das respostas às sondas de descrição da função (e.g., serve "para brincar"), que foram capazes de 
discriminar que os objetos indefinidos eram brinquedos, isto é, alguns dos participantes foram capazes de incluir os novos objetos a esta primeira classe geral de estímulos. Contudo, apenas algumas das crianças de 7 anos foram capazes de agrupar os objetos cuja função era definida pelo contexto da história em uma segunda classe ("brinquedos com função específica").

A dificuldade para o estabelecimento desta nova classe pode ter se dado porque a atribuição de funções conhecidas (prender e guardar) a objetos indefinidos, e que, aparentemente, poderiam ser incluídos também na classe de "brinquedos", pode ter dificultado, ao invés de facilitar, o estabelecimento dessa nova classe de estímulos ("brinquedo que serve para alguma coisa específica"), na medida em que as propriedades de "prender" e "guardar", no repertório das crianças, abrangeriam objetos muito diferentes daqueles indefinidos apresentados na história. Discriminar a intersecção entre classes de estímulos é um repertório ainda mais complexo que apenas estabelecer uma nova classe (Abreu \& Hubner, 2012; De Rose \& Rabelo, 2012; Perez, Nico, Kovac, Fidalgo, \& Leonardi, 2013). Além disso, é possível ainda que a apresentação da função tenha, de certa forma, e especialmente para as crianças menores, dificultado a formação de uma nova classe de estímulos (e.g., "brinquedos novos") por estar concorrendo com outra classe (e.g., “objetos que servem para guardar”). Talvez, por isso, esta tarefa tenha sido muito complexa para as crianças muito novas, que teriam mais dificuldades de ficar sob controle deste tipo de dica contextual, e discriminar entre brinquedos com função e sem função.

Por outro lado, a maior parte dos participantes do grupo de 7 anos foi capaz de discriminar a propriedade da função presente nos objetos indefinidos, ainda que alguns participantes não tenham discriminado especificamente a função/utilidade de cada um destes objetos, confundindo as propriedades dos estímulos, respondendo 
"guardar" e ou "prender" de forma indiscriminada entre S1 e S2. De Rose e Rabelo (2012) relatam que a capacidade de agir de modo mais abstrato está relacionada à experiência prévia com múltiplos exemplares de uma relação, e com a capacidade geral de fazer relações, repertórios que as crianças de 7 anos tiveram mais tempo de desenvolver que as crianças de 3 anos, o que justificaria a diferença entre os grupos. Todos esses aspectos levantados aqui, porém, são hipóteses que necessitam de comprovação empírica, que o presente trabalho não é capaz de fornecer.

A aplicação de sondas que investigassem a nomeação e a descrição da função dos objetos retratados nas figuras permitiu que as crianças pudessem relatar uma "medida de auto avaliação" de sua própria aprendizagem. Em outras palavras, estas sondas estabeleceram a ocasião para que a criança pudesse falar a respeito do que ela mesma já havia discriminado como um repertório que ela soubesse, tal como ilustrado por respostas deste tipo: "acho que é pra guardar coisinha", ou "Eu sei para que que serve, para guardar coisas, mas não sei o nome". Essas respostas informam acerca da relação de interdependência entre os repertórios envolvidos na aprendizagem de novas palavras. Quando o participante diz "acho” (um autoclítico descritivo - Skinner, 1957), dá indicativos do grau de confiança sobre sua resposta, que pode indicar que a aprendizagem não se estabeleceu de forma tão consistente (para que ele tivesse certeza, e pudesse ter dado a resposta diretamente). Quando o participante diz "mas não sei o nome", relata claramente qual repertório já foi estabelecido (o de descrever a função), e qual ainda não foi (o de nomear), demostrando que a aprendizagem de vocabulário envolve uma série de repertórios, e evidenciando a relação de continuidade envolvida no processo de aprender uma nova palavra (Horst, 2013; Swingley, 2010).

Considerando os resultados das sondas de nomeação, aliados a este último exemplo (em que a participante relata saber a respeito da função, mas não saber 
nomear), é possível inferir que a tarefa de nomeação talvez seja a mais difícil no processo de aprendizagem de uma nova palavra e que seja, possivelmente, um dos últimos repertórios verbais adquiridos na aprendizagem completa das relações que caracterizam a aprendizagem de uma palavra. Estudos como os de Almeida-Verdu, Santos, Souza, e Bevilacqua (2008), e o de Souza, Almeida-Verdu e Bevilacqua (2013) evidenciam a importância do comportamento verbal ecoico no estabelecimento da nomeação. Neste segundo estudo, as autoras pesquisaram o efeito do ensino de ecoico na habilidade de nomeação de deficientes auditivos com implante coclear, e demonstraram que, após a exposição ao ensino do ecoico em tarefa de emparelhamento com o modelo, houve aumento da porcentagem de acertos em nomeação de figuras entre os participantes. Barros (2003) ainda defende que, quando a criança produz um comportamento ecoico, tal resposta é reforçada, e quanto mais parecido é o som com o seu modelo, maior é a probabilidade de reforço, havendo, portanto, modelagem por contingências sociais. Outro aspecto que parece ser pré-requisito para a emergência da nomeação é justamente o pareamento ostensivo, tal como feito por Sousa, Souza e Gil (2013), em um estudo sobre a aprendizagem do comportamento de ouvinte por um bebê. Os resultados desse estudo indicam emergência não só do comportamento de ouvinte, como também do comportamento de falante após 27 pareamentos, em média, da relação foto-nome para cada estímulo, com $83 \%$ de acerto da participante nas tentativas. Desta forma, é possível que haja repertórios que sejam pré-requisitos para a emergência da nomeação (como o comportamento verbal ecoico), e que seja necessário, também, maior quantidade de exposição às palavras-alvo, ou uma exposição mais sistematizada (que não ocorreu durante a leitura da história; mas, ver estudos sobre emergência de nomeação a partir de tentativas de exclusão, sem ensino de ecoico: Costa et al., 2013; McIlvane \& Stoddard, 1981). 
Por fim, diferente das sondas de exclusão e de seleção, que exigiam uma resposta de escolha, as sondas de nomeação e de descrição da função solicitavam à criança uma resposta em que não havia uma opção de escolha; desta forma, essas sondas investigaram o vocabulário expressivo dos participantes (por exemplo, nomear um referente, ou usar a nova palavra em uma sentença própria). O uso desses tipos de sondas é recomendado por Wilkinson e Houston-Price (2013), que discutem as vantagens de se ter um conjunto maior de formas de avaliar a aprendizagem das relações em que uma nova palavra participa. Além das sondas de seleção, e, como vem sendo apresentado no presente trabalho, as autoras defendem que a aplicação de uma variedade sondas pode ser útil para a melhor compreensão da extensão do conhecimento da criança acerca das palavras com que teve contato na situação de leitura compartilhada. Neste sentido, no presente estudo foi aplicado, ainda, um último conjunto de sondas, as de generalização, cujo objetivo era verificar se a aprendizagem das relações nome-figura do objeto indefinido poderiam se estender para a aprendizagem da relação nome-objeto indefinido tridimensional. Os resultados destas sondas serão discutidos no tópico a seguir.

\section{Sondas de Generalização}

Os resultados demonstraram que a generalização da função discriminativa das figuras dos estímulos apresentadas na história para os objetos tridimensionais referentes não ocorreu para a maior parte dos estímulos, para ambos os grupos etários. Considerando os resultados das sondas anteriores, em que não houve aprendizagem consistente de todas as pseudopalavras apresentadas, os dados trazidos pelas sondas de generalização não surpreendem, pois não é possível generalizar propriedades não discriminadas dos estímulos (Catania, 1999). Em outras palavras, a discriminação condicional entre a pseudopalavra ditada e a figura do objeto indefinido referente não 
foi estabelecida de forma consistente pelo procedimento de leitura compartilhada, o que, se tivesse ocorrido, poderia garantir um bom desempenho dos participantes nas sondas de generalização.

Ganea, Allen, Butler, Carey e DeLoache (2009), realizaram um estudo sobre a capacidade de crianças bem jovens (15 a 24 meses) de ficar sob controle de aspectos específicos de fotografias, de forma a terem seus comportamentos controlados por aspectos semelhantes no "mundo real". Os resultados deste estudo apresentam evidências de que as crianças compreenderam a relação referencial entre figura e objeto. Entretanto, diferente do presente trabalho, esses autores apresentaram as figuras e os nomes dos dois objetos desconhecidos na forma de um pareamento ostensivo, e seus procedimentos foram compostos por quatro fases: leitura da palavra, sessão de treino, familiarização com o objeto e por fim, os testes. Desta forma, mais uma vez, a quantidade de palavras pode ter sido um dificultador, também, para o processo de generalização.

Além disso, pretendeu-se verificar, por meio da aplicação deste tipo de sonda, se o repertório de generalização seria emergente de uma situação de leitura compartilhada. Segundo os resultados do presente estudo, o estímulo S4 foi o estímulo que foi corretamente escolhido pela maioria dos participantes, de ambos os grupos etários. Contudo, para o grupo de crianças mais novas, parece ter havido uma preferência por este brinquedo, o que não aconteceu entre as crianças mais velhas, indicando que estas últimas realizaram a generalização, de fato, deste estímulo. Este fato vai ao encontro da afirmação de De Rose e Rabelo (2012), de que indivíduos com maior experiência com múltiplos exemplares de uma relação entre estímulos (não apenas determinados estímulos) desenvolvam uma capacidade geral de fazer relações, e tornam-se capazes de formar redes cada vez mais complexas dessas relações, o que 
permitiria a estes indivíduos realizar transferências e transformação de funções entre os elementos relacionados. Justamente em função das crianças mais velhas terem uma experiência maior com a língua, elas podem tornar-se mais aptas a formar essas redes complexas entre estímulos, que é o que parece ter acontecido para o estímulo S4, entre alguns participantes do grupo de crianças mais velhas, que generalizaram o estímulo auditivo ditado da figura para o objeto indefinido tridimensional.

\section{Discussão Geral}

A presente pesquisa se propôs a investigar a aprendizagem incidental de novas palavras por meio da leitura de uma história infantil, para crianças de diferentes faixas etárias, utilizando, pseudopalavras que apresentaram diferentes funções/utilidades definidas pelo contexto da história. Tal como foi apresentado, as diferenças mais evidentes entre os grupos etários foram encontradas nos resultados das sondas de exclusão e de nomeação e descrição da função. Nos resultados dessas sondas, o desempenho das crianças de 7 anos foi superior ao desempenho das crianças de 3 anos. Entretanto, os resultados apresentados pelas sondas de seleção são muito variáveis, para ambos os grupos, e a idade maior e o suposto maior nível de vocabulário das crianças de 7 anos não se mostraram como condições suficientes para uma aprendizagem mais efetiva das pseudopalavras apresentadas na história, como verificadas por meio das sondas de seleção.

Os resultados obtidos neste estudo, porém, precisam ser ponderados em função de algumas limitações metodológicas, tais como a falta de avaliação prévia do vocabulário dos participantes e a quantidade de tentativas nas sondas de seleção. As pesquisas de Robbins e Ehri (1994) e de Sénéchal et al. (1995), que relataram a ocorrência do fenômeno do Matthew Effect na aprendizagem de palavras, avaliaram previamente o vocabulário corrente de seus participantes, diferente do presente trabalho, 
em que as diferenças entre os níveis de vocabulários dos participantes foram presumidas em função da idade. Portanto, é necessário ponderar a afirmação da não ocorrência deste fenômeno no presente trabalho, uma vez que não se verificou previamente um dos aspectos básicos envolvidos em sua investigação: o nível (alto, médio, baixo) de vocabulário.

O segundo aspecto metodológico da presente pesquisa que merece ser reavaliado refere-se ao fato das sondas de seleção apresentarem uma única tentativa para cada pseudopalavra. O número reduzido de tentativas não permite que se tenha clareza a respeito da aprendizagem de cada pseudopalavra, na medida em que uma resposta incorreta a uma tentativa pode ocorrer em função de algum artefato (e.g., falta de atenção do participante, não rastreamento do estímulo solicitado, etc), e não em função do participante não ter aprendido a relação nome-figura. Futuras pesquisas sobre o tema e que empreguem esse tipo de método devem considerar o planejamento de um número maior de tentativas para cada palavra-alvo nas sondas de seleção, a fim de medir a aprendizagem de novas palavras com base em critérios que sejam menos do tipo "tudo ou nada". Por exemplo, aumentando-se o número de tentativas de sonda para cada pseudopalavra para pelo menos três (dois acertos e um erro; ou dois erros e um acerto; ou três erros/acertos consecutivos), é possível estabelecer critérios mais claros para considerar que uma pseudopalavra foi aprendida, o que garantiria afirmar de formar mais consistente que a criança ficou sob controle da relação pseudopalavra ditada-figura do objeto referente, do que apenas com a aplicação de uma única tentativa.

Também é preciso ponderar alguns dos aspectos metodológicos relativos às sondas de generalização. O primeiro deles refere-se ao momento em que estas sondas foram aplicadas: apenas durante a Fase de Sondas de Retenção, o que pode ter dificultado ainda mais esta tarefa. O segundo aspecto refere-se à escolha dos estímulos 
aos quais se solicitou que as crianças demonstrassem generalização: pseudopalavras ditadas e objetos tridimensionais indefinidos. Seria interessante propor este tipo de sonda solicitando também a generalização entre as figuras dos objetos indefinidos e os objetos tridimensionais indefinidos, semelhante ao que fazem Ganea et al. (2009).

Com relação à aprendizagem de palavras por meio da leitura compartilhada, Fontes e Cardoso-Martins (2004) defendem que as histórias contêm pistas contextuais que podem auxiliar na compreensão do significado de palavras desconhecidas, favorecendo a aprendizagem dessas. Contudo, ainda não parece estar completamente esclarecido o papel da dica contextual "apresentação da função" da pseudopalavra durante a aprendizagem incidental decorrente de situações de leitura compartilhada. Pesquisas futuras que investiguem o controle exercido por estas e outras dicas contextuais na aprendizagem de novas palavras, por exemplo, por meio da leitura dialógica (Blewit et al., 2009; Hargrave \& Sénéchal, 2000), ou por meio da solicitação de comportamento verbal ecoico (Almeida-Verdu et al., 2013), podem auxiliar na compreensão e no aprofundamento da discussão sobre quais as variáveis críticas envolvidas na aprendizagem de palavras por meio da leitura de histórias. Além disso, como apontado, o elevado número de palavras apresentadas para as crianças parece ter dificultado a aprendizagem, desta forma, seria interessante também investigar o papel deste tipo de dica contextual em uma situação com menor quantidade de palavras-alvo. Seria interessante verificar ainda as diferenças de desempenho entre os diferentes grupos etários nesta condição com apresentação de menos estímulos.

Por fim, em função da longa tradição deste tipo de pesquisa por estudiosos do campo da Psicolinguística, faz-se necessário pontuar que esta foi uma pesquisa que investigou o comportamento verbal (tal como concebido por Skinner, em 1957) considerando os princípios básicos propostos pela Análise do Comportamento. Desta 
forma, destaca-se como primeira contribuição original da Análise do Comportamento para pesquisas sobre aprendizagem de palavras em contextos de leitura de histórias, é seu rigor metodológico: a) a operacionalização clara das variáveis e seu controle (uso de pseudopalavras, de livros não-comerciais, e de objetos confeccionados para fins de pesquisa); b) a estruturação da avaliação da aprendizagem (aplicação de diferentes sondas para a investigação de diferentes repertórios). O segundo ponto a ser destacado é a contribuição teórica da Análise do Comportamento para este tipo de investigação. Esta abordagem tem, tradicionalmente, investigado questões relativas à formação e manutenção de classes de estímulos de forma isolada, em tarefas experimentais pouco naturais, ou investigado aspectos muito específicos acerca do comportamento verbal (e.g., a instalação e a ocorrência das classes de mando e tato). O corpo de conhecimentos acumulados pela Análise do Comportamento, até este ponto, pode auxiliar na compreensão das funções dos operantes verbais e do processo de formação de classes de estímulos em situações mais cotidianas, como são os contextos de leitura de história. Assumindo que o comportamento verbal tem sido alvo de estudos de autores de diferentes disciplinas e orientações teóricas, que enfatizam o papel da cultura na emergência e desenvolvimento do comportamento verbal (Skinner, 1957; Tomasello, 1999, Vigotsky, 1934) e considerando que a prática de leitura de histórias está presente em diferentes culturas (Bus, et al., 2000; Cornell, et al., 1985; Pellegrini, et al., 1985), pesquisas semelhantes a estas se tornam importantes para a compreensão de fenômenos relativos à aquisição e desenvolvimento da linguagem. 


\section{Referências}

Abreu, P. R., \& Hübner, M. M. C. (2012). O comportamento verbal para BF Skinner e para SC Hayes: uma síntese com base na mediação social arbitrária do reforçamento. Acta Comportamentalia: Revista Latina de Análisis del Comportamiento, 20(3), 367-381.

Akhtar, N., \& Tomasello, M. (2000). The social nature of words and word learning. In: K. Hirsh-Pasek, L. Bloom, L. B. Smith, A. L. Woodward, N. Akhtar, M. Tomasello, \& G. Hollich, (Eds.), Becaming a word leaner: A debate on lexical acquisition (pp. 201-224). New York: Oxford University Press.

Almeida-Verdu, A. C., Santos, S. D. L. R., de Souza, D. G., \& Bevilacqua, M. C. (2008). Ouvir e falar: Repertório de comunicação em surdos que receberam o implante coclear. Revista Eletrônica de Núcleos de Ensino, 902-913.

Antoniazzi, M., Domeniconi, C., \& Schmidt, A. (2014). Efeito da pré-exposição ao objeto no desempenho por exclusão e na aprendizagem da relação nome-objeto. Acta Comportamentalia: Revista Latina de Análisis del Comportamiento, 22(1) $22-36$.

Barros, R. S. (2003). Uma introdução ao comportamento verbal. Revista Brasileira de Terapia Comportamental e Cognitiva, 5(1), 73-82.

Bear, M. F., Connors, B. W., \& Paradiso, M. A. (2008). Neurociências: Desvendando o Sistema Nervoso. Porto Alegre: Artmed.

Blewitt, P., Rump, K. M., Shealy, S. E., \& Cook, S. A. (2009). Shared book reading: When and how questions affect young children's word learning. Journal of Educational Psychology, 101 (2), 294-304.

Bus, A. G., Van Ijzendoorn, M. H., \& Pellegrini, A. D. (1995). Joint book reading makes for success in learning to read: A meta-analysis on intergenerational transmission of literacy. Review of Educational Research, 65(1), 1-21. 
Bus, A. G., Leseman, P. P., \& Keultjes, P. (2000). Joint book reading across cultures: A comparison of Surinamese-Dutch, Turkish-Dutch, and Dutch parent-child dyads. Journal of Literacy Research, 32(1), 53-76.

Carey, S., \& Bartlett, E. (1978). Acquiring a single new word. Papers and Reports on Child Language Development, 15, 17-29.

Catania, A. C. (1999). Aprendizagem: comportamento, linguagem e cognição. Porto Alegre: Artes Médicas.

Cornell, E. H., Sénéchal, M., \& Broda, L. S. (1988). Recall of picture books by 3-yearold children: Testing and repetition effects in joint reading activities. Journal of Educational Psychology, 80(4), 537-542.

Costa, A. R. A., de Rose, J. C., \& de Souza, D. G. (2010). Interferência de variáveis de contexto em sondas de exclusão com substantivos e verbos novos. Acta Comportamentalia: Revista Latina de Análisis del Comportamiento, 18(1), 35-54.

Costa, A. R. A., Grisante, P. C., Domeniconi, C., de Rose, J. C., \& de Souza, D. G. (2013). Nomeação de estímulos novos a partir da seleção por exclusão. Paidéia, 23(55), 217-224.

De Rose, J. C. (1993). Classes de estímulos: implicaçöes para uma análise comportamental da cognição. Psicologia: teoria e pesquisa, 9 (2), 283-303.

De Rose, J. C., \& Rabelo, L. Z. (2012). Teoria das molduras relacionais e possíveis aplicações à educação. DI-Revista de Deficiência Intelectual, 2(3), 10-15.

Debaryshe, B. D. (1993). Joint picture-book reading correlates of early oral language skill. Journal of Child Language, 20(02), 455-461.

Devany, J. M., Hayes, S. C., \& Nelson, R. O. (1986). Equivalence class formation in language-able and language-disabled children. Journal of the Experimental Analysis of Behavior, 46(3), 243-257.

Dixon, L. S. (1977). The nature of control by spoken words over visual stimulus selection. Journal of the Experimental Analysis of Behavior, 27 (3), 433-442. 
Domeniconi, C., Costa, A. R. A., de Souza, D. G., \& De Rose, J. C. (2007). Responder por exclusão em crianças de 2 a 3 anos em uma situação de brincadeira. Psicologia: Reflexão e Crítica, 20 (2), 342-350.

Dunn, L. M., Dunn, L. M., Bulheller, S., \& Häcker, H. (1965). Peabody Picture Vocabulary Test. Circle Pines, MN: American Guidance Service.

Dunn, L. M., Dunn, L. M., Whetton, C., \& Pintilie, D. (1982). British picture vocabulary scale. NFER-Nelson, Windsor.

Elley, W. B. (1989). Vocabulary acquisition from listening to stories. Reading Research Quarterly, 24 (2), 174-187.

Farrant, B. M., \& Zubrick, S. R. (2013). Parent-child book reading across early childhood and child vocabulary in the early school years: Findings from the longitudinal Study of Australian children. First Language, 33 (3), 280-293.

Fontes, M. J, O., \& Cardoso-Martins, C. (2004). Efeitos da leitura de histórias no desenvolvimento da linguagem de crianças de nível sócio-econômico baixo. Psicologia: Reflexão e Crítica, 17(1), 83-94.

Ganea, P. A., Allen, M. L., Butler, L., Carey, S., \& DeLoache, J. S. (2009). Toddlers' referential understanding of pictures. Journal of Experimental Child Psychology, 104(3), 283-295.

Garcia, F. P, Vaz, A. M., \& Schmidt, A. (submetido) Leitura compartilhada de livros e aprendizagem de palavras em crianças pré-escolares. Temas em Psicologia.

Gentner, G. (1982). Why nouns are learned before verbs: Linguistic relativity versus natural partitioning. In Kuczaj, S. II (Ed) Language development, Volume 2: Language, thought and culture (pp. 301-334). Hillsdale: N. J. Lawrence Erlbaum.

Hargrave, A. C., \& Sénéchal, M. (2000). A book story reading intervention with preschool children who have limited vocabularies: The benefits of regular reading and dialogic reading. Early Childhood Research Quarterly, 15(1), 75-90.

Horst, J.S. (2013). Context and repetition in word learning. Frontiers in Psychology, 4 (149), 1-29. 
Horst, J. S., Parson, K. L., \& Bryan, N. M. (2011). Get the story straight: Contextual repetition promotes word learning from storybooks. Frontiers in Psychology, 2(17), 1-11.

Horst, J. S., \& Samuelson, L. K. (2008). Fast mapping but poor retention by $24-$ monthold infants. Infancy, 13(2), 128-157.

Kaminski, J., Call, J., \& Fischer, J. (2004). Word learning in a domestic dog: Evidence for" Fast Mapping". Science, 304(5677), 1682-1683.

MacDonald, R., Anderson J., Dube, W.V., Geckeler, A., Green, G., Holcomb, W., Mansfield, R., \& Sanchez, J. (2006). Behavioral assessment of joint attention: a methodological report. Research in Developmental Disabilities Journal, 27(2), $138-50$.

McIlvane, W. J., \& Stoddard, L. T. (1981). Acquisition of matching-to-sample performances in severe mental retardation: Learning by exclusion. Journal of Mental Deficiency Research, 25, 33-48.

McIlvane, W. J., Wilkinson, K. M., \& de Souza, D. G. (2000). Origens da exclusão. Temas em Psicologia, 8(2), 195-203.

McLeod, A. N., \& McDade, H. L. (2011). Preschoolers' incidental learning of novel words during storybook reading. Communication Disorders Quarterly, 32(4), 256-266.

Nelson, K. (2007). Young Minds in Social Worlds: Experience, Meaning and Memory. London: Harvard University Press.

Ninio, A. (1983). Joint book reading as a multiple vocabulary acquisition device. Developmental Psychology, 19(3), 445-451.

Oshiro, C. K. B., de Souza, D. G., \& Costa, A. R. A. (2006). Responder por exclusão a partir de uma linha de base de discriminações condicionais visuais. Revista Brasileira de Análise do Comportamento, 2(2), 251-276.

Pedromônico, M. R. M., Bragatto, E. L., \& Strobilus, R. (1999). Teste de Triagem Denver II. São Paulo: UNIFESP. 
Pellegrini, A. D., Brody, G. H., \& Sigel, I. E. (1985). Parents' book-reading habits with their children. Journal of Educational Psychology, 77(3), 332-340.

Penno, J. F., Wilkinson, I. A., \& Moore, D. W. (2002). Vocabulary acquisition from teacher explanation and repeated listening to stories: Do they overcome the Matthew effect?. Journal of Educational Psychology, 94(1), 23-33.

Perez, W. F., Nico, Y. C., Kovac, R, Fidalgo, A. P., \& Leonardi, J. L.. (2013). Introdução à Teoria das Molduras Relacionais (Relational Frame Theory): principais conceitos, achados experimentais e possibilidades de aplicação. Revista Perspectivas em Análise do Comportamento, 4(1) 32-50.

Ribeiro, T. A. (2013). Responder por exclusão na aprendizagem de relações simbólicas envolvendo adjetivos. Dissertação (Mestrado) - Universidade Federal de São Carlos, São Carlos.

Robbins, C., \& Ehri, L.C. (1994) Reading storybooks to kindergartners helps them learn new vocabulary words. Journal of Educational Psychology, 86(1) 154-64.

Schmidt, A., Costa, A. R. A., Norberto, M. C., \& Voss, A. (2014). Ocorrência de classes gramaticais na fala espontânea de crianças de 18 a 41 meses com pares. Psicologia: Reflexão e Crítica, 27(3), 573-581.

Sénéchal, M., Thomas, E., \& Monker, J. (1995). Individual differences in 4-year-old children's acquisition of vocabulary during storybook reading. Journal of Educational Psychology, 87(2), 218-229.

Shafer, D. R. (2005). Psicologia do Desenvolvimento. São Paulo: Pioneira Thomson.

Skinner, B. F. (1957). Verbal behavior. New York: Appleton-Century-Crofts.

Skinner, B. F. (1974). About behaviorism. New York: Alfred A. Knopf.

Smeets, D. J., \& Bus, A. G. (2012). Interactive electronic storybooks for kindergartners to promote vocabulary growth. Journal of Experimental Child Psychology, 112(1), 36-55. 
Souza, N. M., Souza, C. B. A., \& Gil, M. S. C. A. (2013). Aprendizagem rápida de comportamento de ouvinte por um bebê. Interação em Psicologia, 17(1), 67-78.

Souza, F. C., Almeida-Verdu, A. C. M., \& Bevilacqua, M. C. (2013). Ecoico e nomeação de figuras em crianças com deficiência auditiva pré- língual com implante coclear. Acta Comportamentalia: Revista Latina de Análisis del Comportamiento, 21(3), 325-339.

Stanovich, K. E. (1986). Matthew effects in reading: Some consequences of individual differences in the acquisition of literacy. Reading Research Quarterly, 21 (4), $360-407$.

Swingley, D. (2010). Fast mapping and slow mapping in children's word learning. Language Learning and Development, 6(3), 179-183.

Tardif, T. (1996). Nouns are not always learned before verbs: Evidence from Mandarin speaker's early vocabularies. Developmental Psychology, 32(3), 492-504.

Tomasello, M., \& Childers, J.B. (2006) Cap.12: Are nouns easier to learn than verbs? Three experimental studies. In: K. Hirsh-Pasek, \& R. M. Golinkoff (Eds.). Action meets word: How children learn verbs. (pp. 311-335). New York: Oxford University Press.

Tomasello, M. (1999). Origens culturais da aquisição do conhecimento humano. (Berliner, C. Trad.) São Paulo: Martins Fontes.

Trivette, C. M., Simkus, A., Dunst, C. J., \& Hamby, D. W. (2012). Repeated book reading and preschoolers' early literacy development. CELLreviews. Center for Early Literacy Learning, 5(5), 1-13.

Vila, I. (1995). Aquisição da Linguagem. In: C. Coll, J. Palacios, A. Marchesi, (Eds.). (Settineri, F. F., Domingues, M. A. G. Trad.) Desenvolvimento psicológico e educação: psicologia evolutiva (pp. 69-80). Porto Alegre: Artes Médicas.

Vygotsky, L. S. (1934). Pensamento e Linguagem. São Paulo: Martins Fontes. 
Walsh, B. A., \& Blewitt, P. (2006). The effect of questioning style during storybook reading on novel vocabulary acquisition of preschoolers. Early Childhood Education Journal, 33(4), 273-278.

Walsh, B. A., \& Rose, K. K. (2013).Impact of adult vocaburaly noneliciting and eliciting questions on the novel vocabulary acquisition of preschoolers enrolled in Head Start. Journal of Research in Childhood Education, 27(1), 31-45.

Wertzner, H. F. (2004). Fonologia. Em C. R. F. de Andrade, D. M. Befi-Lopes, F. D. M. Fernandes, \& H. F. Wertzner. ABFW-Teste de linguagem infantil: nas áreas de fonologia, vocabulário, fluência e pragmática (pp. 5-32). Barueri: Pró-Fono.

Wertzner, H. F. (2009). Fonologia: desenvolvimento e alterações. In: L. C. Ferreira, D. M. Befi-Lopes, S. C. Limongi (Eds.). O Tratado de fonoaudiologia. (pp. 772786). São Paulo: Roca.

Wilkinson, K. M., Dube, W. V., \& McIlvane, W. J. (1998). Fast mapping and exclusion (emergent matching) in developmental language, behavior analysis, and animal cognition research. The Psychological Record, 48(3), 407-422.

Wilkinson, K. S., \& Houston-Price, C. (2013). Once upon a time, there was a pulchritudinous princess . . . : The role of word definitions and multiple story contexts in children's learning of difficult vocabulary. Applied Psycholinguistics, 34(3), 591-6131.

Wilkinson, K. M., \& McIlvane, W. J. (1997). Blank comparison analysis of emergent symbolic mapping by young children. Journal of Experimental Child Psychology, 67(2), 115-130.

Wilkinson, K.M., Rosenquist, C., \& McIlvane, W. J (2009). Exclusion learning and emergent symbolic category formation in individuals with severe language impairments and intellectual disabilities. The Psychological Record, 59(2), 187206. 


\section{Apêndice A - Termo de Consentimento Livre e Esclarecido}

Meu nome é Aline Melina Vaz, sou estudante de mestrado do Programa de Pós-graduação em Psicobiologia da Universidade de São Paulo-Ribeirão Preto e estou desenvolvendo uma pesquisa que busca entender como as crianças pequenas aprendem a entender e a falar palavras novas através da leitura de livros infantis ilustrados. Essa pesquisa é importante para entendermos de que forma a leitura de livros para crianças pequenas pode ajudá-las a desenvolver sua fala e sua compreensão. Para isso, estou convidando seu (sua) filho (a) a participar da pesquisa "Leitura compartilhada de histórias para crianças de 3 anos e a aprendizagem incidental de vocabulário". Na pesquisa, as crianças irão acompanhar a leitura de um livro infantil ilustrado que será lido por mim. No primeiro dia, irei ler a história por três vezes. Nesta leitura a criança terá contato com 4 palavras desconhecidas (palavras criadas por mim e que não têm nenhum significado). Ao final da leitura apresentarei um livro com imagens conhecidas e desconhecidas da criança e pedirei que ela me mostre um objeto conhecido ou desconhecido que estará presente na página mostrada (por exemplo, "mostre onde está o carro" ou "mostre onde está o fulito"). A partir da resposta da criança, será analisado se ocorreu a aprendizagem das palavras novas que ela ouviu na história. Na segunda sessão, que será filmada, haverá apenas a apresentação do mesmo livro com imagens conhecidas e desconhecidas da criança e os mesmos procedimentos para verificar se ela memorizou as palavras que ouviu na história. Vou ler a história para crianças sozinhas (leitura individual), para crianças em dupla, e para crianças em grupos de cinco. Cada sessão de leitura deve durar em torno de 30 minutos, mas essa atividade não irá atrapalhar as atividades normais dela na classe. As crianças participantes e seus pais não serão identificados na pesquisa. A história lida é apropriada para a idade das crianças e não há riscos previsíveis na atividade. Por ser uma pesquisa, a participação dos pais e das crianças é livre e não será remunerada, e também não haverá nenhum custo. Caso a criança não queira participar da atividade, ela terá total liberdade para desistir, ou seja, se, ao chegar na sala a criança chorar ou não quiser participar da atividade, será levada imediatamente para sua classe. Os pais também podem desistir de autorizar a participação de seus filhos a qualquer momento e por qualquer motivo, sem nenhum prejuízo. A orientadora deste trabalho é a professora Andréia Schmidt, professora do curso de Psicologia da Universidade de São Paulo. Qualquer dúvida em relação à pesquisa, ou aos resultados, podem ser tiradas pelo telefone (16) 3602-3742. Caso aceite que seu filho participe da pesquisa, favor preencher e assinar o documento a seguir. Uma cópia desse documento ficará com os responsáveis pela criança. Agradecemos sua atenção

\section{Aline Melina Vaz}

Andréia Schmidt

$\mathrm{Eu}$, RG , responsável pelo (a)

menor , autorizo sua participação na pesquisa

"Leitura compartilhada de histórias para crianças de 3 anos e a aprendizagem incidental na aquisição de vocabulário". Declaro ter entendido os procedimentos e objetivos do trabalho e estar ciente de que a minha identidade, bem como a da criança participante, serão preservados.

Assinatura do responsável

Pesquisadora: Aline Melina Vaz - aluna do Programa de Pós-graduação de Psicobiologia da USP - Ribeirão Preto. Telefone: (16) 3602-3742/ (16) 97991232 Comitê de Ética em Pesquisa: Avenida Bandeirantes, 3900 - CEP 14040-901 - Bairro Monte Alegre - Ribeirão Preto - SP Brasil - Bloco 3 - sala 16. Telefone do Comitê: (16) 3602-4811 (para informações/denúncias sobre aspectos éticos da pesquisa). 


\section{Apêndice B - História criada para a pesquisa}

\section{Cadê meu brinquedo?}

Numa tarde tranquila, João estava brincando com seu carrinho quando sua irmã, Carol, apareceu no quarto e falou:

_Você viu minha boneca? Desde manhã que eu não acho!

_Não, não vi não. Vou prender meu carrinho no nezaca, e te ajudo a procurar, Carol.

Carol agradeceu a ajuda do irmão, e os dois começaram a procurar sua boneca no quarto.

Primeiro, acharam uma pafile do lado da cama.

Continuaram procurando e acharam também um vanito debaixo da estante.

Depois, ficaram cansados e Carol disse:

_Chega, João! Cansei de procurar.

Então João desprendeu seu carrinho do nezaca, e voltou a brincar no seu quarto. Mas logo depois Carol apareceu e falou:

_ João, a mamãe mandou arrumarmos o quarto e guardamos os brinquedos.

_ Puxa vida! Mas eu ainda queria brincar com o vanito!

Carol respondeu:

_Eu queria brincar com a pafile, mas a mamãe mandou arrumar!

E começaram a arrumar o quarto. Colocaram a pafile em cima da estante.

Guardaram o vanito dentro do armário.

A bola, o carrinho e o resto dos brinquedos foram colocados dentro de uma caixa. João disse:

_ Vou prender os óculos no nezaca. 
Carol respondeu:

_Eu vou guardar o giz de cera no fulito.

Quando Carol olhou dentro do fulito, imaginem o que estava guardado ali? A boneca que ela estava procurando!

_João! Que bom que arrumamos as coisas! Achei minha boneca! Ela estava guardada no fulito este tempo todo!

Depois de tanto trabalho, eles acharam a boneca, e ficaram felizes por saber onde estavam todos os seus brinquedos, agora que o quarto estava arrumado. 
Anexo A - Parecer consubstanciado do Comitê de Ética em Pesquisa

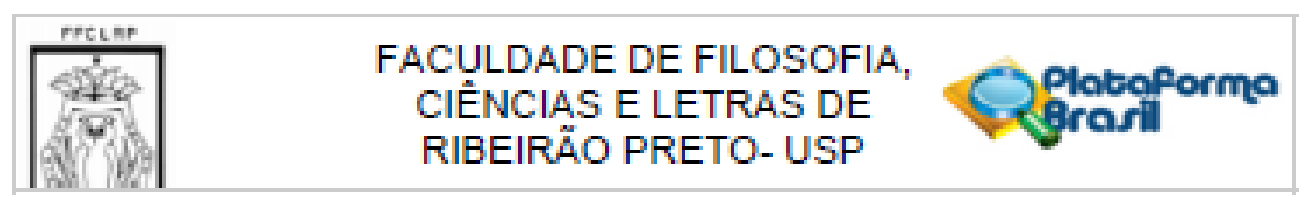

\section{PARECER CONSUBSTANCIADO DO CEP}

\section{DADOS DO PROJETO DE PESQUISA}

Titulo da Pesqulsa: LEITURA COMPARTILHADA DE HISTORIAS E A APRENDIZAGEM INCIDENTAL DE VOCABULARIO

Pesquisador: Allne Mellna Vaz

Área Tematica:

Versăo: 3

CAAE: 19044013.0 .0000 .5407

Instutulçäo Proponente: Faculdade de Flosota, Clenclas e Letras de Ribelido Preto- USP

Patrocinador Principal: Financlamento Proprio

\section{DADOS DO PARECER}

Nümero do Parecer: 639.890

Data da Relatorla: $24 / 04 / 2014$

Apresentaçăa do Projeto:

Justificativa: Trata-se de um projeto de Analse de Aprendizagem infartl que busca entender cono crlanças de 3 anos aprendem a entender e a falar palavras novas atraves da lehtura de llvros infantls llustrados.

Objetivo Gera: Este projeto pretende Investigar a aprendizagem de novos substantivos em crianças de tres anos com desenvolvimento tiplco, em contexto de lehura de livro infantil, manipulando 36 seguintes variavels Independentes:

1) apresentaçăo ou năo da funç̧5o dos referentes no contexto da historla

2) diferentes condlçbes de leltura (indludua, em dupla, em grupo).

Oojettivos especincos:

a) Investigar se as pseudopalavras e seus referentes apresentados na historia sustentam o posterior responder por exclustao na apresentaçăo de uma nova pseudopalavra;

b) Investigar se a aprendlzagem das palavras se mantem em testes de retençalo posteriores.

Metodo: A metodologla e clara, simples e bem delneada. Na pesquisa, as crianças irăo acompanhar a leltura de um livro infartil llustrado que sera lldo por uma das pesqulsadoras. No primeiro dla, a historla sera lida trés vezes. Nesta leitura a criança tera contato com 4 palavras

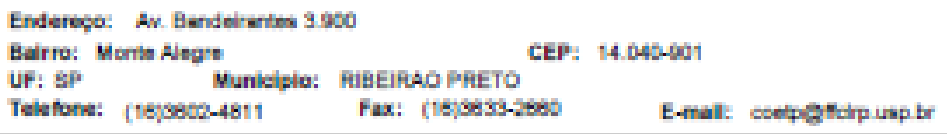




\section{FACULDADE DE FILOSOFIA, CIÊNCIAS E LETRAS DE RIBEIRÄO PRETO- USP}

Conthusib do Paracer as aso

desconhecidas (palavras criadas pelas pesqulsadoras e que năo tem nenhum signiflcado). A0 final da leitura sera apresentado um Ivro com Imagens conhecidas e descorhecidas da criança e a ela sera solicitado que mostre um objeto conhecido ou desconhecido que estara presente na pagina mostrada (por exemplo, "mostre onde esta o carro" ou "mostre onde esta o fulto"). A partir da resposta da criança, sera anallsado se ocorreu a aprendizagem das palavras novas que ela ouviu na historla. Na segunda sessăo, que sera filmada, havera apenas a apresentaçăo do mesmo Ivro com Imagens conhecidas e desconhecidas da criança e 06 mesmos procedimentos para verificar se ela memorizou as palavras que ouviu na historia. Ela devera ainda recontar a historla llda anteriormente com auxillo dos brinquedos apresentados no Ilvro. 0 trabalho sera desenvolvido para crianças sozinhas (leltura Individual), em dupla e em grupos de quatro. Cada sessfóo de leltura deve durar em torno de 30 minutos. O desempenho dos participantes de dferentes condlçbes sera avalado e comparado em funçăo das variaveis manipuladas.

Serấo realzados dols estudos plotos para verificar a validade dos instrumentos criados (Ivros e objetos), anteriormente descritos, assim como a compreensăo das historias e dos testes. Avem dlsso, a reallzaçăo deste tpo de procedimento pretende padronizar o comportamento da pesquisadora durante a conduça da pesquisa.

O que as autoras submetem nesta solcitaçấ e apenas a mudança de titulo. De "Leitura compartihada de historlas para crianças de 3 anos e a aprendizagem Incidental de vocabulario" para "LEITURA COMPARTILHADA DE HISTORIAS E A APRENDIZAGEM INCIDENTAL DE VOCABULARIO"

\section{Objetivo da Pesqulsa:}

Objetivo Gera: Este projeto pretende investigar a aprendlzagem de novos substantivos em crlanç3s de tres anos com desenvowimento tiplco, em contexto de lehura de livro intantil, manipulando 36 seguintes variavels Independentes:

1) apresentaç5̆o ou náo da funç5̆o dos referentes no contexto da historia

2) diferentes condlçbes de leltura (indluduar, em dupla, em grupo).

Cojettvos especincos:

a) Investigar se as pseudopalavras e seus referentes apresentados na historia sustentam o posterior responder por exclustao na apresentaçăo de uma nova pseudopalavra;

b) Investigar se a aprendizagem das palavras se mantem em testes de retençâo posteriores.

Avallaç30 dos Riscos $\theta$ Beneficlos:

Os riscos e beneficlos eståo bem descritos.

Enderege: Av. Bendeirertes 3900

Bairro: Monte Alog:

CEP: $14.045-601$

UF: SP Munkipla: RBEIRAO PRETC

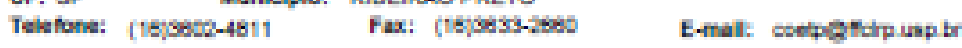




\section{FACULDADE DE FILOSOFIA, CIÊNCIAS E LETRAS DE RIBEIRÃO PRETO- USP

Conthucilo do Pracer exsos

Comentarios e Consideraçoes sobre a Pesqulsa:

Năo ha comentarios

Conalderspoes sobre 08 Termos de apresentaça obrigatorla:

N5̆o ha consideraçbes

Recomendaçoes:

Conclusôes ou Pendénclas e Llata de Inadequaçoses:

N5̆o ha pendenclas

Sltuaçå do Parecer:

Aprovado

Necessita Apreclaçăo da CONEP:

N5̆

Considersçoes Finals a criterlo do CEP:

RIEEIRAO PRETO, 08 de Malo de 2014

Asainador por:

Marina Rezende Bazon

(Coordenador)

Enderego: Av. Bendelrentm 3900

Bairro: Momb Alegre

UF: SP Municiplo: RBEIRAO PRETO

CEP: 14.04500

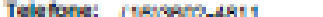

E-mal: esetpettipuap br 